\title{
The study of selected twentieth-century American piano compositions appropriate for use with freshman and sophomore college piano majors: Performance and pedagogical suggestions
}

\author{
Li-Jung Lee \\ West Virginia University
}

Follow this and additional works at: https://researchrepository.wvu.edu/etd

\footnotetext{
Recommended Citation

Lee, Li-Jung, "The study of selected twentieth-century American piano compositions appropriate for use with freshman and sophomore college piano majors: Performance and pedagogical suggestions" (2006). Graduate Theses, Dissertations, and Problem Reports. 3457.

https://researchrepository.wvu.edu/etd/3457
}

This Dissertation is protected by copyright and/or related rights. It has been brought to you by the The Research Repository @ WVU with permission from the rights-holder(s). You are free to use this Dissertation in any way that is permitted by the copyright and related rights legislation that applies to your use. For other uses you must obtain permission from the rights-holder(s) directly, unless additional rights are indicated by a Creative Commons license in the record and/ or on the work itself. This Dissertation has been accepted for inclusion in WVU Graduate Theses, Dissertations, and Problem Reports collection by an authorized administrator of The Research Repository @ WVU. For more information, please contact researchrepository@mail.wvu.edu. 
The Study of Selected Twentieth-Century American Piano Compositions Appropriate for Use with Freshman and Sophomore College Piano Majors:

Performance and Pedagogical Suggestions

\section{Li-Jung Lee}

A Doctoral Research Project submitted to

The College of Creative Arts

at

West Virginia University

In partial fulfillment of the requirements for the degree of

Doctor of Musical Arts

in

Piano Performance

James Miltenberger, D.M.A., Chair

Connie Arrau Sturm, Ph.D.

Mary Ferer, Ph.D.

William Haller, D.M.A.

Bruce Kang, Ph.D.

Division of Music

Morgantown, West Virginia

2006

Keywords: Twentieth-Century, American Music, Ginastera, Barber, Copland, Piano Performance

Copyright 2006 Li-Jung Lee 


\title{
ABSTRACT \\ The Study of Selected Twentieth-Century American Piano Compositions Appropriate for Use with Freshman and Sophomore College Piano Majors: Performance and Pedagogical Suggestions
}

\author{
Li-Jung Lee
}

Studying and performing twentieth-century compositions are important for piano students to become well-rounded musicians. This study presents a performance analysis of repertoire from three highly influential American composers: Four Piano Blues (19261948) by Aaron Copland, Excursions Op. 20 (1944) by Samuel Barber and Suite de Danzas Criollas Op. 15 (1946) by Alberto Ginastera. Although these works are not the most technically demanding works by these composers, the nationalistic character of the Argentine and American folk melodies and dances; the popular styles of ragtime, blues and jazz; as well as their incorporation into twentieth-century compositional technique will challenge students in their performance approach.

The purpose of this research project is to provide performance and pedagogical suggestions based on stylistic and interpretive analyses. The analyses of these pieces focus on aspects of piano performance, such as the basic technical approach, interpretation suggestions for specific sound production, interpretation of complex meters and jazz rhythms, as well as examinations of pedaling, dynamics, and articulation. Selected aspects of timbre, texture, harmony, melody, rhythm, and form are discussed as they relate to the interpretation and performance of these pieces. It is hoped that this study will help students not only in playing each selected composition, but also in making twentieth-century American music more accessible to interested musicians.

There are four chapters in this study. Chapter I provides an introduction for this research. Chapter II is divided into three parts, with each part reviewing scholarly books, theses, dissertations and journal articles related to one of the selected composers. Chapter III offers suggestions and guidelines for performance as well as an investigation of style elements of the selected compositions. Chapter IV presents a summary, conclusions, and recommendations for further research. 


\section{TABLE OF CONTENT}

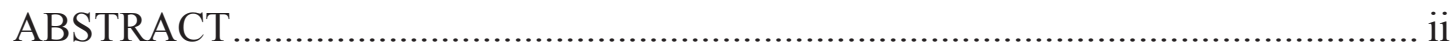

\section{CHAPTER}

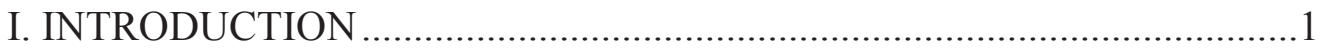

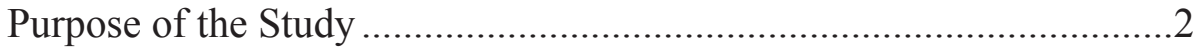

Need for the Study ........................................................................ 2

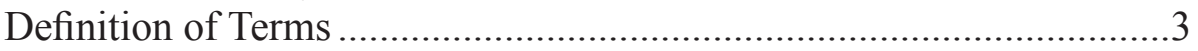

Limitations of the Research ........................................................... 3

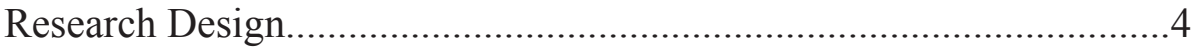

II. REVIEW OF RELATED LITERATURE ..........................................5

Alberto Ginastera (1916-1983) ........................................................5

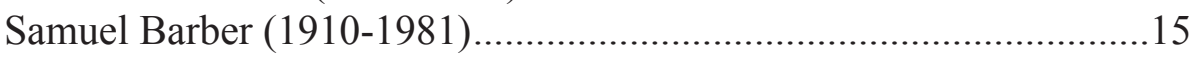

Aaron Copland (1900-1990) ........................................................27

III. SUGGESTIONS AND GUIDELINES FOR PERFORMANCE OF

SELECTED TWENTIETH-CENTURY AMERICAN PIANO

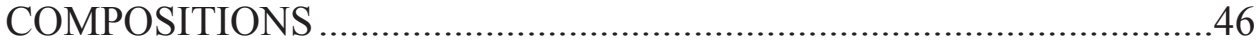

Alberto Ginastera: Suite de Danzas Criollas, Op. 15 .......................46

Samuel Barber: Excursions, Op. 20 ...............................................71

Aaron Copland: Four Piano Blues .................................................. 111

\section{SUMMARY, CONCLUSIONS, AND RECOMMENDATIONS FOR}

FURTHER RESEARCH …......................................................... 136

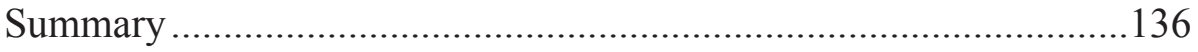

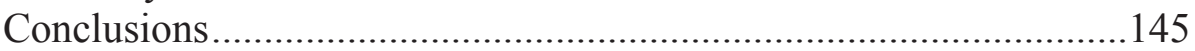

Recommendations for further research ......................................148

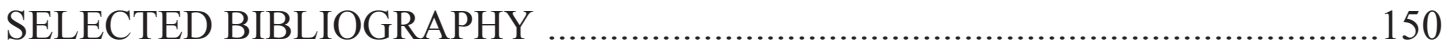




\section{CHAPTER I INTRODUCTION}

There is great amount of music written for the piano in the twentieth century, and much of it makes use of new sounds, notations and compositional techniques. For many students, music from this century is quite attractive to hear and interesting to learn. Certainly, all piano students should study and perform twentieth-century compositions in order to become wellrounded musicians. Therefore, piano teachers must be knowledgeable about this music, and should regularly examine unfamiliar pieces with an open mind in a continual effort to expand their teaching repertoire.

In Taiwan, familiarizing students not only with music from earlier periods but also with contemporary compositions can be a big challenge. The teaching of twentieth-century music can present a problem for the typical piano teacher if he or she lacks the analytical skills or pianistic techniques necessary for its study and performance. Unfortunately, many Taiwanese teachers and students are unable to approach many twentieth-century compositions with the same confidence they demonstrate toward music of earlier eras. Furthermore, this situation will not improve unless teachers overcome prejudices against music with which they are unfamiliar.

The introduction of applied saxophone lessons in several music departments in Taiwan around the turn of the twenty-first century further increases the likelihood that many music students will become involved with jazz and other types of contemporary music. Teachers, therefore, can no longer ignore this type of music if they wish to serve the needs of their students. 


\section{Purpose of the Study}

The purpose of this paper is to provide a stylistic overview and performance suggestions for selected piano compositions appropriate for study by collegiate freshman and sophomore piano majors. Detailed discussions focus on interpretations and appropriate pianistic approaches to tone production and pedaling and offer some specific observations on rhythm, articulation, and dynamics. Aspects of timbre, texture, harmony, melody, and form are also discussed as they relate to interpretation and performance. This study also makes recommendations on guiding and controlling physical movement when playing this repertoire. Efficient and appropriate finger action, arm movement, and their coordination can cause difficulties to disappear.

The specific repertoire chosen for this study includes Aaron Copland's Four Piano Blues (1926-1948), Samuel Barber's Excursions, Op. 20 (1944), and Alberto Ginastera's Suite de Danzas Criollas, Op. 15 (1946). Copland, Barber, and Ginastera are among the most significant North- and South American composers in the twentieth century. Each has influenced contemporary musical thought and development. Their music represents various styles ranging from traditional classical to contemporary jazz. The compositions chosen are all sets of character pieces, and are all accessible to college freshmen and sophomores at early-advanced levels of ability. Also, since the less-experienced students will often do better on works that combine compositional idioms of this century with those idioms from

prior centuries, these works all combine classical form with contemporary harmonic and rhythmic elements. For the purpose of study the term American composers will include both North and South American.

\section{Need for the Study}

A review of literature related to the selected pieces shows that many sources consist of biographical studies of composers or theoretical analyses of structural patterns and harmonic designs. But, very few studies were found that focused on issues directly related 
to performance practice. To complement existing historical and theoretical sources, there is a need for studies related to the applied teaching and performance of twentieth-century piano compositions. Such studies will help increase teachers' and students' knowledge of contemporary music styles and repertoire, and offer insights into its interpretation.

\section{Definition of Terms}

1. Early-advanced level of performance difficulty - This refers to moderately difficult pieces that could be performed by talented high school students or average collegiate freshman or sophomore piano majors. For example, the difficulty level of J. S. Bach's French Suites; Beethoven's Sonatas, Op. 10 and 13; Chopin's Etudes, Op. 25 no.1 and no. 2; and Debussy's Preludes, first book is considered early-advanced.

2. Finger pedaling - This is one of the most useful aids for legato pedaling. This technique consists of holding notes through with the fingers when no pedal is used or when the pedal has to change frequently.

3. Slide pedaling - This special sonority is inspired by the slide technique of a trombone. On the piano, this kind of sound effect can be achieved by lifting the damper pedal gradually from the bottom to the top thus creating a blur between notes or chords.

\section{Limitations of the Research}

This study is limited to performance-related discussions of major stylistic elements that will help students understand and interpret the selected pieces. The analyses of these pieces focus on aspects of piano performance, such as the basic technical approach, interpretation suggestions for specific sound production, interpretation of complex meters and jazz rhythms, and examinations of pedaling, dynamics, and articulation. Selected aspects of timbre, texture, harmony, melody, rhythm, and form, as well as information related to style are discussed as they relate to interpretation and performance of these pieces; however, this paper is not intended as an in-depth historical or theoretical study of these pieces. 


\section{Research Design}

There are four chapters in this study. Chapter I provides an introduction for this research. Chapter II is divided into three parts, with each part reviewing scholarly books, theses, dissertations and journal articles related to one of the selected composers. Chapter III offers suggestions and guidelines for performance of the selected compositions. Chapter IV presents a summary, conclusions, and recommendations for further research. 


\section{CHAPTER II REVIEW OF RELATED LITERATURE}

Many scholars have examined the life, works, and influence of Aaron Copland, Samuel Barber, and Alberto Ginastera. A total of seven books, nine articles and nineteen dissertations were reviewed for this chapter. This variety of sources includes detailed biographies of these composers, discussions of their musical styles, and analyses of their specific compositions for piano. The large number of scholarly studies devoted to these composers demonstrates their acceptance by the academic community and the popularity of many of their piano pieces. This chapter is divided into three sections, with each section reviewing scholarly books, theses, dissertations and journal articles related to Ginastera, Barber and Copland, respectively.

\section{Alberto Ginastera (1916-1983)}

Ginastera was one of the most important South American composers in the twentieth century. His musical achievements generated a great deal of research on his life and music. Gilbert Chase, who wrote an entry of Ginastera in the New Grove Dictionary, ${ }^{1}$ is one of the most important scholars on Ginastera's music. Chase showed an early interest in Ginastera's music and provided several articles surveying Ginastera's music. According to his article written in 1957, he felt that Ginastera had achieved an original synthesis of urban and rural and of international and national elements by combining two prominent Argentine folk traditions associated with the gaucho and the region of the pampas. ${ }^{2}$ In

\footnotetext{
${ }^{1}$ G. Chase: 'Ginastera, Albert', The New Grove Dictionary of Music and Musicians, ed. S. Sadie and J. Tyrrell (London: Macmillan, 1980), vol. 7, 387-390.

${ }^{2}$ Gilbert Chase, “Alberto Ginastera: Argentine Composer,” The Musical Quarterly 43 (1957): 439-60.
} 
describing the roots of Ginastera's music within the gauchesco movement, Chase noted that the composer "deliberately identifies himself with the most powerful (national) current in the arts and letters," thus enabling him to achieve "the creative synthesis to which his music, in line with the best Argentine tradition, aspires."3 The Suite of Creole Dances for piano (1946) is one of the pieces that Chase felt had established Ginastera's position of leadership in the national movement of Argentine music. In his inventive study, Chase suggested the possibility of combining the study of music, language, and literature within an interdisciplinary topic.

Chase felt the chord produced by open guitar strings, which he called the symbolic chord, the use of creole dance rhythms, especially that of the malambo and the relationship of lyrical episodes to the copla (an eight-syllable quatrain) of Spanish folk styles are three of the most important Argentine music elements. ${ }^{4}$ According to Chase, the guitar is the characteristic instrument of the gauchos and of the folk music of the pampas. Chase traced the development of the guitar chord over a period of nearly twenty years starting from the three Argentine Dances for piano (1937), and also including the Malambo for piano (1940), Pampeana No. 1, Rhapsody for Violin and Piano (1947), the first String Quartet (1948), Sonata for Piano (1952), Pampeana No. 3, and Symphonic Pastoral (1954). Chase identified the malambo as a typical dance of the gauchos that is derived from the Argentine rural dance tradition. Malambo rhythms animate many of Ginastera's compositions from Estancia (1941) to Pampeana No. 3, Piano Sonata, and Variaciones concertantes (1953). A chronological list of Ginastera's compositions as well as information on the first performance date and publisher conclude Chase's article.

While Chase studied Ginastera's entire output, Mary Ann Hanley focused on his solo piano music. In 1968, Hanley analyzed and discussed Ginastera’s solo piano music based on interviews with Ginastera and on the composer's lectures at Dartmouth College. ${ }^{5}$

\footnotetext{
${ }^{3}$ Ibid., 445-46.

${ }^{4}$ Ibid., 456.

${ }^{5}$ Mary Ann Hanley,’The Solo Piano Music of Alberto Ginastera Part I." The American Music Teacher 24/1 (June/July 1975): 17-20.
} 
According to Hanley, Ginastera divided his compositions into three style periods. The first period, marked as "an objective nationalism", spaned the years 1937 to 1946; the second, "subjective nationalism", began in 1946; and the third, "New Romanticism or Expressionism", began in 1960. In her two-part article, Hanley explored Ginastera's use of harmony, texture, and rhythm in several piano compositions. In Part I of her article, Hanley discussed piano works such as Danzas Argentinas, Piezas Infantiles, Tres Piezas, Malambo, and Twelve American Preludes from Ginastera's first style period, while in Part II she covered Rondo on Argentine Children's Folk Tunes, Suite de Danzas Criollas and Sonata para Piano from Ginastera's second style period.

According to Hanley, Ginastera regarded Suite de Danzas Criollas and Sonata para piano as his best compositions for piano. In her discussion of Suite de Danzas Criollas, Hanley noted that Ginastera felt this composition represented the beginning of his second style period characterized by subjective nationalism. Ginastera told Hanley that "all the melodies and rhythms in the Suite are Argentine; however, this material is used in a new, personal and imaginative way, as if inspired by a folklore dream. ${ }^{\prime 6}$ Ginastera also discussed each piece in detail with the author, describing his use of Argentine folk elements as well as the basic structure and harmonic design of these works. Hanley praised this dance collection as pianistic and rewarding to play although it demands power and good rhythmic control. A list of Ginastera's piano solo compositions based on the information extracted from Chase's article ${ }^{7}$ concludes Part II of Hanley's article.

Several doctoral dissertations, master's theses and performance treatises have also been devoted to Ginastera's music. David Edward Wallace's 1960 dissertation provides an early analysis of Ginastera's musical style and compositional techniques. ${ }^{8}$ Wallace became

. "The Solo Piano Music of Alberto Ginastera Part II." The American Music Teacher 25/6 (September/October 1975): 6-9.

6 Hanley, "Piano Music of Ginastera", 6.

${ }^{7}$ Gilbert Chase, “Alberto Ginastera: Argentine Composer,” The Musical Quarterly 43 (1957): 439-60.

${ }^{8}$ David Edward Wallace, "Alberto Ginastera: An Analysis of His Style and Techniques of Composition" (Ph.D. diss., Northwestern University, 1964). 
acquainted with Ginastera's compositions in a university seminar devoted to a few wellknown Latin American works. This in turn gave the author a strong interest in Ginastera's music since the composer's style appeared to be more international and was moving in exciting directions at that time.

The purpose of Wallace's study was to illustrate the evolutionary character of Ginastera's works; therefore the compositions are presented and analyzed in chronological order. Wallace's analyses are based on the melodic, rhythmic, structural, and harmonic devices utilized by Ginastera in compositions completed up to 1960 . The author also included a brief survey of Argentine history and music as well as a biography of the composer.

Wallace organized Ginastera's music into four periods: early works from 1934-40, works characterized by consolidation and expansion from 1941-46, works using old and new techniques from 1947-54, and works from 1958-63 incorporating what Ginastera called "principal tendencies" (serial expressionism and post-Webernian pointillism) of contemporary compositions. ${ }^{9}$ His attention was given to every phase of the composer's compositional technique in an effort to understand Ginastera's music overall.

The Suite of Creole Dances was composed during what Wallace described as Ginastera's second compositional period. He feels the suite contains idealizations of Creole dance styles in both slow and fast tempos within its five movements. ${ }^{10}$ The rhythmic pattern and melodic contours of the first movement reflect the Spanish influence of Creole folksong. Wallace analyzed the piece in a $\mathrm{G}$ tonality with repetition of a four-measure harmonic pattern of I, IV, flat VI, I. The last phrase ends in an impressionistic fashion, with an embellished extension using arpeggiated chords with altered fourths. The second movement alternates two rhythmic and textural patterns (i.e., measures 1-2 and 7-8) that Wallace associated with

\footnotetext{
${ }^{9}$ Ibid., 220, quoting Albert Ginastera, untitled review of Inter-American Music Festival (Boletin Interamericano de Música, No. 14, Nov., 1959), 3-4.

${ }^{10}$ Wallace, "Ginastera, An Analysis of His Style," 113.
} 
the style of gato, an idealized version of gaucho dance of the nineteenth century. ${ }^{11}$ Most interesting is the polytonality used in several sections where the right hand is sometimes a step below the left in tonality.

As for the third movement, Wallace believes an Indian influence is obvious with its uneven rhythmic pattern and descending melodic line. The fourth movement is in a habanera-like rhythm of $6 / 8$. According to Wallace, its Andalusian origin is evident from its melodic and rhythmic characteristics as well as from the use of parallel thirds below the melody in the middle section. The last movement, Scherzando, is a very fast movement with a meter signature of 3/4-6/8. Wallace thinks this is an indication that this movement is based on the malambo dance. The ostinato chordal pattern of the left hand and metric alternation among $3 / 4,6 / 8$, and $5 / 8$ in the first section are noteworthy. The harmonies in this movement are often based on perfect intervals, for example measures 24-27 where ostinato open fifths contrast with a descending scale line harmonized with octaves and fifths. ${ }^{12}$ The Coda is played attacca to the preceding movement and shares characteristics resembling its rhythmic design and thematic materials.

In his conclusion, Wallace summarized Ginastera's use of form, rhythm, melody, harmony, tone color, and twelve-tone technique in all compositions surveyed. He then drew conclusions regarding the evolution of Ginastera's musical style.

While Wallace studied the works of one composer - Ginastera - in a variety of genres, Patricia Montgomery investigated the works of several composers in a single genre. In 1978, Montgomery surveyed twentieth-century Latin American piano suites including the Suite de Danzas Criollas by Ginastera. ${ }^{13}$ She provided a brief survey of the keyboard suite in Europe, beginning with the dance suites of Rameau and Couperin in the Baroque period to Schoenberg's Suite Op. 25 in the first quarter of the twentieth century. She traced Latin

\footnotetext{
${ }^{11}$ Ibid., 114.

${ }^{12}$ Ibid., 116.

${ }^{13}$ Patricia Montgomery, "The Latin American Piano suite in the Twentieth Century" (D.M.A. diss., Indiana University, 1978).
} 
American musical traditions (organized by the traditions of folk and art music) as well as the styles reflecting provincialism, nationalism and universality. Montgomery also offered detailed discussions of thirty piano suites by composers from seven countries including Argentina, Chile, Brazil, Cuba, Venezuela, Peru, and Guatemala. Regarding the place of Latin American piano suites in contemporary music, the author examined and drew conclusions concerning (1) the relationships of these works to the suite genre in Europe, (2) the extent to which the suite is a reflection of musical styles in Latin America, and (3) the place of contemporary Latin American suites in piano literature. ${ }^{14}$

When discussing the Suite de Danzas Criollas of Ginastera, Montgomery focused on the folk style of gauchesco that had been identified by Chase, ${ }^{15}$ and offered theoretical analyses covering aspects of melody, harmony, form, texture, and rhythm. Two major gauchesco elements, the guitar chord and the malambo, are obvious in Ginastera's writing. The "natural" chord (E-A-D-G) of the guitar was used in the fourth movement of the suite. The fifth movement of the Suite is a malambo. Montgomery's discussion of those musical elements used in Ginastera's Suite de Danzas Criollas can be summarized as follows: 1) the melodies are made up of short motives within a narrow range, 2) the harmony uses added notes such as seconds and sevenths for coloristic effect and occasional polytonality, 3) the formal structure consists of frequent use of short sectional forms such as ABA, 4) the texture often includes tone clusters and melody with arpeggiated accompaniment, and 5) the most outstanding feature of rhythm is characterized by hemiola and irregular meters. ${ }^{16}$

Roy Wylie and Deborah Schwartz-Kates have both studied Argentine influences on Ginastera's compositions. In 1986 Roy Wylie examined specific Argentine folk music idioms that are used in Ginastera's piano music. Wylie feels that part of the attraction of Ginastera's music comes from his drawing on rhythm, melodies and structures of

\footnotetext{
${ }^{14}$ Ibid., 118.

${ }^{15}$ Ibid. 22, quoting Gilbert Chase, “Alberto Ginastera: Argentine Composer,” The Musical Quarterly 43 (1957): 456.

${ }^{16}$ Ibid., 29.
} 
Argentine folk music. ${ }^{17}$ Therefore, the purpose of this dissetation was to ascertain what Argentine folk elements are exhibited in Ginastera's music; this knowledge will help the performer and teacher to understand his music more clearly and thus be able to interpret it better. The author explored those folk resources in a discussion of Argentine folk music and examined various ethnic cultures such as Inca, Spanish and Black African that contributed to the folk music of the area. Discussions of the different types of folk songs, traditional folk instruments and styles of folksongs in the aspects of meter, tempo and rhythm were included.

After providing a biographical chapter tracing Ginastera's life and musical development, Wylie identified specific musical works such as Danzas Argentinas, Tres Piezas, Malambo, Doce Preludios Americanos, Suite de Danzas Criollas, and Sonata para Piano in which Argentine folk idioms were represented prominently. The analysis of each piece concludes with a discussion of specific technical difficulties to be encountered in the performance of the work. According to Wylie the pianistic challenges of Suite de Danzas Criollas emerge from the playing of tone clusters and the complexity of meters. ${ }^{18}$ The importance of tone clusters can be seen from the very start of the "Adagietto pianissimo" immediately through the second movement "Allegro rustico" where chords are played either with two notes per finger or with the palm of the hand. The unusual meter of $11 / 8(6 / 8$ plus $5 / 8)$ of the third movement "Allegro cantabile" and the rapid meter change of the fifth movement "Scherzando" and Coda create rhythmic drive and provide technical challenges for the performer.

While Wylie examined the use of Argentine folk elements in Ginastera's music, Deborah Schwartz-Kates studied the gauchesco tradition and its influence on Argentine music. In 1997, Schwartz-Kates wrote an excellent entry on Ginastera in the revised edition

\footnotetext{
${ }^{17}$ Roy Wylie, "Argentine Folk Elements in the Solo Piano Works of Alberto Ginastera," (D.M.A. diss., University of Texas, Austin, 1986), 1.

${ }^{18}$ Ibid., 110.
} 
of The New Grove ${ }^{19}$ exploring the relationship between Argentine musical nationalism and the symbolic heritage associated with the gaucho (the cowboy of the Argentine plains). ${ }^{20}$ She began her research in Buenos Aires under a fellowship from the Institute of Latin American Studies of the University of Texas in 1990. Her research was undertaken by studying musical manuscripts and books (some out-of-print) from Argentine musical institutions, listening to archival tapes provided by Argentine National and Municipal Radio, and conducting personal interviews with Argentine composers' families. SchwartzKates's dissertation investigated the gauchesco symbol in Argentine culture, folkloric traditions and repertoire of the gaucho, the construction of Argentine musical nationalism (1880-1910), the consolidation of this nationalism during the Centenary Age (1910-1930), the artistic renovation during the Authoritarian Age (1930-1950), and new horizons in Ginastera and the Argentine gauchesco tradition. In general, her research provided a comprehensive study of Argentine art music of the late nineteenth and twentieth centuries, how it motivated and shaped the development of national expressive forms, and how it was influenced by the gauchesco tradition.

According to Schwartz-Kates, composers during the years of 1890-1955, when nationalism arose in Argentina as a form of cultural expression, have closely identified with the gauchesco tradition. Schwartz-Kates's studied four different generations of Argentine nationalist musicians: the first generation consists of the first professionally-trained group of composers, the founders of the Argentine nationalism; the second generation (born during late1870's and early1880's) intensified the nationalist principles of the first generation; the third generation (born during late 1880s and 1890s) reacted negatively by adopting an increasingly abstract and cosmopolitan musical language; and the fourth generation (born during the 1900's and 1910's) is dominated by the work of a single composer, Alberto

\footnotetext{
19 D Schwartz-Kates. 'Gingstera, Alberto', Grove Music Online ed. L. Macy (accessed 1 August 2005), http://www.grovemusic.com

${ }^{20}$ Deborah Schwartz-Kates, "The Gauchesco Tradition as a Source of National Identity in Argentine Art Music (ca. 1890-1955)" (PhD. diss., University of Texas at Austin, 1997).
} 
Ginastera (1916-1983). ${ }^{21}$

Schwartz-Kates viewed Ginastera as a dominant member of the latest generation of Argentine composers. She felt his unique musical style concluded the musical era based on the gaucho by synthesizing native folk idioms with contemporary compositional techniques. Schwartz-Kates noted that the goal of her discussion of Ginastera was to re-examine Ginastera's nationalist position from a culturally integrated viewpoint, and to suggest new paths of investigation based on previous examination of the gauchesco tradition. ${ }^{22}$ Schwartz-Kates emphasized the Argentine roots of Ginastera's nationalist experience, and the guiding precept of her study was to explore how Ginastera used nationalism as an expression of cultural identity. An examination of Ginastera's earliest known music prior to 1955 revealed the connection with criollo heritage. The majority of these works consist of either short piano pieces (including the Suite de Danzas Criollas) or of songs that show the composer's employment of highly traditional stylistic formulas (such as the miniature genres that were based on simple formal schemes and the use of folk dances, the triste, gato, zamba, and chacarera) ${ }^{23}$ After 1955, the gauchesco influence diminished due to Ginastera's depletion of such resources and to the decline in nationalist sentiment. ${ }^{24}$ In her conclusion, Schwartz-Kates stressed the importance of remembering the musical heritage of the gauchesco tradition as a cultural significance that shaped Argentine musical nationalism during its most fruitful years.

Scholars have written little concerning Ginastera's pedal indications. Joanna Tuley Burnside's 2000 monograph, Use of Pedal in Selected Piano Music of Alberto Ginastera, is one of only a few studies that explored the use of pedal in Ginastera's music and provided guidelines for the instruction of pedaling. ${ }^{25}$ Repertoire chosen to illustrate those guidelines

\footnotetext{
${ }^{21}$ Ibid., 10-11.

${ }^{22}$ Ibid., 854.

${ }^{23}$ Ibid., 859-860.

${ }^{24}$ Ibid., 908-909.

${ }^{25}$ Joanna Tuley Burnside, "Use of Pedal in Selected Piano Muisc of Alberto Ginastera" (D.M.A. diss., Louisiana State University and Agricultural and Mechanical College, 2000).
} 
includes Danzas Argentinas, Op. 2; Twelve American Preludes, Op. 12; Suite de Danzas Criollas, Op. 15 and Rondo on Argentine Children's Folk Tunes, Op. 19. These pedal suggestions were offered basically for pedagogical purposes - to assist teachers in their instruction of piano students. Since Ginastera included relatively few pedal markings in his piano music, Burnside felt it is important to find authentic and convincing pedal suggestions for pianists.

When formulating her pedaling suggestions, Burnside considered the following: 1) terminology and notation, 2) scholarly writings of performance practice concerned with pedaling and 3) the relationship between Ginastera's works that contain pedal markings and those that do not. She also considered the harmony, texture, dynamics, and rhythm of the compositions. Furthermore, the author noted that studying manuscripts and listening to various recordings would also help pianists make informed pedaling choices.

The Suite de Danzas Criollas features many elements that are characteristic of Ginastera's writing, such as lyrical folk melodies, Latin harmonies and rhythms, and chord clusters. However, the composer included a few original pedal indications in these dances. He specified the use of "due pedali" (two pedals) in the beginning of dance four, and indicated $\mathrm{Ped}$. markings six times in the closing section of dance five. Burnside feels that because there are so few original pedal markings, the performer will need to chose his preferred pedaling based on notation (such as slurs) and articulation indications (such as legato, and marcatissimo). She feels that textures such as the simple singing melodies with broken chord accompaniments in the first and third dances should be pedaled in such a way that both the melodic line and the harmonies are clear. ${ }^{26}$ She also noted that the second dance, the fifth dance, and the Coda will need frequent pedal changes due to their fast tempi and frequent use of rests. A touch of pedal with accurate timing can be effective in these movements. When passages use the pitches of the open string guitar chord, Burnside felt the use of pedal could help to create a special blurred atmosphere.

\footnotetext{
${ }^{26}$ Ibid., 67.
} 
In conclusion, Burnside emphasized the importance of practicing pedaling just as the pianist practices other aspects of performance. When making pedaling choices, one should not only pay attention to the original tempo markings offered by the composer in the score, but should also look carefully for additional elements as well. In terms of teaching, Burnside suggested that teachers should present different ways of pedaling to students playing Ginastera's music.

\section{Samuel Barber (1910-1981)}

Barber was one of the most important American composers in the twentieth century. Nearly every musical genre is represented in his output, and his works enjoy great popularity, being widely performed. His works represent nearly every musical genre and enjoy great popularity, being widely performed. In spite of Barber's prominent position, extensive scholarly research on his music has not been conducted. The majority of this research consists of DMA and MM documents and shows the appreciation of Barber's piano music since the 1950s, when Barber's reputation was well established.

Only two books on Samuel Barber and his piano music could be found. The short biography by Nathan Broder is the first and most frequently cited work about Barber. ${ }^{27}$ This book includes a revised version of an earlier article, written in $1948 .{ }^{28}$ In this article, Broder offered generalizations about many aspects of Barber's musical style - particularly related to melody, harmony, counterpoint, rhythm, and form, illustrated with several music examples. Broder felt the melodic structure in Barber's music is governed by tonality. Musical excerpts reveal that the tonal structure in Barber's early music is lyrical but becomes chromatic and angular in his later music. The harmonic texture grows more dissonant in his later works. In addition to works based on a tonal center, polyharmonies are introduced to

\footnotetext{
${ }^{27}$ Nathan Broder, Samuel Barber (New York: G. Shirmer, 1954).

${ }^{28}$ Nathan Broder, “The Music of Samuel Barber," Musical Quarterly 34 (July 1948): 325-335.
} 
color a passage in boogie-woogie style such as in Excursions No. $1 .{ }^{29}$

Broder felt the Excursions No. 1 is unified more by linear aspects of melodic and intervallic relationships than by vertical characteristics of harmony. The use of intervals of a second or a ninth is important in many works. Broder noted that Barber also emphasized counterpoint by combining old polyphonic principles with twentieth-century harmonic language in his fugal writing. In addition, Barber's rhythmic organization is "varied and active." ${ }^{\prime 30}$ Barber's Excursions No.3 shows an unusual rhythmic organization even with a simple folk-like tune. Barber has a strong feeling for form. Broder felt that Barber's large works, based primarily on traditional procedures of sonata form, present the closest ties with the past. ${ }^{31}$ The article concludes with a list of works up to the Piano Sonata in 1947 and provides information about their first performance.

Broder later revised and extended this article in the second part of his book, the first about Samuel Barber and his music. Broder's study is divided into two parts, "The Man" and "The Music." There are eight untitled sections in the first part, tracing Barber's life from 1916 to the mid-1950s. At the time of publication (1954), this was the only biographical material on Barber that was based on information provided by Barber, his family, and newsletters from the Curtis Institute of Music. In the second part of his book, Broder analyzed practically the whole of Barber's output, his two symphonies, two Essays, three concertos, two sonatas, choral works, and short instrumental pieces. Both these sections of Broder's text are illustrated with photographs and musical quotations. His analyses are interesting and valuable, but not detailed. The appendix is very short and includes a list of works and available recordings at that time, as well as a list of eight articles about Samuel Barber.

Broder included Excusions, Op. 20 (1944), Piano Sonata, Op. 26 (1949) and Souvenirs (1952) in his discussion of Barber's piano music. He noted that the Excursions illustrate

\footnotetext{
${ }^{29}$ Ibid., 327.

${ }^{30}$ Ibid., 329.

${ }^{31}$ Ibid., 330.
} 
four types of American music. According to Broder, the first is in boogie-woogie style, the second is an elegant blues, the third is a set of variations on a folk-like melody, and the last is a brilliant barn dance in which the scoring of folk instruments (such as fiddles and mouthorgans or accordions) is easily recognized. ${ }^{32}$ Broder observed that the Piano Sonata, which is based on traditional formal patterns and has a key center of E-flat minor, is Barber's first work that uses twelve-tone writing. Broder provided several musical examples to illustrate the thematic development of each of the four movements, giving special emphasis to the twelve-tone rows in the first and third movements.

Barbara Heyman's book, which appeared forty years after Broder's, is the most recent and exhaustive study of Barber. ${ }^{33}$ According to Don Hennessee, this is the most detailed and the most authoritative published work on Barber to date. ${ }^{34}$ The primary source material for the study, according to Heyman, consisted almost entirely of letters, diary and journal entries, sketchbooks, holographs, autograph manuscripts, and other related documents from the Barber estate. Unlike Broder, Heyman did not divide Barber's life and works into two separate sections, but traced his life in relation to all of his musical works. She discussed Barber's life in strict chronological order by examining many primary source documents, and conducted numerous interviews with Barber's family and friends.

Heyman discovered some major influences in Barber's life which created a consistent connection to the nineteenth century: 1) his formal musical education, 2) the impact of European travel on his intellectual development, and 3) the personal guidance he received from his uncle Sidney Homer, who was Barber's mentor for over twenty-five years. ${ }^{35}$ Moreover, Heyman mentioned that most of Barber's instrumental compositions were written with a particular performer or performance group in mind. Changes were

\footnotetext{
32 Broder, "Samuel Barber," 68-69.

${ }^{33}$ Barbara Heyman, Samuel Barber: The Composer and His Music (New York: Oxford University Press, 1992).

${ }^{34}$ Don Hennessee, Samuel Barber: A Bio-Bibliography (Westport, Conn.: Greenwood, 1985).

${ }^{35}$ Barbara Heyman, Samuel Barber: The Composer and His Music (New York: Oxford University Press, 1992), 4.
} 
made in many compositions based on the strengths of the particular performer(s) as it was tested in performance. In her interviews with artists who gave first performances of Barber's works, Heyman focused on several topics, such as discussions of special performance challenges or innovations, and general suggestions about performance.

In general, the abundance of interesting photographs and the presence of selected musical examples from manuscripts and published scores in Heyman's book are valuable. The extensive notes and references offer additional information on the composer. Even though Heyman provided a chronological overview of Barber's entire output, she felt there was a pressing need for a more comprehensive, descriptive thematic catalogue because new sources received from scholars, performers, and conductors continued to emerge. Despite this fact, Heyman's book is very useful in itself and will serve as a guide for further research on Samuel Barber and on performances of his music.

Five doctoral dissertations provide significant information on Barber's Excursions. Russell Edward Friedewald's dissertation, for instance, focused on the style and formal structure of Barber's compositions. ${ }^{36}$ Written in 1955, this study shows an early interest in Barber's music. Since this dissertation was completed three years after Nathan Broder's extensive biographical study, Barber declined to be interviewed again about his life and work by another author. Therefore, Friedewald could only write a brief sketch outlining Barber's career compiled from Broder's book. Both studies show the popularity of Barber's music, though the surveys of his music are not complete because the composer was still active as a composer at that time.

The technical details of melody, harmony, rhythm, and orchestration are important factors that Friedewald considered when analyzing Barber's music. Friedewald organized Barber's music according to instrumental type - vocal, piano, chamber, symphony, and other orchestral works. He covered only two piano works in this study, Excursions, Op.

\footnotetext{
${ }^{36}$ Russell Edward Friedewald, "A Formal and Stylistic Analysis of the Published Music of Samuel Barber," (Ph.D. diss, Iowa State University, 1957).
} 
20 and Piano Sonata, Op. 26. Both works were first performed by the legendary pianist Vladimir Horowitz.

Friedewald feels the four short pieces in Excursions are subtly refined treatments of four popular styles of American music. He analyzed each piece based on its formal structure, chord progression, and unusual rhythmic organization. He feels the formal pattern of the first piece consists of a five-part rondo within a style of piano blues known as boogie-woogie. The special interest of this work lies in the ostinato bass figure (with its sharp rhythm in the left hand against the rhapsodically free right hand) as well as in the syncopated block chords in the middle section. ${ }^{37}$ The second piece is a rich and elegant blues that Friedewald divided into four twelve-measure sections, each being improvisatory in nature. He thinks the simultaneous use of the "blue" note and the leading tone scale degree is a unique harmonic feature. ${ }^{38}$ As for the third piece, he feels the unusual rhythmic organization in a set of variations on a folk-like melody makes this piece interesting within this group. The last movement, an Allegro molto, is a joyous barn dance according to Friedewald. He analyzed the structural design according to a tripartite pattern of ABA, and noted that the chords are limited to the tonic and subdominant triads in the key of F major throughout the entire composition. The B section provides contrast through mutations of the original melodic material from the A section.

The Piano Sonata is a masterpiece that is emotionally more profound and technically farther advanced than the Excursions. It is one of Barber's most important works because he used the twelve-tone technique for the first time. Friedewald's analysis of this piece focused on pitch patterns, melodic figures, thematic design, and rhythmic figures.

In 1960, Lawrence Samuel Wathen studied dissonance treatment in Barber's instrumental music and attempted to determine under what circumstances the dissonance occurs. ${ }^{39} \mathrm{He}$

\footnotetext{
${ }^{37}$ Ibid., 124.

38 Ibid., 127.

${ }^{39}$ Lawrence Samuel Wathen, "Dissonance Treatment in the Instrumental Music of Samuel Barber," (Ph.D. diss, Northwestern University, 1960).
} 
examined all of Barber's published instrumental music from Op.1 through Op. 31 (dated 1957) as a theoretical aid to solve the problem of dissonance treatment. Wathen chose the music of Barber because of his conventional writing style, and his standardized treatment of dissonance. Generally, Wathen's study is based on analyses of the music from melodic and harmonic viewpoints. He organized his discussion into two major parts: the first part is concerned with contrapuntal dissonance and the second part is concerned with harmonic dissonance. When examining the use of contrapuntal dissonance, seven basic types of non-harmonic tones are investigated, such as the suspension, appoggiatura, anticipation, auxiliary, passing tone, cambiata and échappée. Further exploration of the seventh chord and fourth chord formation was conducted in order to examine harmonic dissonance.

When Wathen examined Barber's use of contrapuntal dissonance in Excursions, he found that Barber used the appoggiatura, cambiata, and échappée. The appoggiatura is prominent due to its strong rhythmic position when approached by step. In the third movement (mm. 40) of Excursions, Barber used two appoggiaturas simultaneously. Wathen thinks the composer's method of double appoggiatura is regular regarding its resolution by a second descending to a chord tone. ${ }^{40}$ The cambiata occurs in a weak rhythmic position and is a non-harmonic tone approached by an interval larger than a second (usually a third); it progresses by a second to the succeeding tone. ${ }^{41}$ Wathen felt Barber used irregular cambiata technique in the third movement (mm. 48-49) because the approach to the cambiata is made by an interval larger than a third. ${ }^{42}$ The échappée also occurs on a weak beat, but it is approached by the interval of a second, and progresses by an interval larger than a second to the succeeding tone. The échappée appearing in the first movement (mm. 49) is unique, for it progresses by an interval of fourth, creating a simultaneous cross relation between a sounding B-flat and a B natural. ${ }^{43}$

\footnotetext{
${ }^{40}$ Ibid., 59.

${ }^{41}$ Ibid., 86.

${ }^{42}$ Ibid., 87-88.

${ }^{43}$ Ibid., 90.
} 
Following his chapter on contrapuntal dissonance, Wathen examined harmonic dissonance in Barber's music. Based on Wathen's analysis, Barber's dissonance treatment in both contrapuntal and harmonic writing has common characteristics. Wathen concluded that,

The dissonant treatment in the music of Barber has its foundation in established regularity. The irregular modifications of the defined essentials of each kind of treatment proceed from this established regularity. ${ }^{44}$

In conclusion, Wathen stressed the importance of the role of the dissonance approach played in Barber's style, and saw that Barber had established a standard in his own treatment by frequent employment.

After Wathen completed his study in 1960, Barber's keyboard music continued to appeal to performers and became an important part of the contemporary American piano repertoire. In 1980, Susan Blinderman Carter identified a growing interest in Barber's music as well as a need for a performance guide. She therefore conducted a study of Barber's five piano compositions that was intended as a performance guide for both piano teachers and students. Her goals were three-fold in nature: (1) to provide a current biography of the composer, (2) to place Barber's works within the stylistic framework of contemporary music, and (3) to furnish an analysis of Barber's published piano music. ${ }^{45}$

In Chapter I, a rather detailed biography and personality sketch provided insight into the man and his ideas. Carter feels that knowledge of the composer's life is essential to understanding his music. Carter also made an effort to update Nathan Broder's 1954 biography with information from more recent articles in periodicals and newspapers.

When discussing Barber's musical style, Carter focused on Barber's general musical characteristics and wide variety of styles. Carter feels Barber's style is characterized by

\footnotetext{
${ }^{44}$ Ibid., 138.

45 Susan Blinderman Carter, "The Piano Music of Samuel Barber” (Ph.D. diss., Texas Tech University, 1980), iv.
} 
the broad lyricism and dramatic expression typical of neo-Romanticism. ${ }^{46}$ The piano composition Excursions shows Barber's experimentation with diversified style, drawing upon such American influences as blues and boogie-woogie. Other compositional techniques that Barber used are discussed as they relate to the evolution of his later style. Carter saw Barber as a conservative composer because elements such as lyricism, traditional form, preserved tonality, and contrapuntal texture are deeply rooted in his traditional compositional procedures.

In subsequent chapters, Carter offered analyses of five selected piano works: Excursions, Op. 20 (1945), Piano Sonata in E-flat Minor, Op. 26 (1950), Nocturne Op. 33 (1959), Ballade, Op. 46 (1977) and Piano Concerto (1962). She included information on the background and early performance of the works; analyses of the melodic, formal, harmonic, and rhythmic elements, as well as discussions of interpretive and technical problems.

The last chapter contains concluding remarks based upon the formal, motivic and tonal analyses of the piano music. This chapter supports the author's belief that Barber's piano music has represents a significant contribution to the twentieth-century keyboard repertoire. In terms of performance, Carter feels Barber's piano music provides the pianist with both interpretive and technical challenges because of the fusion of contemporary and traditional procedures. She concluded that the most effective performances will result from an interpretation that projects the meaning found in the musical structure itself based upon valid analytical principles.

In 1982 Sifferman analyzed Barber's Excursions, Op. 20 (1945), Piano Sonata, Op. 26 (1950), Nocturne, Op. 33 (1959), and Ballade, Op. 46 (1977). ${ }^{47}$ Numerous musical examples are included in Sifferman's discussion as he explored Barber's writing style, formal structures, and compositional techniques. A short biography and a review of existing studies were presented to illuminate Barber's career and compositional process. In the final

\footnotetext{
${ }^{46}$ Ibid., 25-26.

${ }^{47}$ James Philip Sifferman, "Samuel Barber's Works for Solo Piano" (D.M.A. diss., University of Texas at Austin, 1982).
} 
chapter Sifferman discussed Barber's incorporation of twelve-tone rows in the first and third movements of the Sonata and in the Nocturne.

According to Sifferman, there are three important stylistic elements in Barber's piano writing: (1) the use of traditional formal structures coupled with great clarity within these forms, (2) romantic expression, and (3) incorporation of idioms found in American folk music and jazz. ${ }^{48}$ Sifferman felt one or more of these prominent characteristics distinguish most of Barber's piano writing. The Excursions represents an example of using American folk idioms; the Piano Sonata encompasses all three of those characteristics; the Nocturne and Ballade make use of first two elements, exemplifying the typical nineteenth-century Romantic character pieces in terms of harmonic and textural piano writing.

Sifferman believed that the Excursions exhibit more "Americanisms" than most other Barber works. The American folk and popular elements include the boogie-woogie in the first; blues in the second; lively folk melody with a distinctive Latin flavor in the third; and the country square dance in the last. ${ }^{49}$ One of Sifferman's most useful theoretical analyses is the arch form diagram he provided in his discussion of the fourth Excursion.

In 1989 Lauri L. Young investigated the musical style of Barber's four solo piano works, Excursions Op. 20, Sonata Op. 26, Nocturne Op. 33 and Ballade Op. 46 in her dissertation entitled "The Solo Piano of Samuel Barber." ${ }^{50}$ Young started her dissertation with a biographical sketch of Barber since she believed that man's life experiences and professional training is reflected in his art. She highlighted Barber's relationship with Gian Carlo Menotti because it influenced the most serious creative works of the composer. Then Young analyzed each of the four solo piano works in great detail from a structural, harmonic, motivic and even sociological viewpoint.

In her analysis of Excursions, Young showed how Barber incorporated the unique American sources of jazz and folk materials in his compositional technique. Barber

\footnotetext{
${ }^{48}$ Ibid., viii.

${ }^{49}$ Ibid., 5.

${ }^{50}$ Lauri L. Young, “The Solo Piano Music of Samuel Barber” (DMA diss, University of Cincinnati, 1989).
} 
borrowed rhythmic and formal jazz elements such as boogie-woogie and blues and then altered them slightly to produce his own original interpretations. ${ }^{51}$ Young also observed how Barber portrayed a romantic view of life on the frontier. According to Young, Barber's use of an American cowboy tune as thematic material in Excursions is parallel to Copland's use of such material in Rodeo, written in $1942 .{ }^{52}$ The Excursions is quintessential American music and represents the rise of American nationalism in the 1940s.

Young analyzed the Piano Sonata movement by movement with attention to motivic construction, specific intervallic structure and serial technique. The analysis of specific intervals and tone rows in Barber's Nocturne and Ballade shows his further interest in serialism. However, in spite of his use of serialism, the pianistic writing in Barber's Nocturne resembles that in Chopin's Nocturnes.

In her concluding chapter, Young traced the stylistic development of ballades from Chopin onward and then analyzed Barber's Ballade based on serial chord structures and tonal progressions. In many respects, Young feels the chromaticism of the Ballade and the Barber's treatment of thematic material are highly successful. ${ }^{53}$

Three master's theses written by Elaine K. Miller, Lynda Lee Freeman Oswalt, and Jeannette Owens also include valuable information on Barber's piano works. In 1960, Miller provided a brief biographic sketch of Barber and a discussion of the composer's piano works, the Excursions, Op. 20; Sonata, Op. 26; Souvenirs, Op. 28 and Nocturne, Op. 33 (Ballade was not included because it had not yet been composed at the time of her writing) ${ }^{54}$ Miller praised the originality and lively expression of Barber's modern musical language. She described each of the four Excursions from an analytical standpoint, focusing on the development of melody, tonality, rhythm, and formal pattern. An abundance of musical examples illustrating basic motivic and bass patterns were included. According to

\footnotetext{
51 Ibid., 26.

52 Ibid., 47.

53 Ibid., 200.

54 Elaine K. Miller, “A Study of Samuel Barber's Piano Music,” (MM Thesis, Kent State University, 1960).
} 
Miller, the style of the first piece is a boogie-woogie in which an ostinato bass is employed to accompany a freely improvised right hand melody; the second piece is in blues style established by two motives and their varied treatment with triplets, repeated notes and canonic imitation; the third piece is a folk-like tune in the form of a theme and variations; and the fourth piece is a barn dance based on the sound of a country fiddler. ${ }^{55}$

Miller used a similar analytical method in her investigation of the Sonata, except for her extensive analysis of the contrapuntal structure of the fourth movement. In her analysis of Souvenirs, she presented only musical examples with principal thematic material without further comment. As for the Nocturne, she felt the piece combines twelve-tone writing characteristic of the mid-twentieth century with a character piece style, prevalent during the Romantic period. In summary, Miller commented that these works composed after 1939 are less traditional and conservative in style and tonality than Barber's earlier works. Since Barber incorporated various twentieth-century compositional techniques in his piano music, Miller felt that by studying it, one can learn much about modern music as a whole. In her opinion, although Barber's music is difficult to learn and play, it is very rewarding to perform and study.

In 1971, Oswalt provided a comprehensive stylistic analysis of Barber's piano works including the Excursions, Sonata, Souvenirs, Nocturne and Piano Concerto. ${ }^{56}$ The Ballade, composed one year after Oswalt's study, was not included. In the introduction Oswalt offered a brief overview of Barber's life, piano compositions, and a few other works, and an examination of "forces influencing Barber's musical style." 57

She then analyzed each piano composition in detail in individual chapters. She began each analysis with introductory comments on the compositional background and general style. The major part of her analysis consists of investigations of thematic motives, musical

\footnotetext{
55 Ibid., 7-12.

${ }^{56}$ Lynda Lee Freeman Oswalt, "The Piano Music of Samuel Barber: A Brief Stylistic Analysis," (MM Thesis, University of Nebraska, 1971).

57 Ibid.,
} 
examples, and analytical charts that exemplify melodic content, texture, and tonal centers for each section of the movement.

Oswalt felt the first movement of Excursions is in three parts, each beginning with a brief introductory statement of the single-line ostinato accompaniment. ${ }^{58}$ Each hand performs two important motives in the opening three measures, and the three-measure theme starts afterwards. The second movement is a thirteen-measure theme with three variations in slow blues tempo. ${ }^{59}$ The theme in the third movement is followed by eight variations, which are set in polyrhythms and are reminiscent of popular contemporary Latin-American music. ${ }^{60}$ The final movement has three melodic motives which are repeated and varied using different rhythmic patterns within a ternary design. ${ }^{61}$

In the study of the Piano Sonata, Oswalt made a comparison of thematic relationships between movements, and examined twelve tone rows that constituted the theme in the first three movements. In her discussions of the fourth movement, she observed Barber's application of fugal devices in the textural treatment of motives. Oswalt paid special attention to the difference between the piano solo and the duet arrangements of the Souvenirs. The Nocturne, according to Oswalt, is similar to the third movement of the Piano Sonata in that they both combine serialism and tonal procedures in a ternary form. ${ }^{62}$ The author analyzed the Piano Concerto based on the formation of thematic groups.

Owens's 1993 thesis focused on the interpretation and performance of Samuel Barber's solo piano music. ${ }^{63}$ Owens explored the formal styles and pianistic devices of Barber's four piano works: Excursions, Op. 20, Piano Sonata, Op. 26, Nocturne, Op. 33 and Ballade, Op. 46. She began her study with brief biographical information on Barber in the introduction.

\footnotetext{
58 Ibid., 12.

59 Ibid., 21.

${ }^{60}$ Ibid., 30.

61 Ibid., 44.

62 Ibid., 143.

63 Jeannette Owens, “Aspects of Interpretation in the Solo Piano Music of Samuel Barber," (M.M. thesis, Royal College of Music, 1993).
} 
The following four chapters, each devoted to a respective piano work, are organized based on the chronological order of composition. In general, Owens did not intend to provide an in-depth, formal scholarly analysis, but rather a useful musical commentary for performers to consult when interpreting Barber's music. In order to gain insight into the emotional context of the music, the author outlined important characteristics of the texture, harmony, rhythm, and melody as well as quotations from scholarly writings.

The author offered many interpretative suggestions for Excursions based on performances on seven commercially available recordings. She felt the first piece needed to be played with energy, percussive technique and a quick enough tempo to achieve drive and momentum. ${ }^{64}$ Constant awareness of Barber's notated nuances, especially the number of expressive and rhythmic indications, is crucial for the second piece. She felt that the third piece presents the performer with complex rhythmic challenges. Along with the rhythmic diversity, playing with a consistent flow while gently merging one variation with another is the most important performance goal for this movement. The fourth piece is fairly straightforward; the creation of an ebullient mood should be the performer's main concern. ${ }^{65}$ The postscript in Owens's study is a short conclusion summarizing the significance of Barber's style.

In 1976, Fred Kern studied the use of ragtime in selected twentieth-century compositions including both Barber's Excursions and Copland's Four Piano Blues. His findings will be discussed in the following section of this paper devoted to sources on Copland.

\section{Aaron Copland (1900-1990)}

Aaron Copland is certainly one of the most popular and best-known composers of twentieth-century American music. Although many Americans were familiar with his music in the 1950s, it was not until the mid-1980s that scholarly studies on the composer

\footnotetext{
${ }^{64}$ Ibid., 16.

${ }^{65}$ Ibid., 29.
} 
could be found. Around mid-century, several biographies and comprehensive studies were written, while more recent dissertations and theses by a new generation of scholars displayed renewed interest in Copland.

Arthur Berger's and Julia Smith's studies on Copland's life and music showed an early interest in the composer in the early 1950s. Berger's text was divided into two major parts, The Man (biography) and The Music (analysis of technique), as well as three appendices listing Copland's compositions, his recordings, and his critical works. ${ }^{66}$

Copland had a great influence on American music. When Berger studied Copland's personal memoirs of traveling abroad, of music events and of his relationship to the public, he gained insight not only into the stages of Copland's musical development, but also into his relationship to the American musical scene as a whole. Berger explored important compositional issues such as techniques on variations, triads, and chord building, and the use of folk and jazz elements. He believed the jazz style incorporated in the Four Piano Blues was different from that used a decade earlier in the mid-thirties, for the raw sonorous jazz material was now treated artistically in order to appeal to a wider audience. ${ }^{67}$ An indepth analysis of Copland's Third Symphony was also provided in Berger's text.

Julia Smith's monograph provided further comprehensive research on Copland's life and music. ${ }^{68}$ She believed that an artist's work should not be separated from his life; therefore, instead of dividing the text into two main parts as Berger did, she traced Copland's individual development and musical works simultaneously. This procedure offers readers a clear, chronological view of Copland's growth as a person and as a musician, and helps inform readers about twentieth-century musical techniques and styles.

One of the most prominent aspects of Smith's text was her division of Copland's works into "Americanistic/accessible" and "abstract/serious" classifications. According to JoAnn

\footnotetext{
${ }^{66}$ Arthur Berger, Aaron Copland (New York: Oxford University Press, 1953).

${ }^{67}$ Ibid, 30.

${ }^{68}$ Julia F. Smith, Aaron Copland: His Works and Contribution to American Music (New York: E. P. Dutton, 1955).
} 
Skowronski, that dichotomy of Copland's works has been employed frequently since the publication of Smith's book in $1955 .{ }^{69}$ Smith identified three stylistic periods of Copland's compositions: the first was influenced by French composers and jazz (1921-1924), the second was based on abstract technique (1929-1935), and the third was based on American folk song (1934-1955). As for the Four Piano Blues, Smith felt that even though they are not to be counted among the composer's important works, they nevertheless reveal the composer's style development of jazz. According to Smith, Blues No. 1, composed in 1947, reflects the composer's folksong period. Blues No. 2, although written in 1934, does not present any aspects of composer's abstract period; on the contrary, it reflects his usage of literal jazz materials. Blues No. 3, composed in 1948, shows the composer's second or abstract period, and Blues No. 4, composed in 1926, represents the composer's first usage of literal jazz materials and stands well beside the other three. ${ }^{70}$

In comparing the Berger and Smith studies of Copland's music, Skowronski felt that Berger, as a composer, took a more theoretical approach than Smith. ${ }^{71}$ However, she also felt that Smith's bibliography was very useful for information on Copland's articles written prior to 1955 .

Neil Butterworth, the British composer and music critic, surveyed Copland's entire musical output thirty years after the publication of two pioneering books on Copland by Arthur Berger and Julia Smith. The Music of Aaron Copland follows Smith's book closely especially in describing Copland's compositions and biography. ${ }^{72}$ Published only five years before Copland's death, Butterworth's book surveys Copland's entire compositional output. It is most useful in covering works after 1954, during the time Copland wrote some of his most important works and became a major figure in American music. The Music of Aaron Copland is illustrated with musical examples, photographs and drawings, and includes an

\footnotetext{
${ }^{69}$ JoAnn Skowronski, Aaron Copland: A Bio-Bibliography (Westport, Connecticut: Greenwood Press, 1986), 150.

${ }^{70}$ Julia F. Smith, Aaron Copland: His Works and Contribution to American Music, 250.

${ }^{71}$ JoAnn Skowronski, Aaron Copland: A Bio-Bibliography, 150.

${ }^{72}$ Neil Butterworth, The Music of Aaron Copland (New York: University Books, 1985).
} 
interview with the composer on his piano music. An extensive bibliography as well as a conversation on piano music between the author and Leo Smit are also included.

The survey of Copland's music was organized in chronological order with short discussions. For those works written after 1954, Butterworth discussed them by genre (vocal or instrumental music) and by compositional technique (serialism); he also devoted a separate chapter to Copland's late works (after 1969). In the investigation of the Four Piano Blues, the author provided a brief history of each composition and offered short musical examples to accompany the discussion. Regarding the character of these works, Butterworth felt the improvisatory quality with contrapuntal textures in Blues No. 1, the polytonality in Blues No. 2, the contrasting texture between thick chordal phrases and light passages in Blues No. 3, and the cross-rhythms in Blues No. 4 were most prominent.

Music historian Vivian Perlis collaborated with Aaron Copland on a two-volume definitive autobiography. ${ }^{73}$ This valuable resource is illustrated with photographs, letters, and scores from Copland's personal collection. The first volume tells the story of Copland's early years in Brooklyn, his studies in Paris in the twenties with Nadia Boulanger, and his return to the States followed his increasing success as a promising young American composer. The second volume begins in 1943, at a time when America was deeply involved in the war. During the next decades, Copland not only composed a great variety of music including patriotic music, a score for a pro-Russian film, and ballet music, but also launched a new career as a conductor. Both volumes distinguish between Copland's own words (which are written in the first person) from Perlis's interludes (which are written in the third person).

After the two pioneering studies of Arthur Berger (1953) and Julia Smith (1955), Neil Butterworth's monograph (1985), and the two Copland-Vivian Perlis publications (1984, 1989), Howard Pollack in 1999 offered an updated study of Aaron Copland. ${ }^{74} \mathrm{He}$

\footnotetext{
${ }^{73}$ Aaron Copland and Vivian Perlis, Copland: 1900-1942 (New York: St Martin's/Marek Press, 1984). , Copland since 1943 (New York: St. Martin's Press, 1989).

${ }^{74}$ Howard Pollack, Aaron Copland: The Life and Work of an Uncommon Man (New York: Henry Holt,
} 
examined many sides of Copland's accomplishments not only as a composer, but also as a critic, teacher, and conductor. Pollack felt the story of Copland's career reflects the story of twentieth-century art music in America. Therefore, the author broadened his search of Copland's activities and influence by investigating relevant secondary sources on such matters as the immigrant experience in America, the history of American theater in the twentieth century, techniques of writing music for film, and the history of Mexico and its music.

In Pollack's book, Copland's musical thoughts are organized into the subject areas relating to the great European tradition, the music of the United States and Latin America, the post-war avant-garde, jazz, and rock. Copland was extremely reserved about his private life, and nowhere in his own writings does he refer to his homosexuality or to his intimate relationships. One of the valuable aspects of Pollack's text is that his interviews with Copland's colleagues, friends, and former lovers provide insights into how Copland's homosexuality influenced his life and music.

Pollack discussed all of Copland's compositions, providing information about their creation, reception, and performance history, and dealing with important issues of style and form. No musical examples were included by Pollack due to his intention to use "minimal technical jargon." Pollack's discussion of Four Piano Blues provides historical background and brief analysis. He felt bitonality provides a distinctive context to the melodies. ${ }^{75}$ An appendix provides a very useful, complete list of Copland's works, grouped by genre and with information on first performance and arrangement.

Allen Forte, a well-known American music theorist, provided an extensive analysis of Copland's Third Piano Blues in his Contemporary Tone-Structures. ${ }^{76}$ Forte analyzed twelve compositions representing all types of twentieth-century styles selected from composers

1999).

${ }^{75}$ Ibid., 137.

${ }^{76}$ Allen Forte, Contemporary Tone-Structures (New York: Teachers College, Columbia University, 1955), v. 
such as Stravinsky, Milhaud, Sessions, Copland, Bartok, Hindemith, and Schoenberg. According to Forte, this book undertakes two related tasks: to provide effective procedures and techniques for the analysis of contemporary tone-structures, and to demonstrate the application of those procedures and techniques. Forte felt analyzing traditional music and analyzing a modern work required different procedures; therefore he explained his specific analytic procedures and techniques. Basically, Forte examined the individual tones in a horizontal, linear context based on Schenkerian analytic reductions. The reduction procedure consists of three structural levels: the foreground, middleground, and background.

Forte's analysis to the Blues No. 3 reveals that he hears the entire work as an expansion of the single sonority: $\mathrm{Bb}-\mathrm{Db}-\mathrm{F}-\mathrm{Ab} \cdot{ }^{77}$ Forte provided a total of six reductive sketches in his analytical study. Each successive sketch includes fewer and fewer details until only the skeletal structure (background) remains. He claimed his attempt was to present a direct analysis without distortion. Besides intensive harmonic and intervallic discussion of individual lines, Forte also offered the following observations on the effect of rhythm in this work:

It provides a forward impulse, particularly at the beginning of each pattern, where a short unit is followed by a long one. It also, paradoxically, gives the effect of holding back, of retarding the larger forward movement. ${ }^{78}$

Generally speaking, Forte's study is valuable in building an understanding of the composition of this piece.

A total of five dissertations related to Copland's Four Piano Blues were reviewed. In 1974, Joan Singer Spicknall produced a performance tape and study of Copland's original piano works. ${ }^{79}$ Copland was a pianist and many of his important compositions are written for piano. However, according to Spicknall, among the many scholarly works written about

\footnotetext{
77 Ibid., 63.

78 Ibid., 69.

79 Joan Singer Spicknall, "The Piano Music of Aaron Copland: A Performance-Tape and Study of His Original Works for Piano Solo” (D.M.A. diss., University of Michigan, 1974).
} 
Copland, few have dealt only with the composer's piano works. Therefore, Spicknall feels his dissertation project makes a valuable contribution to the study of both Copland's works and contemporary music.

Spicknall consulted with Copland himself when compiling the list of Copland's piano music to date. As a result, the numerous solo piano arrangements of orchestral works, ballets, and film scores, and a few of Copland's unpublished youthful works are not included in this project.

One of the most prominent aspects of this dissertation is the authoritative content verified by the composer himself. The main portion of this study is the tape recording of Spicknall's performance. According to Spicknall, Copland granted a private six-hour interview and coaching session, and listened to performances of each piano composition. ${ }^{80}$ Copland made valuable comments with particular attention to accurate and authentic performance. The discography and part of the document examining the compositional background of Copland's original piano works were approved by Copland as well.

In terms of the Four Piano Blues, Spicknall included information on the date and place of composition, first performance, dedication, and publisher. Descriptions of each piece, comprised mainly of material quoted from Julia Smith and Arthur Berger, are also available.

In his 1981 dissertation, Sammie G. Whitten studied Copland's piano compositional style. This study contains an examination and comparison of three piano pieces, Passacaglia (1922), Piano Variations (1930), and Four Piano Blues (1948). Whitten provided an analysis of each of three pieces with emphasis upon thematic development, harmony, rhythm, and sonority. A comparison between the pieces was then made in the final chapter.

Aaron Copland lived a long and productive life and his stylistic focus changed at various points in his career. These piano works were composed during a span of over twenty years and reflect different influences in the composer's musical life. The Passacaglia, Copland's

${ }^{80}$ Ibid., 4. 
early work written during Nadia Boulanger's instruction, was strongly influenced by the French neoclassic school. ${ }^{81}$ The Piano Variations show Copland's early interest in serial technique that was influenced by Arnold Schoenberg and other composers of the twelvetone school. This work consists of a theme, twenty variations, and a coda with a basic motive consisting of a series of only four notes. Copland's Four Piano Blues has significant jazz influence in terms of rhythmic pattern, formal design and harmonic progression. However, besides these basic characteristics of early blues songs, Whitten feels these pieces are more sophisticated due to the enormous variety of thematic material, constant time signature change, frequent shifting of accents and use of polytonal chords.

Finally, Whitten discussed the similarities and differences between these three pieces. As for the similarities, they all show Copland's technique of constantly varying short and compact themes. They also all use polytonal chords and show a preference for the same intervals. ${ }^{82}$ The main differences in style are in the areas of texture and sonority. Based on Whitten's analysis, the Passacaglia has a full texture with much simultaneous use of quartal and quintal harmony. ${ }^{83}$ The Passacaglia, however, is a much more percussive piece; its sparse texture features notes used pointillistically and rearranged in serial-like permutations of the theme. The Four Piano Blues has none of these features. Overall, the themes of the Passacaglia and the Four Piano Blues are less abstract and far more melodic.

In 1984 Nelly Maude Case investigated Copland's style throughout his career and studied four principal piano solo works in detail: Piano Variations, Piano Sonata, Four Piano Blues and Piano Fantasy ${ }^{84}$ Basically, Case's measure-by-measure analysis focused on Copland's harmonic and rhythmic practices, thematic and motivic procedures, textural characteristics, and in particular, his approach to serial technique. Case pointed out that

\footnotetext{
${ }^{81}$ Sammie G. Whitten, “A Stylistic Comparison of Aaron Copland's Passacaglia, Piano Variations, and Four Piano Blues, A Lecture Recital, Together with Three Recitals of Selected works of Beethoven, Brahms, Chopin and Others" (D.M.A. diss., North Texas State University, 1981), 5.

${ }^{82}$ Ibid., pp.29.

${ }^{83}$ Ibid., pp. 30.

${ }^{84}$ Nelly Maude Case, "Stylistic Coherency in the Piano Works of Aaron Copland" (Ph.D. diss., Boston University, 1984).
} 
his analytical approach in this paper was guided by what he actually heard or sensed in the music. An extensive bibliography of works by Copland and others was provided as a reference for further studies.

A preliminary overview, which focused on the compositional backgrounds, dedications, a survey of scholarly writings, and stylistic comparisons between Copland's Four Piano Blues, Gershwin's Rhapsody in Blue (1924), and Grofe's Grand Canyon Suite (1931), precedes Case's discussion of Four Piano Blues. Case felt a comparison of these pieces with two other American composers' compositions in the same genre, could help readers examine Copland's jazz-influenced compositions with greater perspective. Case noticed that both Copland's and Gershwin's works were written with classical techniques borrowed from the repertoire of jazz. However, Gershwin's music is much easier to understand than Copland's because of what Case called its "immediately understood sound", i.e., music that could be more easily appreciated by an untrained listener. ${ }^{85}$

Case felt although the composition of the Four Piano Blues spanned several years, we can infer that Copland intended for them to function as one work. The author noticed that Blues No. 1, No. 2 and No. 4 begin with no sharps or flats in the key signature. Case noted that, despite the absence of sharps or flats in the opening key signature and the frequent use of accidentals, these pieces have a clear tonal center. ${ }^{86}$ However, the tonality can be identified from cadences, pitch content and harmonic progressions in the left hand parts. Case thinks Blues No. 1 also belongs to Copland's later, "neo-classic" period due to its intensive motivic development and to its resemblance to a miniature first-movement form, with its use of thematic material and systematic transposition down a fifth of "secondtheme" material during the recapitulation. ${ }^{87}$ With its lyrical nature and song-like ABA form, Blues No. 2 resembles the archetype of a second, slow movement in a multi-movement

\footnotetext{
${ }^{85}$ Ibid., 496.

${ }^{86}$ Ibid., 499-500.

${ }^{87}$ Ibid., 543.
} 
classical form. ${ }^{88}$ The predominantly chordal texture, square phrases, motivic idea derived from one-measure single musical element, and interplay of elements alternately simple and complex, stimulating and tranquil reflect classical ideals in the Blues No. $3 .{ }^{89}$ Blues No. 4, the earliest composition of the four, is closest to ragtime in spirit. This piece can also function as a preparatory study for the jazz-oriented Piano Concerto. These two works share several motives in common and altogether they afford good examples of Copland's jazz expression.

In 1996 John Patrick Lynch examined Copland's four works: Emblems for wind band, the opera The Tender Land, the short piano collection Four Piano Blues, and the serial composition Inscape in order to demonstrate that Copland achieved stylistic coherence. ${ }^{90}$ As described by Lynch, stylistic in Copland's music consists of those elements that make Copland's style American. Although his analysis of Copland's four works revealed contrasting genres and styles, Lynch found common characteristics in the areas of rhythm, harmony, melody, form and timbre. According to Lynch, the consistent treatment of American themes and the incorporation of jazz elements, including the blues, make Copland's style unique and recognizable.

A brief look at Copland's life and musical goals as well as a discussion of his general stylistic traits are also offered in order to explain the coherence between these four works. An in-depth analysis of Emblems provided further support of Lynch's assertion of stylistic coherence in the music of Aaron Copland. Despite the lack of popular acceptance of Emblems, Lynch felt the piece exemplifies Copland's finest work.

In the examination of Copland's Four Piano Blues, Lynch provided an historical background and complete analysis in the areas of melody, harmony, rhythm, form, and pianistic colors and textures. In general, these four pieces developed a unique keyboard

\footnotetext{
88 Ibid.

${ }^{89}$ Ibid., 575.

90 John Patrick Lynch, "Emblems: Signifiers of Stylistic coherence in the Formulation of an American Sound in This and Other Selected Works of Aaron Copland" (D.M.A. diss., University of Cincinnati, 1996).
} 
sound through the use of jazz elements, extended harmonic structure, rhythmic complexity, open chord voicings, and rounded binary formal structure. Due to the many shared elements of each movement, Lynch felt the Four Piano Blues makes for a very cohesive suite, although its composition spanned nearly four decades..$^{91}$

In 2000, Richard Sayer examined the tonal organization of the following works composed early in Copland's life: Two Pieces for String Quartet (1923, 1928), As It Fell Upon a Day (1923), Music for the Theatre (1925), Four Piano Blues No. 4 (1926) and No. 2 (1934), and Statements for Orchestra (1935). ${ }^{92}$ This study began with background information regarding the period during which the compositions were written in order to provide an accurate understanding of Copland's methods of tonal organization. Sayer included an overview of twentieth century American music and an investigation of Copland's perception of compositional techniques in the late nineteenth and early twentieth centuries. Next he summarized some of Copland's published articles, and notes from lectures presented between 1924 and 1935. Then, he analyzed seven Copland works using layered reduction analysis techniques derived from the theories of Heinrich Schenker. Moreover, set theory was employed to examine less traditional pitch relationships.

According to Sayer, Copland's early music was written in two distinct periods of his life. The first period (to 1928) was characterized by the influence of his student days in the 1920s in Paris, and by the influence of his contact with jazz. The second period (to 1935) contains works which have been called abstract or severe because of their complex harmonic language. ${ }^{93}$ Sayer's examination of Copland's early works revealed one or more of these style traits, and a similarity of tonal organization and compositional methods as well. In general, Sayer found that Copland often used the following compositional techniques in these early works: 1) consecutive leaps of a fifth in his melodies 2) the third as an

\footnotetext{
${ }^{91}$ Ibid., 63.

${ }^{92}$ Richard Sayers, "Tonal Organization in Selected Early Works of Aaron Copland" (Ph.D. diss., The Catholic University of America, 2000).

${ }^{93}$ Ibid., 410.
} 
interval of organization, 3) chords based on triads but including added sixths and/or ninths in structurally prominent roles, and 4) bitonality and tonal ambiguity created by alternating between the raised and lowered third and by using pitch collections other than the diatonic scale (e.g., pentatonic, or whole-tone scales). ${ }^{94}$

In his study of Piano Blues No. 4 and No. 2, Sayer provided general and analytic background consisting mostly of quotations from scholarly writings related to Copland's biographies and music. Sayer mentioned that Blues No. 4 belongs to the beginning of Copland's "severe" or "austere" style period, while the Blues No. 2 was composed at a time when Copland was occupied with abstract works. Sayer provided three or more layered reduction analyses to explain the form and tonal organization of each piece. According to Sayer, the most important characteristics of Blues No. 4 are the bitonal constructions, the tension between A-flat and A-natural, the added sixth chords, and the use of the tritone as a structural element. ${ }^{95}$ In his discussion of Blues No. 2, Sayer stated he felt that bitonal sonorities, harmonic planning, pandiatonicism, and passages that utilized pentatonic, octatonic, or whole-tone collections are the most significant compositional materials and techniques used. ${ }^{96}$

In conclusion, Sayer summarized and compared the melodic and harmonic organization in Copland's early works in order to discover common aspects of tonal relationships and compositional methods. An extensive bibliography is also included, divided into two major headings: works by Copland and works by others.

Five articles examining Copland's rhythmic devices, general performance approach, and/or other stylistic traits were also reviewed. In 1976, Fred Kern studied the use of ragtime in twentieth-century music. Ragtime, according to Kern, is a fusion of African, white American, and European musical elements. ${ }^{97}$ He discussed ragtime elements from

\footnotetext{
${ }^{94}$ Ibid., 396-399.

${ }^{95}$ Ibid., 268.

${ }^{96}$ Ibid., 299.

${ }^{97}$ Fred Kern, “Ragtime Wins Respectability,” Clavier 15, no. 4 (April 1976): 24-30.
} 
Gottschalk's The Banjo, Barber's Excursions (1944), Debussy's Golliwog 's Cake Walk from Children's Corner Suite (1908) and Minstrels from Prelude Book I (1910), Copland's Four Piano Blues (1926-48), and Stravinsky's Ragtime (1918) and Piano Rag Music (1919); he also mentioned ragtime works by other composers including Satie, Milhaud, Thompson, Hindemith, and Gershwin. Kern also examined the ragtime influence on more recent composers such as Rochberg, Albright, Bolcom and Ramey. An analysis and comparison between Ramey's Leningrad Rag (1972), subtitled Mutations on Scott Joplin, and Joplin's Gladiolus Rag (1907) are provided in order to trace the development of ragtime elements.

In Kern's brief discussion of Barber's Excursions, he noted that the fourth piece brings to mind the banjo, based on Barber's comments preceding this set:

These are 'Excursions' in small classical forms into regional American idioms. Their rhythmic characteristics, as well as their source in folk material and their scoring, reminiscent of local instruments, are easily recognized..$^{98}$

Mostly, the use of syncopation characterized the American ragtime style. Regarding Copland's Four Piano Blues, the author mentioned "Aaron Copland wrote Four Piano Blues with each movement concerned with one or two features that parallel ragtime." Kern investigated those ragtime features and discovered that the fourth blues was actually composed first in 1926 and is therefore "closest to the actual rag period." 99 He also felt the first piece is a blue note study in pastoral style, and the second piece is more syncopated and uses ragtime texture in the second theme. ${ }^{100}$

In 1984, the score to the first of Copland's Four Piano Blues was featured in the Keyboard Classics and Piano Stylist. ${ }^{101}$ A one-page introduction which briefly surveyed Copland's compositional history and piano works accompanied the score. Performance

\footnotetext{
${ }^{98}$ Ibid., 28, quoting Samuel Barber, Excursions (New York: G. Schirmer, Inc., 1945), 2.

${ }^{99}$ Ibid., 29.

${ }^{100}$ Ibid.

101 "New Music Corner: Aaron Copland.” Keyboard Classics and Piano Stylist, 4 (March-April 1984): 2225 .
} 
suggestions from pianist Leo Smit, to whom the piece was dedicated, was also presented in the article. Leo Smit had a lifelong friendship with Copland and has recorded all of Copland's piano music. He felt this music "has a lyrical and poetic quality" and that "its counterpart might be Chopin's treatment of the Mazurka". The open call and jazzy answer are two important elements of blues style. Smit also suggested using lots of pedal in order to maintain "a very relaxed, pensive but spontaneous quality".

In the same year, Newlin studied several of Copland's piano compositions including The Cat and the Mouse Op. 1 (1920), Concerto for Piano and Orchestra (1927), Four Piano Blues (1926-1948), Sunday Afternoon Music (1935), The Young Pioneers (1935), Piano Variations (1930), Piano Sonata (1921), Piano Fantasy (1952-57), and Night Thoughts (Homage to Ives) (1972). ${ }^{102}$ In this article, he investigated information relating to Copland's works such as sources on commissions, public reaction upon premiere and important stylistic characteristics. Notes on editions and suggested readings were also included.

According to Newlin, the light-hearted character piece, The Cat and the Mouse, inaugurated Copland's career as one of the most distinguished composers in American music, while the Concerto for Piano and Orchestra showed Copland's eagerness to develop the American musical idiom, jazz, upon completion of his studies with Boulanger. ${ }^{103}$ Copland's fascination with jazz and blues continued after he composed the Piano Concerto. In many of Copland's later works, the alternating modality of major and minor thirds, and the "blue" flatted seventh are featured prominently in his style. ${ }^{104}$

Newlin felt the Four Piano Blues was composed based on the style of jazz blues. Blues No. 1 shows an improvisational tone. Blues No. 2 is in a three-part song form. Its F major opening (spiced with D-sharps, F-sharps, C-sharps and G-sharps) is followed by a graceful and flowing D-flat major middle section based on staccato dotted rhythm; it then ends with

\footnotetext{
${ }^{102}$ Dika Newlin, “The Piano Music of Aaron Copland,” Piano Quarterly, 28, no. 111, (1980): 6-8.

${ }^{103}$ Ibid., 6.

${ }^{104}$ Ibid., 8 .
} 
a brief, dreamy recapitulation. ${ }^{105}$ Blues No. 3 is muted, sensuous, and sonorous, with subtle metric changes $(4 / 4,7 / 8,6 / 8)$, while Blues No. 4 is a bouncy syncopated piece highlighting a flatted seventh $-\mathrm{F}-$, the essence of blues harmony. ${ }^{106}$ Newlin thinks pianists should feel free to program the four Blues together or individually since they were not originally composed as a suite.

Newlin mentioned that Copland began producing many functional works, for example radio music, music for schools, film music, and ballet, to create larger audiences for contemporary music. Copland's Sunday Afternoon Music and The Young Pioneers were composed for an educational piano series. As for the three major pieces, Variations, Sonata and Fantasy, Newlin stated that the Variations is a key piece in Copland's evolution to the abstract style; its material (twenty variations and a coda) drawn from the opening four-note motif is derived from the motivic development principles of Beethoven and Schoenberg. The style of Copland's Piano Sonata recalls Beethoven's late piano writing, especially the Piano Sonata Op. 111. The Piano Fantasy is composed with a series-like theme of ten tones growing out of a four-note motif. ${ }^{107}$ The Night Thoughts (Homage to Ives) is a dreamy, five-page piece that uses varied piano sonorities in an Ivesian fashion.

In 1995, pianist Mark Anderson's performance study of Copland's Piano Blues No. 3 (1948) appeared in a journal column called "master class." 108 As in a live master class, Anderson's text began with a general stylistic overview of all Four Piano Blues, and then focused on the Blues No. 3, which he discussed from a performance point of view. Blues No. 3 is dedicated to William Kapell, a young pianist whose life was cut short in an airplane crash. Anderson felt his approach to the performance of this piece came from a deeply spiritual perspective and uses Kapell's tragic death as an inspiration.

A major issue in Anderson's discussion is the contrast on performance between sections.

\footnotetext{
105 Ibid.

106 Ibid.

107 Ibid., 10-11.

108 Mark Anderson, “Aaron Copland's Piano Blues No. 3,” Keyboard Classics and Piano Stylist 15, (March-April 1995): 62-63.
} 
Anderson identified two opposing forces between lines 1 and 3, and lines 2 and 4 . He read the score carefully and suggested that performers observe Copland's original metronome markings literally since they help to produce a flow while giving time to create the sensuous sonorities as Copland denoted. Anderson feels that the dynamic suggestions are important because they indicate the exact quantity of sound to play. He was cautious about pedaling, recommending use of the una corda pedal as a coloristic device to express the muted sound indicated by Copland. Anderson also mentioned the importance of observing the subtle metric changes and of listening cautiously to the inner harmonies between sections. The author believed all the above elements were crucial in searching for the inner meaning of the piece.

In 2003 Stanle V. Kleppinger examined the use of jazz rhythms in Copland's music. ${ }^{109}$ Kleppinger felt that although existing studies frequently viewed the music of Aaron Copland as influenced by jazz, little work had been done to describe the details of Copland's approach and the ways this approach was related to jazz. Therefore, Kleppinger offered his study to explore in greater detail how Copland's use of rhythm was influenced by jazz. He reviewed contemporary scholarly descriptions of jazz rhythm, focusing especially on Copland's own study of the subject. In Copland's earliest article discussing the rhythms of jazz, he recognized the prominent position of rhythm as "the essential character of jazz" and noted that jazz's metrical structures had provided a source of inspiration. ${ }^{110}$ Kleppinger examined Copland's jazz-influenced works such as the Piano Concerto and Four Piano Blues No. 2 in order to investigate Copland's conception of jazz's metrical structure.

According to Kleppinger, Copland identified four steps in the rhythmic development of jazz: 1) ragtime, 2) secondary rag, 3) polyrhythm, and 4) the abandonment of the strictly regular accompaniment. Kleppinger reported that the composer regarded ragtime as jazz's "nearest ancestor." Copland made a distinction between rags and jazz though the musicians

\footnotetext{
${ }^{109}$ Stanley V. Kleppinger, “On the Influence of Jazz Rhythm in the Music of Aaron Copland," American Music 21:1 (Spring 2003): 74-111.

${ }^{110}$ Aaron Copland, “Jazz structure and Influence,” Modern Music 4, no.2 (January 1927): 9-13.
} 
in the 1920s interchanged these two terms freely. Copland cited Don Knowlton's article and discussed Knowlton's description of “secondary rag” musical practice:

Knowlton inherited the term 'secondary rag' from 'a Negro guitar player,' according to whom 'primary rag' refers to united syncopation, while secondary rag is the 'superimposition of one, two three upon the basic one, two, three, four'. ${ }^{111}$

Knowlton provided the following two illustrations of secondary rag patterns (See Example 1). ${ }^{112}$
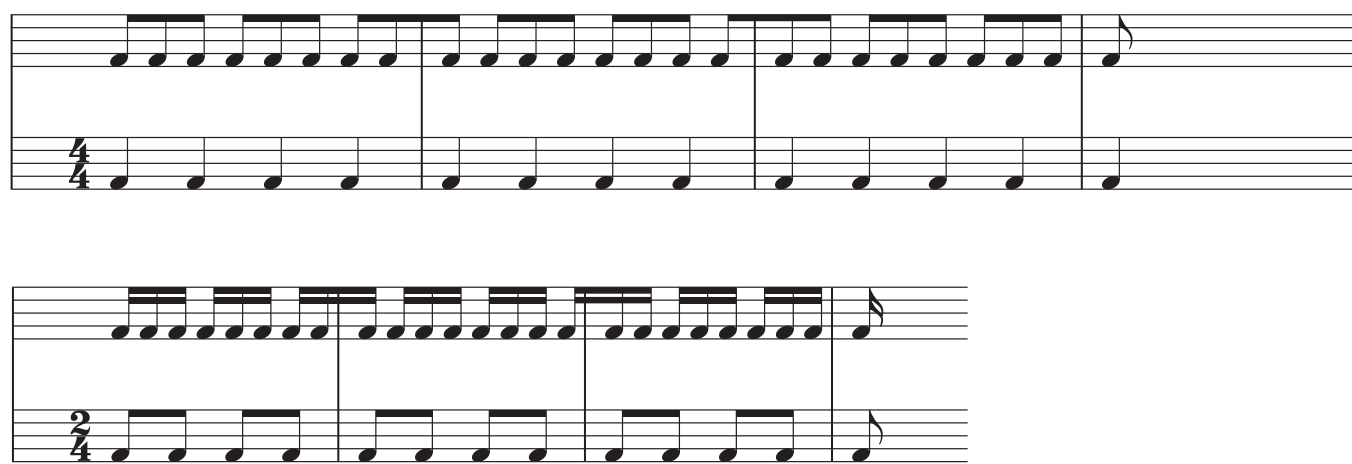

Example 1. Two musical realizations of secondary rag patterns

Since Kleepinger felt the practice of secondary rag proved essential to Copland's conception of jazz rhythm, he included an extended discussion of secondary rag:

Here, as in most instances of secondary rag, the contour of the melody repeats a set of three sixteenth notes a total of four times. The fourth set of sixteenths, which begins with the second sixteenth note of the second measure, is altered and followed by new melodic material. ${ }^{113}$

Kleepinger's investigation of secondary rag led him to conclude that Copland used it as

${ }^{111}$ Ibid., 10, quoting Don Knowlton, “The Anatomy of Jazz,” Harper's 154 (April 1926): 581.

${ }^{112}$ Ibid., 78.

${ }^{113}$ Kleepinger, “Jazz Rhythm of Copland,” 78. 
a basis for his radical interpretations of melodic jazz patterns as metrical rather than merely rhythmic phenomena. ${ }^{114}$ Kleepinger also described Copland's idea of polyrhythm (with musical excerpts from the song Stumbling), as the simultaneous use of two independent rhythms with their downbeats not coinciding (See Example 2). ${ }^{115}$

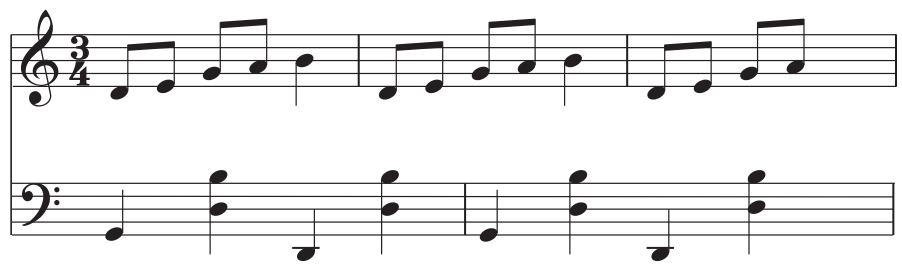

Example 2. Polyrhythms illustrated by excerpts from the song Stumbling

Regarding the discussion of the final step in the evolution of jazz, Copland pointed out that the strictly regular accompaniment has evolved into the "prototypical Charleston." He further quoted four measures from George Gershwin's Clap Yo' Hands to illustrate how the simple-meter pattern in the prototypical Charleston is replaced by a grouping pattern (See Example 3). ${ }^{116}$

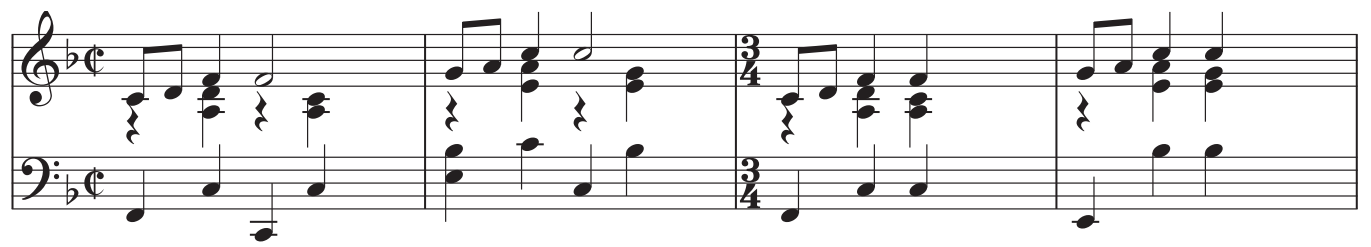

Example 3. Clap Yo' Hands, re-barred by Copland

In his study of Four Piano Blues No. 2, Kleepinger felt rhythmic analysis would illustrate clearly the rhythmic features we might expect to find in Copland's jazz-influenced work. Kleepinger's analysis included the historical background of this composition and an investigation of Copland's harmonic and rhythmic approaches. Kleepinger felt this

\footnotetext{
${ }^{114}$ Ibid., 79.

115 Ibid., 81.

${ }^{116}$ Ibid., 83.
} 
movement displayed the influence of Debussy more than that of jazz considering the use of a pentatonic melody in the beginning. ${ }^{117}$ However, the jazz influence is clear in passages that suggest secondary rag or its related practices. Kleepinger's observations of this piece revealed that he found Copland's rhythmic approach can be distinguished independently from other devices (blue notes or particular timbres) common to jazz. ${ }^{118}$

This literature review reveals that many of these sources focus more on biographical, historical, or theoretical information rather than on performance issues related to these pieces. Dissertations by Case and Sayers provided lengthy, measure-by-measure compositional analyses of Copland's piano works, but make no mention of performance practice. Heyman and Smith explored Barber's or Copland's life and musical style, and although Heyman interviewed performers who worked with Barber, she suggested only a few performance guidelines.

Sources by Burnside, Wylie, Owens, and Anderson all provide limited pedagogical information on Ginastera, Barber, or Copland. While Burnside simply investigated and offered suggestions for the use of pedal, Wylie provided brief discussions of the technical requirements of selected piano music by Ginastera. Owens' master's thesis is a valuable source on the interpretation and performance of Barber's music, yet she made no comments regarding the use of pedal. Anderson's in-depth discussion of Copland's Blues No. 3 is an interesting source on the subject; however, it lacks stylistic discussions and pedal suggestions. Since few authors have provided more thorough recommendations for the performance of these selected compositions, this will be the focus of the present study.

\footnotetext{
${ }^{117}$ Ibid., 85 .

${ }^{118}$ Ibid., 86.
} 


\section{CHAPTER III}

\section{SUGGESTIONS AND GUIDELINES FOR PERFORMANCE OF SELECTED TWENTIETH-CENTURY AMERICAN PIANO COMPOSITIONS}

This chapter presents a performance analysis of the three selected twentieth-century piano suites: Suite de Danzas Criollas Op. 15 by Alberto Ginastera, Excursions Op. 20 by Samuel Barber, and Four Piano Blues by Aaron Copland. Each work will be discussed movement by movement, and its analysis will highlight compositional and performance aspects as they relate to stylistic interpretation.

Alberto Ginastera: Suite de Danzas Criollas Op. 15

\section{I. $\quad$ Adagietto pianissimo}

The first dance is in a folk song with a singing melody and simple accompaniment. Characteristics of this dance include tone clusters, short repetitive phrase structures, and bitonal arpeggios. It begins with eight measures of introduction. The melody begins on the fifth beat of measure 8 , accompanied by the introductory material. In the coda, from measures 28 through 33, an embellished version of the first four measures of the introductory material returns. Montgomery felt that there is a clear delineation of "instrumental" and "vocal" sections in this movement. ${ }^{119}$ The instrumental sections (measures 1-8, 12-15, 1922, and 28-33) have tone clusters which punctuate the accompaniment (See Example 4); the vocal sections (measures 9-12, 16-18, and 23-27) contain a simple melody in G Major (See Example 5).

\footnotetext{
${ }^{119}$ Montgomery, "Latin American Piano Suite," 26.
} 


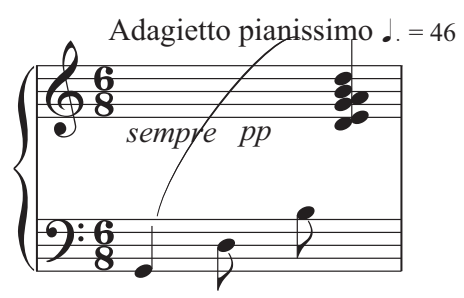

Example 4. Opening of "Instrumental" sections with tone clusters, Ginastera's Suite de Danzas Criollas, I, mm. 1-1

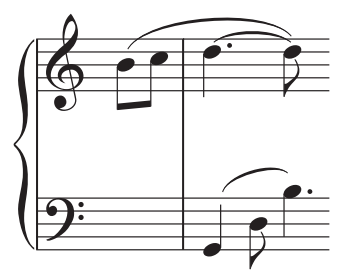

Example 5. Opening of "Vocal" sections containing simple melody, Ginastera's Suite de Danzas Criollas, I, mm. 8-9

The underlying harmony also distinguishes the instrumental sections from the vocal sections. The instrumental sections are usually repeated with the following four-measure pattern: I, IV, ${ }^{b} \mathrm{VI}, \mathrm{I}$. The pianistic approach between these two sections is different. While the instrumental sections should be played with an airy, mystic atmosphere created by using a floating forearm and a gentle touch, the vocal sections should be played with slightly heavy fingers in order to create a singing melody.

This dance is not as technically demanding as the more robust movements of the Suite. However, in pieces with such a simple structure, good musicianship is required to shape each phrase with a sensitive touch and to produce each sound with a beautiful singing tone. In the introduction, a light touch aided by the una corda pedal is required to achieve the airy, misty atmosphere in sempre $p p$. For a smooth connection and emotional prolongation between passages, it is important that the student responds to the length of every note not simply by counting but by listening to its duration.

As for the pianistic technique on the cluster chords, it is necessary to use firm fingers in order to make those four, five or six notes sound together. Perfect timing for the connection 
of the cluster chords is critical. Performers should hold the cluster tones a bit longer with a ringing sound, and try not to rush into the next measure. Let the ear be the judge of the appropriate length of those cluster chords. The student must produce a flow for these long chords as well as a smooth connection between these phrases of the introduction. As for the left hand, the bottom note of the bass voice should be focused and supportive.

The second part of the introduction (measures 5-8) contains a hint of the theme in the top voice. The student will need to emphasize the thematic material that is carried by the long note of the right hand. Try to differentiate this melody from the other two voices by using firm fourth or fifth fingers. The other pitches in the right-hand cluster chords should be played quietly. In this way, one hand can produce two sounds. The vocal sections (e.g., Example 5) require a very beautiful singing tone. The fingers alone will not be able to produce such a sound; therefore, a correct coordination of the entire playing mechanism is important. Here, a gentle, slower action into the keys will most likely help to produce a lyrical sound. In terms of the playing distance from the keyboard, the fingers will need to keep close contact with the keys for legato playing. A rotary motion will help the freedom of the hand when transferring weight from note to note.

When the theme enters on the pick-up eighth notes of measure 8 , it is essential to use a slightly heavier touch to bring out the melody. The student will need to use arm weight when playing the longer notes, the downbeat for both voices. An unbroken legato, as well as the sustaining of musical emotion through the tie, challenge the student's sensitivity and musical feeling. Marching from one measure to another without feeling the flow of the music must be avoided. In measures 13 and 14, the introductory accompanying figure returns and creates the same hazy, misty color.

More dissonance occurs as the melody is repeated with a different harmonic accompaniment in measures 16 through 18 . The student should notice the tritone dissonance between $\mathrm{Ab}$ and $\mathrm{D}$ (measure 16, beat 4) as well as between $\mathrm{Gb}$ and $\mathrm{C}$ (measure 18, beat 4). Measure 19 is crucial for being the pivot point from the theme to the restatement of the 
second half of the introduction (See Example 6).

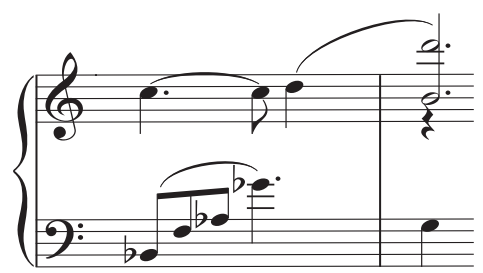

Example 6. Pivot point to the restatement of the second half of the introduction, Ginastera's Suite de Danzas Criollas, I, mm. 17-18

In this measure, carefully planning the performance of the interval of a tenth in the right hand first beat is required. Play the B with the right hand on the beat and the D soon after. In this way, the student can catch all three notes in the same pedal, and the final melody note in the phrase (B) is not delayed. Much attention should be paid to the smooth connection between these two measures.

The concluding theme occurs from measures 23 through 27 . In measure 23, it is necessary to keep the rhythmic flow of the three against two rhythms (See Example 7). Do not allow the rhythmic motion to become static on the dotted half note $\mathrm{E}$ in measure 24 , since the phrase is not finished yet.

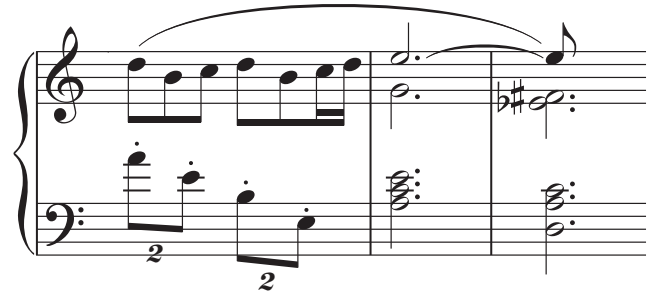

Example 7. 3 against 2 rhythms, Ginastera's Suite de Danzas Criollas, I, mm. $22-24$

Tempo rubato should be used at the end of measure 27 at the unresolved cadence. Beginning in measure 28 through the remainder of the dance, a fragment of the introductory material is recalled with extension. Both the abrupt texture and harmonic change create 
a surprise in measure 28. Listeners expect the melody to go to D, but Ginastera leaves it unresolved and writes a rest instead. Therefore, avoid blurring the harmonies between measures 27 and 28 as well as between measures 28 and 29 by using a clear pedal.

In the coda (from measures 28-33) the bottom note of the bass harmony must be emphasized to give a strong harmonic support. There are several ways to interpret the final three measures, based on personal preference (See Example 8).

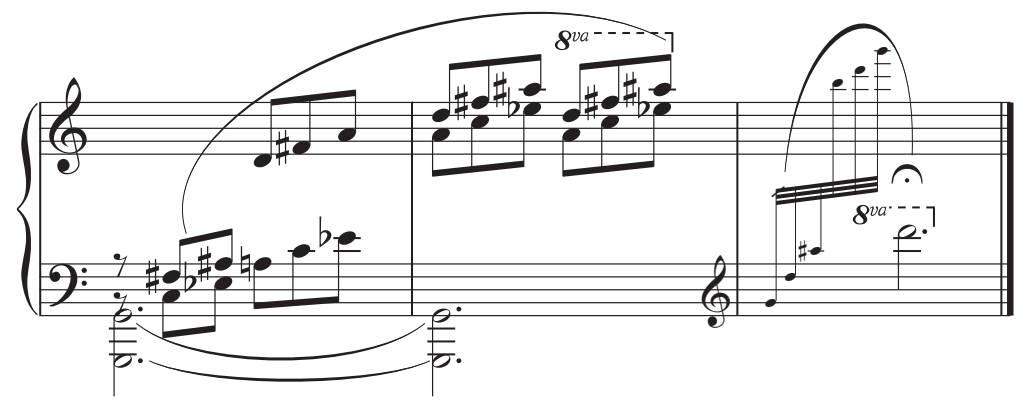

Example 8. Eighth-note arpeggios in the coda, Ginastera's Suite de Danzas Criollas, I, mm. 31-33

The author recommends starting the phrase a bit stronger, and then creating a decrescendo to the end. This can give the effect of smoke disappearing in the air. The eighth-note arpeggios should be played with one gesture with slight tempo acceleration, but without agitation. It is important to play the fast thirty-second note arpeggio evenly in the last measure. Coordination between the hands will require some practice for students.

There are no pedal indications in this piece. Therefore, the performance of the slurs, phrasing, and articulation will help in making pedaling decisions. It is important to use both the damper and una corda pedals to sustain and color the sound. The author suggests two options for the use of the una corda pedal in this dance: one is to use it in the introductory passage and whenever it returns (measures 1-8, 12-15, 19-22, 28-33); another is simply to use it for the entire dance. In the first option, clear color and dynamic contrasts between the instrumental and vocal sections can be achieved while, in the second option, the overall mystical atmosphere can be retained and the performer will have the freedom to play with 
heavy fingers without interrupting the color. It is important that the student experiment with different sound effects made by different pedaling and eventually make pedal decisions based on his/her personal taste.

In the introduction, try to use one pedal in every measure. The damper pedal helps to blend the harmonies and sustain the bass. When a change of pedal is desired, the student must be sure that there is no carry-over from the old harmony and no break in the sound. As a general rule, the una corda pedal should be used cautiously. Try to play soft tones not only with the pedal but also with the hand. Also, when changing the pedal, the foot should always be in contact with the pedal, and the heel should remain on the floor.

In measures 8 and 15, do not pedal through the rests. Control of the pedal is crucial in measure 19. The pedal must be used carefully to connect the disjunct chords on the first beat in order to produce a rhythmic flow. Special attention should be given to measure 25 because the student might be unable to hold the fifth finger from the tie in measure 24 and play the chord in measure 25 (See Example 7). Then, the fifth finger must be released early, even before the pedal change.

The damper pedal can be used to blur scales and arpeggios to achieve color and special effects such as in the coda. Blending measures 31 and 32 in one pedal and using a strong harmonic support of the bass and moving arpeggios in the upper voice will create an impressionistic effect (See Example 8). A clear pedal change is required before reaching measure 33. A special coloristic effect is created in measure 33 as the pedal blurs the rapid figuration in the high register.

\section{II. $\quad$ Allegro rustico}

The second piece is a vigorous dance with two alternating rhythmic/textural ideas used throughout. The first section is characterized by eighth-note cluster chords that Ginastera indicates may be played with the palm of the hand (See Example 9); the second section is more melodic and consists of Argentine folk elements such as the gato rhythm (e.g., 
in measures 7-8, eighth-note, quarter-note, quarter-note, eighth-note), simple repetitive structures, and hemiola rhythmic patterns (See Example 10).

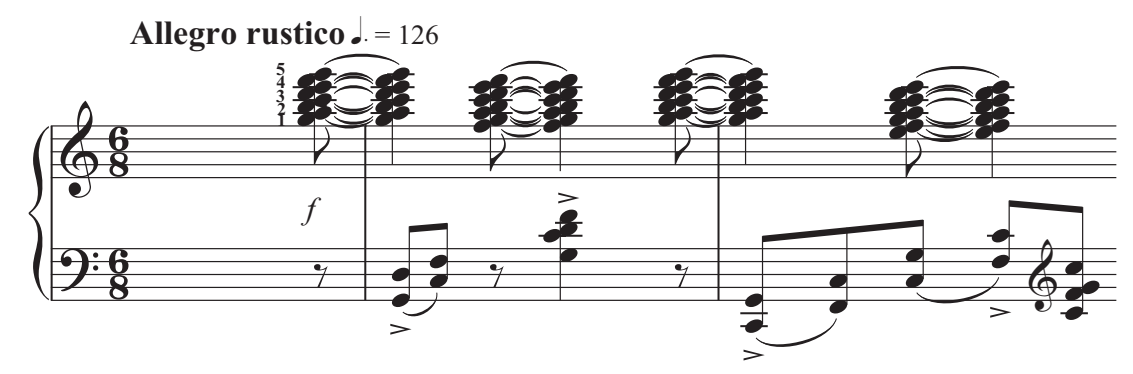

Example 9. Syncopated cluster chords, Ginastera's Suite de Danzas Criollas, II, mm. 1-2

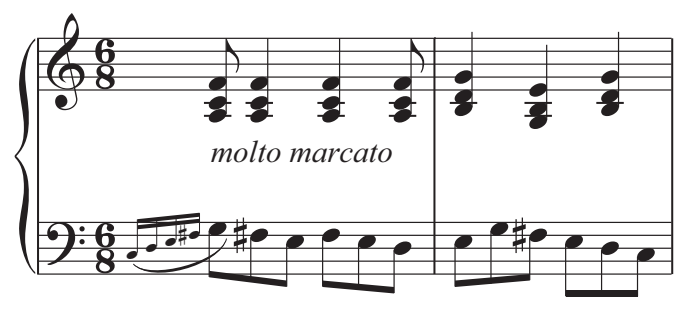

Example 10. Gato rhythm, Ginastera’s Suite de Danzas Criollas, II, mm. 7-8

The beginning measures employ syncopated cluster chords in the right hand and a succession of chords in the left hand (See Example 9). These six measures are dissonant in harmony. Montgomery felt that the tone clusters suggest vigorous foot stamping, a feature of Creole dances, especially the gato. ${ }^{120}$ In order to play these right-hand chords forte, the student must use power for each chord created by a fast motion into the keys, supported by a free-falling arm. It is important to feel the entire playing mechanism, from shoulder to fingertip, as one piece at the moment power is used. Also, bring out the top voice in order to achieve a brilliant sound.

The section from measures 7 through 12 is bitonal, with the right hand a step below the left hand in tonality (See Example 10). A sharp finger stroke can help to express the

${ }^{120}$ Ibid. 
exciting, fanfare motion suggested by molto marcato. The $6 / 8$ meter is organized in two ways: as three groups of two eighth notes, and two groups of three eighth notes. This irregular rhythm becomes extremely difficult to play when an emphasis of the downbeat is required. The grace notes on the first beats of measures 7, 9, and 11 are played before the beat with a strong sound on the downbeat G.

The cluster chord motive returns in measures 13 and 25 as interludes. Some musical elements of the sempre marcato, measures 19 to 24, are similar to the molto marcato, in measures 7 to 12 , but the molto marcato is more complex harmonically. In the bichordal passage beginning in measure 19 , the technical difficulty lies in playing fast, successive chords (See Example 11). The student needs to put accents on the strong beats (first and fourth beats) in both voices.

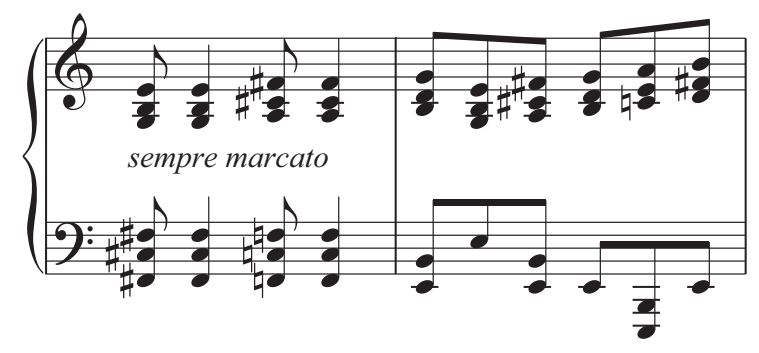

Example 11. Successive bitonal chords, Ginastera's Suite de Danzas Criollas, II, mm. 19-20

In measures 19, 21 and 23, use the first, second, and fifth fingers (the strongest and most balanced fingers) for these right-hand chords. Remember to emphasize the top voice of the chords by leaning the arm weight towards the fifth finger. Be sure the fingers support the power from the forearm. During the chord progressions in measures 20 and 22, it is crucial to use the hand as one unit to achieve the equal lengths of the notes and the same tone quality. The student also needs to keep the elbow close to the body, allowing the elbow to be the point of reference for the fingers throughout this rapid chord movement. ${ }^{121}$

121 "Point of reference" refers to a stable point from which the hand moves. Such a point is essential for the fingers; otherwise, the performer will confuse the amount of distance moved between keys. 
From measures 25 through 30, while strong force is used in the right-hand cluster chords, the left hand is playing disjunct and fast-moving chords. Landing, lifting, and dropping are the basic left-hand movements. Those movements should coordinate arm weight and appropriate finger action.

The last four measures reach a climax with bitonal chords moving up and down the keyboard in parallel and contrary motion (See Example 12).

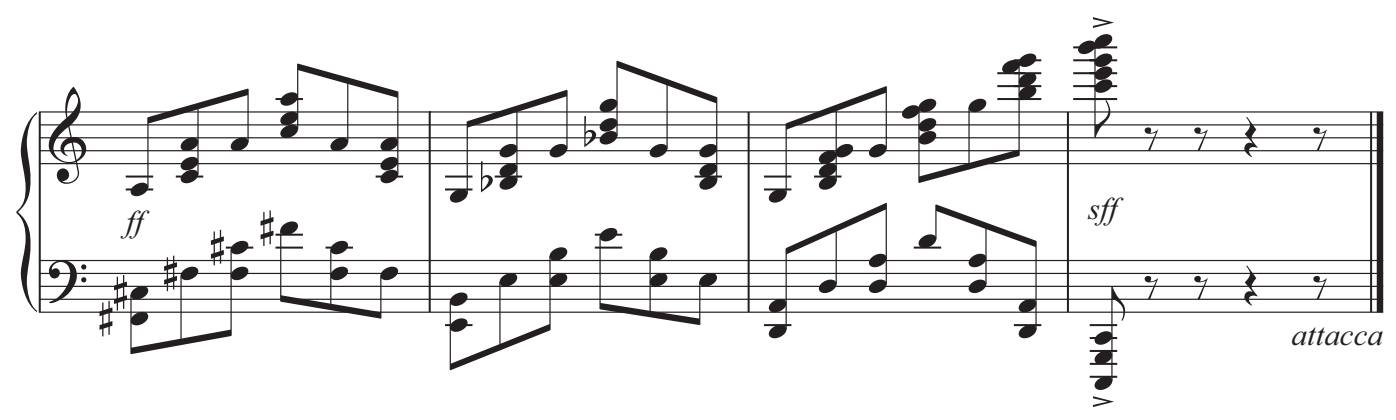

Example 12. Bitonal chords, Ginastera's Suite de Danzas Criollas, II, mm. 3134

As a general rule, the following two motions are always taking place in tone production: finding the key, and delivering weight into the key. The synchronization between the vertical action of key depression and horizontal motion of finding the key positions must be well coordinated. In such a fast tempo, these two motions (locating the key and producing the tone) must be done at the same time. When you reach to the desired position just go straight into the keys. It is critical that the student not reach for the notes with the fingers alone. Remember to use the elbow as the point of reference during this movement and to use arm weight to produce the energetic $f f$.

Basically, using touches of pedal is appropriate in this dance. Whenever the cluster chords occur, be sure the pedal is able to sustain the chords without any break. Pedaling on the pick-up cluster chords and changing on the last eighth notes are appropriate to add fullness to the sound without blurring the harmonies. In measures 7 through 12 , the student should adjust the pedal according to the texture changes. Basically, pedaling following the 
left-hand quarter notes instead of the gato rhythm of the right-hand chords is recommended to minimize the possible break between chords. As for the first-beat grace notes in measure 7, Burnside felt that touches of pedal are needed to add substance to the sound (See Example 10). ${ }^{122}$ In the sempre marcato, from measures 19 through 24 , pedal is necessary to create a rich sonority with the fast-moving chords and to make a smooth connection in the disjunct bass line (measures 20 and 22). Although the pedal will help to maintain the forte dynamic level in this section, less pedal is required due to the rapid harmonic changes.

\section{Allegretto cantabile}

The third dance immediately changes mood by a melodic line with simple accompaniment. Whereas Hanley stated that Ginastera described this piece as "subjective, and not really Creole," 123 Wallace felt an South American Indian influence is visible in the rhythmic pattern and melodic line. ${ }^{124}$ In this piece, the rhythm is the most interesting feature. The meter, indicated as $11 / 8$, is the combination of two groups of different rhythms: $6 / 8$ plus $5 / 8$. In addition, each hand plays a different rhythm; the accompaniment in the first half of most measures is in $6 / 8$ and the melody is in $3 / 4$.

The performance difficulties in this piece lie in the rhythmic complexities and the canon in the middle section. The abundance of slurs indicates the phrasing and the legato style. The student will probably need some practice to feel the irregular meter of the unusual 11/8 rhythm. Most commonly, incorrect counting will occur in the $5 / 8$ sections of measures. Be sure if you use tempo rubato or a breath after the $5 / 8$ sections, not to change this rhythm to $6 / 8$.

Voicing becomes important in the simple melody and accompaniment style in this dance (See Example 13).

\footnotetext{
122 Burnside, "Use of Pedal of Ginastera," 50.

${ }^{123}$ Hanley, "The Solo Piano Compositions of Alberto Ginastera," 6.

124 Wallace, "Ginastera, An Analysis of His Style”, 114.
} 


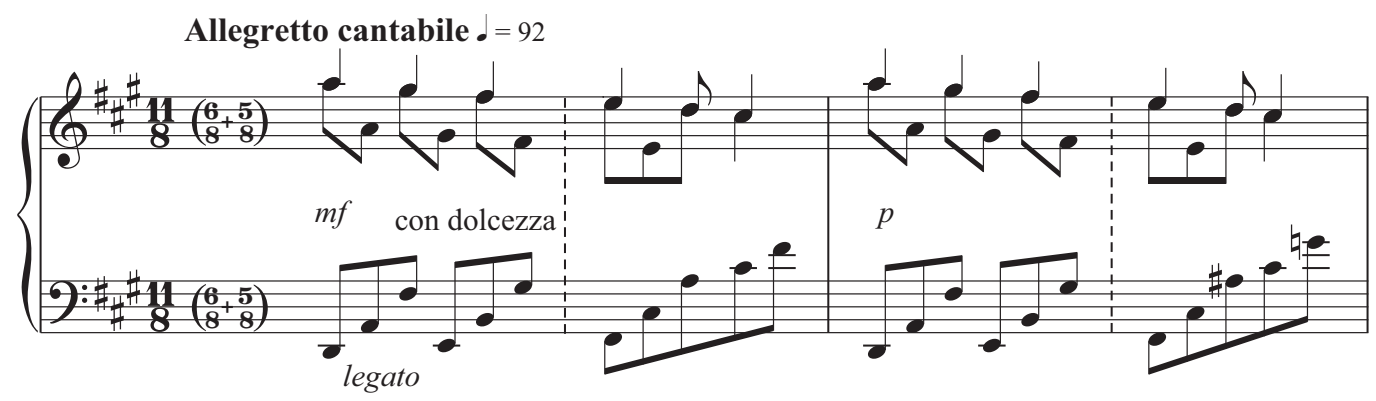

Example 13. Opening motive, Ginastera’s Suite de Danzas Criollas, III, mm. 1-2

In general, the soprano voice needs to be projected over the other voices, and needs to flow. In performance, the broken octaves in the right hand and the continuous broken-chord accompaniment in the left hand should not interfere with the flow of the melody notes, which are usually double-stemmed. In the first three measures of the A section (measures 1-3) and in the return of this section (measures 14-17), the student should practice the stepwise outer melodies (i.e., the descending double-stemmed notes in the right-hand and the ascending first, fourth and seventh eighth notes of each measure in the left-hand) alone with the actual fingering.

At the end of measure 3 , be sure to prepare your ear for dissonance, such as the clash of $\mathrm{A}$ and $\mathrm{A \#}$, and then the tritone created by A and D\#. Since Ginastera is specific about dynamics and articulation in this movement, students should follow these suggestions literally in their performance.

The canon from measures 5 through 9 challenges the student in many ways (See Example 14). The irregular meter makes it difficult to voice and to pedal. The complicated polyphony starts when the left hand enters on the second half of measure 5. This canonic writing between the two hands creates rhythmic tension. According to Wylie, perhaps this rhythmic tension comes from many Argentine folk dances. ${ }^{125}$ The left hand requires special attention since it plays both melody and accompaniment.

The tempo rubato indicated by Ginastera is important for creating a specific mood.

${ }^{125}$ Wylie, “Argentine Folk Elements in the Solo Piano Works of Alberto Ginastera," 106. 

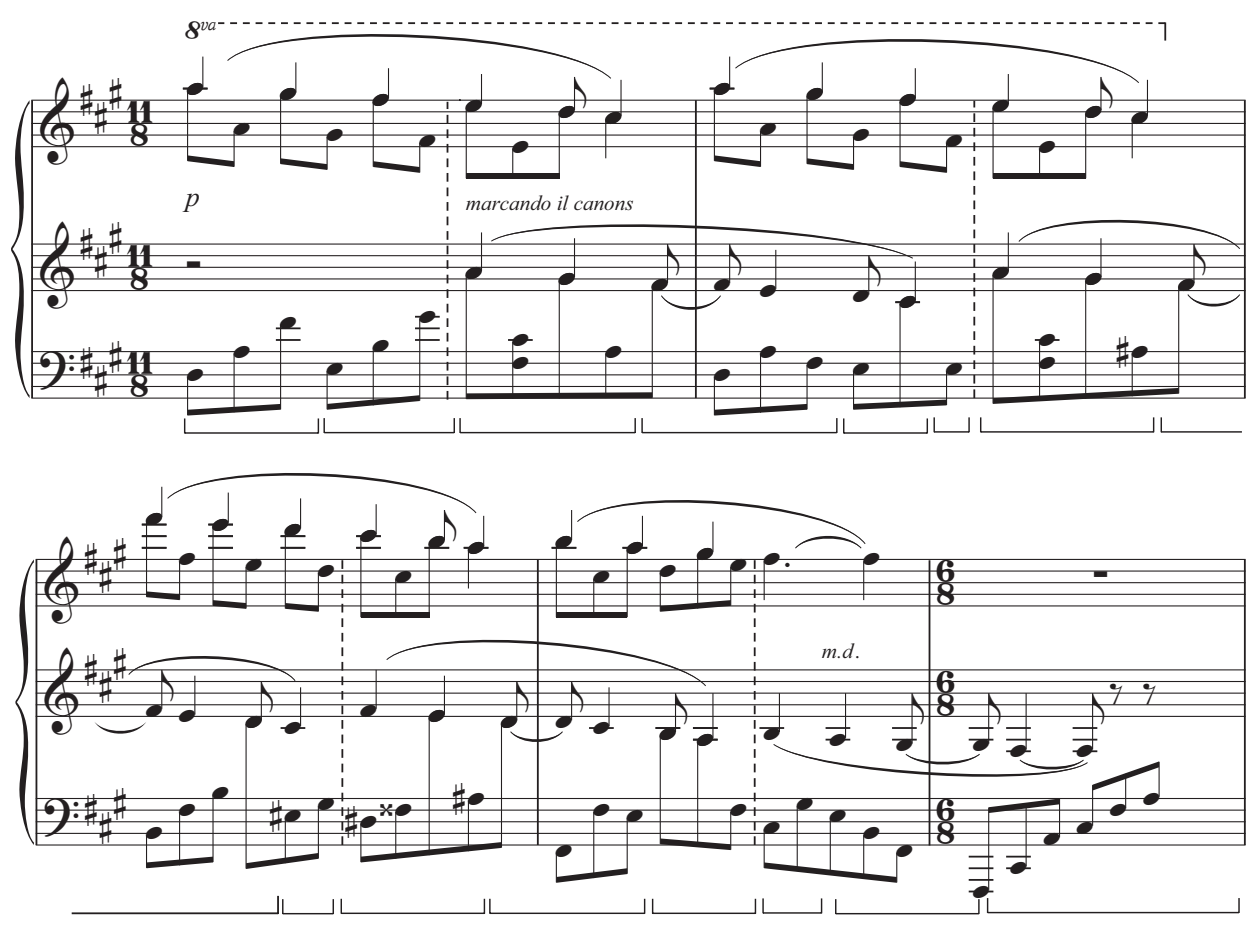

Example 14. Canon with pedal suggestions, Ginastera's Suite de Danzas Criollas, III, mm. 5-9

Playing rubato is always an issue that concerns many teachers because it can be abused easily. The important factor in using rubato is to feel its regular pulse first. In this dance, it is essential to keep the beginning tempo steady in order to sense the standard tempo. Freedom is limited since Ginastera is specific about his rubato markings. It is his intention to make the return of the main theme special by slowing down before its arrival (as indicated by the allarg. marking in measure 13), and then by stretching the tempo once it does arrive in measure14. The feeling of moving forward in measure 15 marked incalzando, and $a$ Tempo in measures 16 and 17, will need to be carefully planned. Thinking of an eighthnote pulse will help the student to make an evenly paced ritard. In a very slow tempo such as ritardando molto in the last two measures, it is important that the student continues to think and gradually expands the eighth-note pulse. A better molto rit. can be achieved if the performer takes time to roll the two final arpeggiated chords.

Technically, this dance presents few problems. Since the piece is organized almost 
entirely on the A section and its repetitions, much attention should be paid to varying the interpretation of these sections to avoid a uninteresting performance. It is crucial that the performer express subtle color, dynamic and rhythmic nuances to create variety between the repetitious sections. Different layers of sound can be achieved depending on what playing mechanism is used. The coordination between the arms and hands as well as the fingers can help to create various sound colors.

The abundance of slurs in this piece suggests legato pedaling. The changes of damper pedal must follow the harmonic changes of the left-hand, broken chords (changing on the first, fourth, and seventh eighth notes of most measures). Finger legato in the right hand is important. The quarter notes must be held during the pedal changes; otherwise, the melodic line will have breaks. The pedaling for the canon will also require using some finger pedaling in both hands. The canon creates difficult pedal choices. Careful pedal decisions based on the harmonic changes are essential (See Example 14). The una corda pedal can be used in the last measure, marked $p p$, in order to reduce the volume of the chords. Although the dynamic level is already soft, the student should still continue to create the diminuendo by gradually releasing the damper pedal on the final tied chord.

\section{IV. $\quad$ Calmo e poetico}

The fourth dance is the third lyrical movement of the suite (besides the first and the third movements). According to Hanley, Ginastera described the fourth dance as a "poetic nocturne inspired by the pampas." ${ }^{126}$ The opening motive is stated three times and establishes the rhythmic and melodic patterns of the entire piece (See Example 15). Wylie felt, based on the rhythmic pattern and the repetitive phrase structure, that this movement is a zamba. ${ }^{127} \mathrm{He}$ further identified references to Argentine folk sources in the harmonizations in thirds of the middle section (mm. 9-17), the use of 6/8 meter, and the presence of the

\footnotetext{
${ }^{126}$ Hanley, "The Solo Piano Compositions of Alberto Ginastera," 6.

${ }^{127}$ Wylie, “Argentine Folk Elements in the Solo Piano Works of Alberto Ginastera," 107.
} 
typical "guitar" chord (See Example 16). ${ }^{128}$

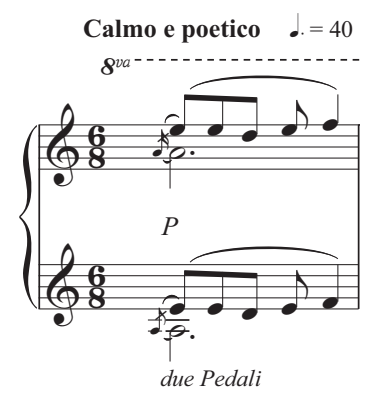

Example 15. Opening motive, Ginastera's Suite de Danzas Criollas, IV, m. 1

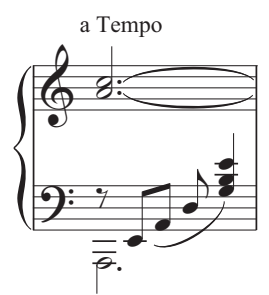

Example 16. Guitar chord accompaniment, Ginastera's Suite de Danzas Criollas, IV, m. 16

The guitar chord appears in measures 4, 8, 12,16, and 17 using the original pitches produced by open guitar strings (E-A-D-G). The abundance of ornamentation and rolled chords are imitations of guitar technique.

Playing this dance quietly and poetically is the major pianistic challenge. To depict the tranquil mood of the piece, a soft and delicate tone quality is necessary. Some pianists believed that not curving the fingers and playing with the cushions of flat fingers makes producing various shades of sound much easier. In order to control the sound and produce a mysterious mood, some pianists go to the extreme of recommending playing with flat fingers and a low wrist. However, using both the una corda and the damper pedals may make such unusual finger technique unnecessary. More attention should be paid to dynamic shaping and legato touch.

The many rolled chords and guitar chords challenge the student performer in his/her

${ }^{128}$ Ibid., 107-108. 
interpretation. Basically, these chords are regarded as guitar accompaniment (plucking and strumming) to the vocal melodic line. Therefore, try to achieve a clear but subtle sonority whenever possible. Wylie also felt it is essential that these chords be played delicately to avoid disturbing the tranquil mood of the piece. ${ }^{129}$ In the middle section (mm. 9-17), the voicing of thirds is crucial in making the chordal texture light. In measure 10, the broken octave in between the second and sixth beat could be treated as a varied guitar chord (See Example 17). These rolled chords should sound like an echo, which vibrates sympathetically in $p p$ with controlled and delicate touch. Basically, the sound of the guitar chord needs to be held over from the previous harmony.

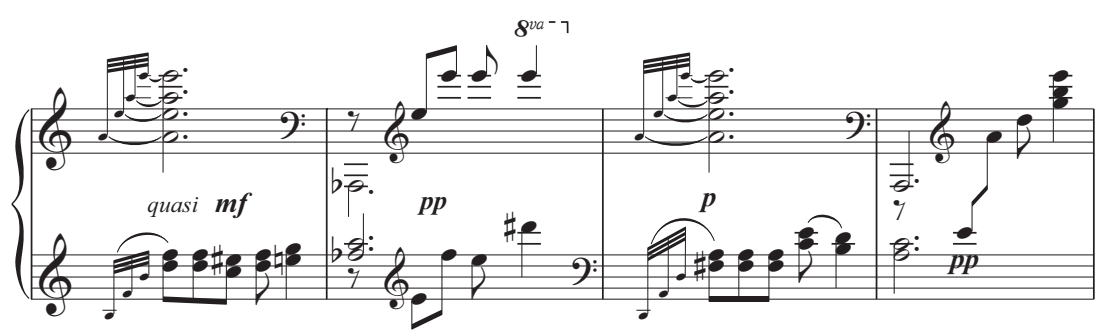

Example 17. Chords imitate plucking and strumming on the guitar, Ginastera's Suite de Danzas Criollas, IV, mm. 9-12

This movement contains the first pedal indications notated by Ginastera. The original pedal marking of due pedali is put at the beginning of the piece without any release indication. We can assume that the composer intended for both the damper and una corda pedals to be used throughout the entire dance. Both pedals are vital to helping create a specific atmosphere and coloring. Using both pedals at the same time will most likely produce blurred harmony at a soft dynamic level. However, though the una corda pedal is used throughout the whole movement, the performer still needs to create variety in dynamics.

The damper pedal will need to be changed at least on the downbeat of every measure to avoid excessive dissonance and blur. Also, to prevent too much sonority from building up

${ }^{129}$ Ibid., 114 . 
in the parallel thirds in the middle section, the pedal will have to be changed on the fourth beat of measures 9,11 , and 13 . Besides that, long pedals in each measure are necessary. It is particularly important to use the damper pedal to blend the guitar chord references with the dotted half notes on the downbeats. The pedal must also be used carefully to catch every note of the grace notes and rolled chords that occur on downbeats. Finally, use one pedal for the last two measures (mm 27-28) of this movement to achieve a special sound effect created by the same harmonies in both the high and low registers.

\section{V. $\quad$ Scherzando and Coda}

The excitement of this dance comes from the rhythmic complexities which are inspired by Argentine folk tradition. This dance is a typical malambo containing hemiola and repetitive passages. According to Chase, Ginastera's malambos are faster than their folkloric models since he is not interested in literal borrowing from the genre, but more concerned with the symbolic concept of the dance. ${ }^{130}$ The malambo gives Ginastera a model for building the rhythmic excitement in the shifting meters of $3 / 4$ and $6 / 8$, and the occasional $5 / 8$ and $7 / 8$ meters.

The "Scherzando" and "Coda" are two of the most technically demanding parts of this Suite. The performer must be sensitive to the hemiola rhythm in the right hand and different metrical patterns in each hand (See Example 18).

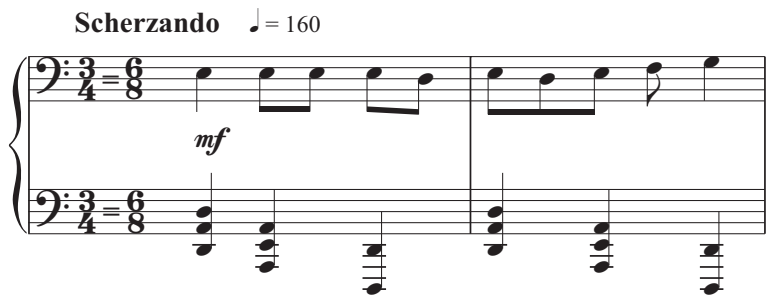

Example 18. Hemiola rhythm in the opening motive, Ginastera's Suite de Danzas Criollas, V, mm. 1-2

\footnotetext{
${ }^{130}$ Chase, “Alberto Ginastera: Argentine Composer,” The Musical Quarterly 43 (1957): 454.
} 
This movement begins with a repeated chord accompaniment under the right hand melody. According to Montgomery, the melodic material of this dance is made up of "short motives within a narrow range". ${ }^{131}$

Burnside feels that the Scherzando marking "implies humor and playfulness that can be realized with a more detached sound."132 Although there are no staccato indications in the music, a heavy, slightly detached, non-legato touch is suggested throughout the piece except where the composer notated slurs. The repeated $\mathrm{E}$ in measures 1 and 3 must be played with clarity. As a general rule, alternating fingers are used for very fast repeated notes. Here, since the tempo is not very fast, the student can play the repeated notes with the same finger. Using a supported finger, a motion of the hand from the wrist, and arm weight will create strong, even repeated notes.

The hemiola rhythm challenges the student from the beginning of the piece. Wallace felt "the meter signature of this piece is an indication that the malambo is the dance basis of the form." ${ }^{133}$ Ginastera's beaming of the notes indicates the rhythmic division of each measure. The pulse in the right hand changes from the first measure in $3 / 4$ to the second measure in 6/8 (see Example 18). Much attention should be paid to measures 2 and 4 due to the rhythmic conflict between the hands; the right hand plays in duple meter while the left hand plays in triple meter. A practice suggestion for playing the hemiola is to focus on the right hand because it varies from triple to duple meter and is therefore more difficult to play correctly. The music intensifies in measures 5 through 9 with the texture becoming thicker and thicker, and with a crescendo increasing from $m f$ to $f$. Emphasize the strong beats (1 and 4) by dropping the arm weight into the keys and then lifting on the weak beats ( 3 and 6). Be very precise in these physical motions to distinguish the $6 / 8$ rhythms in the right hand from the 3/4 rhythms in the left hand. The repeated chords in the left hand require an even touch. The climax of this section (measures 9-13, marked $f$ to $f f$ ) features some of

\footnotetext{
${ }^{131}$ Montgomery, "The Latin American Piano Suite in the Twentieth Century," 29.

${ }^{132}$ Burnside, "Use of Peal in Selected Piano Music of Alberto Ginastera," 54.

${ }^{133}$ Wallace, "Ginastera, An Analysis of His Style", 116.
} 
the clearest examples of guitar strumming in the entire piece. The performer must draw attention to this section and imitate the sound by playing sharp, strong chords with firm fingers supported by weight and power emanating from the body and shoulders.

The hammer-like touch indicated by the martellato in measures 14 and 37 can be achieved by striking the key bed with firm fingers and with great energy originating from the wrist (See Example 19).

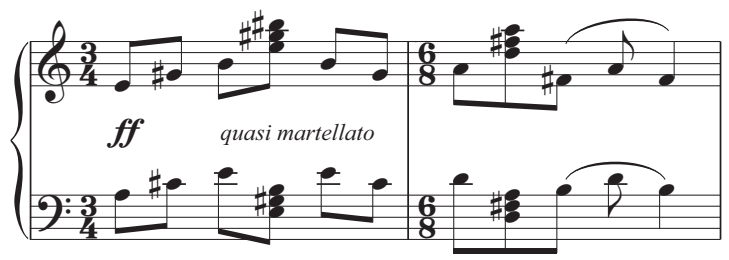

Example 19. Quasi martellato with constant meter change, Ginastera's Suite de Danzas Criollas, V, mm. 14-15

The first legato sign appears in measure 15. It is interesting to note that, in this dance, non-legato touch is the norm, while legato touch serves as a surprise element. Therefore, observe the slurs exactly as the composer marked them in order to create a different mood. In this section with constant meter changes among $3 / 4,6 / 8,7 / 8$, and $5 / 8$, it is important to keep the eighth notes steady. In measure 23, make sure to accent the fourth beat as well.

The open-fifth repeated notes in measures 24-25, 28-29, and 47-48 must be played evenly but with accents on beats 1 and 4 (See Example 20).

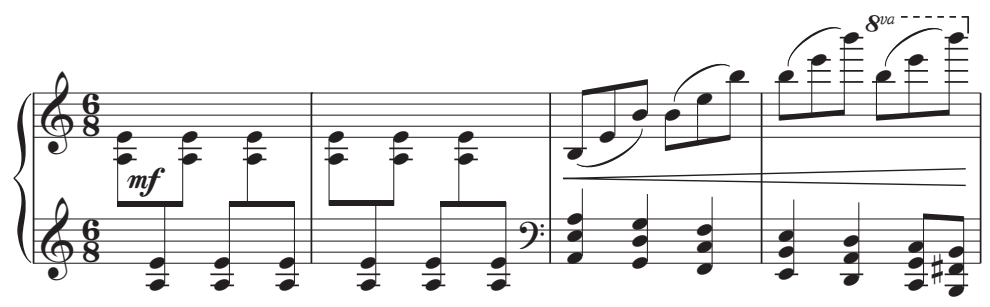

Example 20. Alternating open-fifth chords followed by four-octave arpeggio, Ginastera's Suite de Danzas Criollas, V, mm. 24-27 
The sweeping effect of the four-octave arpeggio in measures 26-27 in the right hand and measures 30-31 in the left hand must be played with precise rhythm. Be sure to emphasize dropping on the thumb to create accents on the strong beats. As a general rule, the rhythm of the hand motion must reflect the rhythm of the passage.

In measures $32-35$, the different rhythms in each hand are difficult to play for many students (See Example 21).

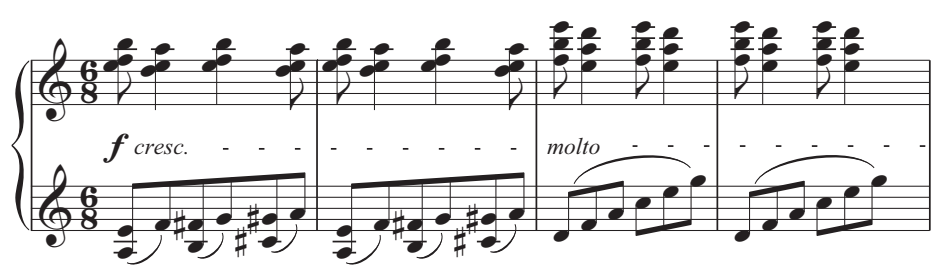

Example 21. Syncopated rhythm, Ginastera's Suite de Danzas Criollas, V, mm. $32-35$

Try to practice each hand alone, exaggerating the dropping and lifting. The right hand will be more difficult because the tendency is to play the syncopated note stronger. Be very certain that you feel the proper pulse for each voice and do not eliminate the contradictory rhythmic feeling.

The martellato section is repeated with slight variation beginning in measure 37 . As in the original martellato section, the stylized malambo maintains its rhythmic drive through the frequent meter changes; however the martellato section beginning in measure 37 features harmonic expansion as the original single-note accompaniment has now become chords. Here, the left-hand part achieves added significance because of the new accent marks, harmonic complexity, and rhythmic interest. The right hand non-legato melody should be played with a quick finger stroke, while the left-hand material should be played with long, steady force and a pointed and percussive tone. Particularly at the end of the martellato section in measure 45, use full force on the long, accented chords.

In measures 55, 57, 59, 61, and 63, Ginastera used dotted half notes several times as a 
tool to mark the two-measure phrases (See Example 22).

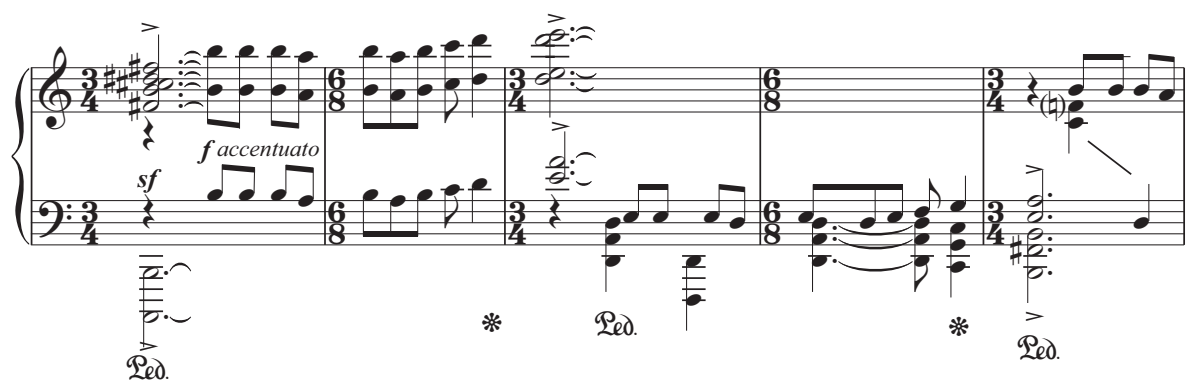

Example 22. Dotted half notes punctuating phrases, Ginastera's Suite de Danzas Criollas, V, mm. 55-59

The performer must use the damper pedal to sustain the sound of these chords for their full duration. Enjoy the long chords before starting the octave eighth notes. Instead of playing in a strict tempo, ask the student to listen to the ringing sound of the chords, and to use his ears to judge when to begin the octave passages. Be careful to keep the tempo moving during the meter change from $6 / 8$ to $4 / 8$ in measure 68 . It is wise to broaden the sound of these four octaves without too much ritardando.

This movement requires only touches of damper pedal due to the use of detached touch and fast changing harmony. The pedal can be valuable when projecting rhythm if it is handled intelligently. The pedal can be used to accentuate the downbeats of measures 1 to 8 as well as the chords in measure 9. A long pedal in measures 10 and 11 helps to build the crescendo. The slurs in measures 15, 17, and 19 will benefit from brief touches of the pedal. The texture change from staccato to slurs must be emphasized with different pedaling and articulation. At the cadences in measures 23 and 46, pedal only on the downbeats. Use little or no pedal with the open fifths in measures 24-25 and similar passages. The upwardmoving glissando in measure 36 will benefit from one unbroken pedal to enhance the brilliance as well as to increase the dynamic level. The martellato section from measures 37 through 45 can be pedaled based on the harmonic changes in the left hand.

Ginastera notated his own pedal markings in measures 55 through 68 (See Example 
22). Burnside felt there is a need for further explanation to students because some of the pedal markings appear to be inconsistent with the notation. ${ }^{134}$ Basically, a long pedal for two measures is needed to sustain the dotted half notes regardless of whether they appear in the top or bottom voice. Therefore, measures 57 and 63 should be pedaled on the downbeat instead of on the second beat as Ginastera notated. Although the composer marked one pedal from measures 66-68, there are other options (See Example 23). The student may choose either one pedal for each measure or change pedal between the meter changes (i.e., the last beat of measure 67). Choose a pedaling that helps create excitement (big effect, big sounds, even "noise") for the Coda.

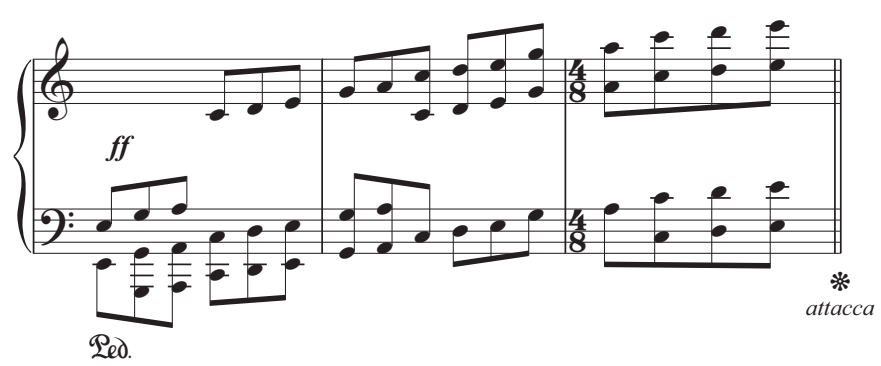

Example 23. Pedaled octaves, Ginastera's Suite de Danzas Criollas, V, mm. 66-68

The material in the Coda is related to that which precedes it both thematically and rhythmically. As in the Scherzando section, there are repeated passages, hemiola rhythms and frequent changes of meter. Ginastera heightened the excitement in the Coda by using octaves, chords, a strong dynamic level, a faster tempo, and a wide keyboard range. The restless, perpetual motion is created with frequent changes of meter. ${ }^{135}$ Montgomery argued that the connection between these two sections is particularly strong, suggesting that the Suite is composed as a unit. ${ }^{136}$ Although Wallace felt that the Coda achieves sufficient status

\footnotetext{
${ }^{134}$ Burnside, "Use of Peal in Selected Piano Music of Alberto Ginastera," 55.

135 Hanley, "The Solo Piano Compositions of Alberto Ginastera," 7.

${ }^{136}$ Montgomery, “The Latin American Piano Suite in the Twentieth Century," 29.
} 
to be a separate movement, ${ }^{137}$ the composer's indications suggest otherwise. The fact that Ginastera numbered all other dances in the suite I-V but did not indicate a dance VI in this movement, and his unusual eighth-note rest at the beginning of the Coda all indicate that this movement should not be a separate movement from Scherzando, and should be connected in performance as well (as indicated by the attacca marking).

Generally speaking, the pianistic challenges of this dance involve playing with great power and good rhythmic control. A carefully planned dynamic range is required since Ginastera demands $f f$ to $f f f f$. The excitement from the long, sweeping descending scale passage at the end of Scherzando must be carried immediately to the Coda. For many students, the continuous octave notes with the middle voice secundal chords in $f f$ challenge the student's endurance. The octave chords are much more important than the inner harmonies in the melodic structure. Therefore, firm fingers are used for strong octave chords, and the light inner voices are played slightly detached.

In order to prevent the buildup of tension in the forearm when playing continuous, strong octave chords, the fingers should release quickly after each group of notes. For a small hand, the stretched hand position from playing octaves should be relaxed by closing the hand in the secundal chords. For creating powerful octaves, it is essential that the performer feel the hand and arm as one unit, not as two separate entities. Also, be sure that the arms maintain a close relationship with the torso. Besides power, a faster tempo and motion into the keys are necessary to achieve a brilliant, percussive tone on chords and octaves.

Like the Scherzando, the rapid meter change of the Coda will challenge the student performer's rhythmic control (See Example 24).

${ }^{137}$ Wallace, "Ginastera, An Analysis of His Style", 116. 


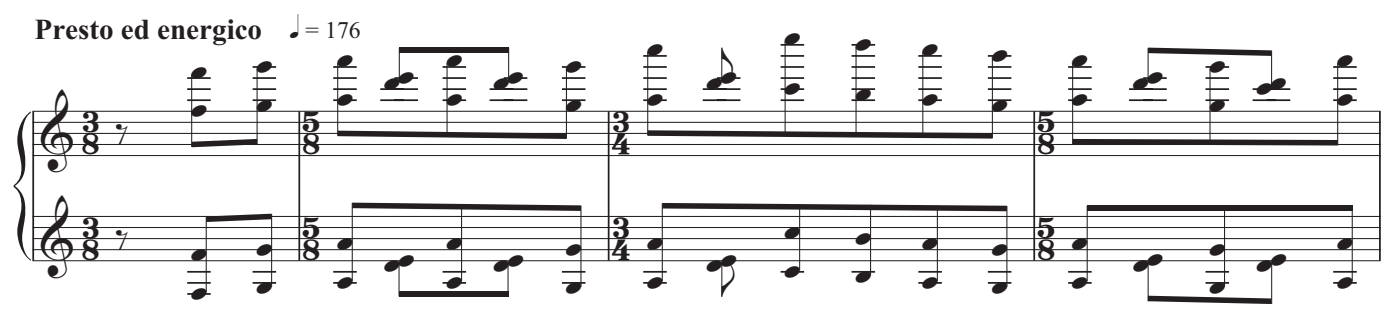

Example 24. Rapid meter changes, Ginastera's Suite de Danzas Criollas, Coda, mm. 69-72

Besides keeping the eighth notes steady, the student needs to emphasize the downbeat of each measure, clearly indicating the changing meter. The disjunct sections will create another technical challenge for students. It is important to play many large jumps (e.g., measures $76-77,80-81,85,88,90,93,96-97,105,106,108,109)$ smoothly without any break. If the tempo is hard to maintain, using a well planned "tempo rubato" can achieve the right effect. The jumps can be prepared by slowing down a few beats before the leap and then gradually returning to the tempo. However, it is also possible not to change the tempo by using appropriate coordination between the muscular reflexes and the finger actions. First of all, prepare each new position earlier by mentally measuring the amount of space for the leap. Then, let the horizontal movement of finding the keys occur simultaneously to the vertical action of playing. It is important not to get stiff in either the wrist or the arm. Make the elbow the point of reference in moving from one position to another. Also, never forget to use the damper pedal to help sustain the notes and eliminate possible gaps between sounds.

In measure 96, a breath, not a ritardando, between sections is necessary. Pay attention to the rhythmic pattern of $8 / 8$ in measures 112 and 113 since it is divided irregularly as $3+3+2$, but not $4+4$. In measure 115 , the bass melody is very important because it is the beginning of the new section (See Example 25). Try to draw the listener's attention to this melody with an accented staccato touch in order to depict the coarse and rough sound that Ginastera indicated by ruvidamente. 


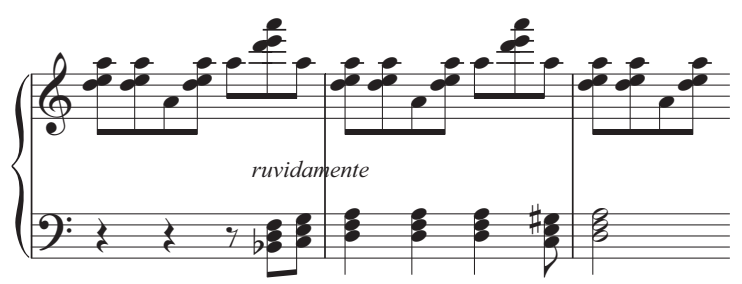

Example 25. Beginning of new, ruvidamente theme, Ginastera's Suite de Danzas Criollas, Coda, mm. 115-117

In measure 124, the opening theme returns and should be played stronger than before. Both the Scherzando and Coda sections end similarly, sweeping up and/or down the keyboard with extreme excitement (See Example 26).

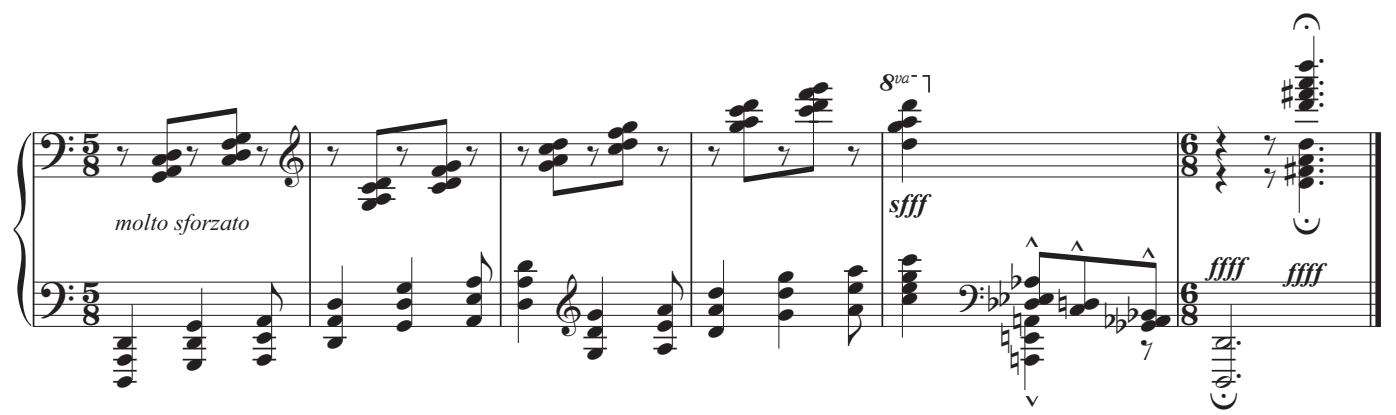

Example 26. Molto sforzata ending, Ginastera's Suite de Danzas Criollas, Coda, mm. 138-143

In measures 138 through 141, although the left-hand chords must lead, the right-hand chords should be strong as well. In order to achieve the ffff, both voices must be played equally strongly. To create such strong dynamics, the student needs to be taught how to use his/her body effectively. In addition to using weight from the shoulders and arms, the torso should act as an extension of the upper arm and help to build up the force.

Like the Scherzando, the Coda will need only touches of pedal. Such pedaling helps create a continuous melodic line from the non-legato, repeated chords. Also, because the pedal sustains the octaves, the student can play the secundal harmony without holding the octaves (See Example 24). This will benefit especially the performer with a small hand in sustaining endurance in this passage. In sections with large intervallic leaps, the pedal 
should be used to avoid gaps between notes. It is critical to hold the pedal throughout measures 134 to 137 , to reinforce the repeated octaves on D and to enhance the crescendo. The dotted half notes in the last measure (measure 143) must be held with one pedal.

\section{Summary}

The Suite de Danzas Criollas as a whole features various Creole subjects, notably characteristics of Argentine folk melody, of the stylized dance the malambo, and of the harmony created by open strings on the guitar. There are melodic, rhythmic, harmonic and motivic similarities among movements. The folk-derived melodies are usually in fourmeasure phrases and two-measure repeated motives as Wallace mentioned. ${ }^{138}$ Rhythm is characterized by the use of compound meters, such as $6 / 8$ and $11 / 8$. Harmony usually exploits the use of fourth chords and cluster chords, and includes dissonance created by tertian harmony with added notes. A typical motivic design is use of short, repeated motives based on the ABA form.

As Ginastera was a fine pianist, the performance technique that he featured and the specific sound effects that he incorporated in this suite are appropriate and idiomatic to the piano. While he used Argentine songs and dances as models, he also adopted new compositional techniques, such as cluster tones, glissando, abrupt jumps, polyrhythm, and especially, the complexity of cross-accenting between voices. It is because of these technical demands that Wylie felt the Suite de Danzas Criollas makes an excellent set of studies to expand a student's technique. ${ }^{139}$ A wide dynamic range from $p p p$ in the fourth movement to ffff in the Coda and contrasting sonority from impressionistic tone color in the first and fourth movements to the percussive sound of cluster chords, parallel chords, and octave notes in the second, fifth movements and Coda show Ginastera's expertise and virtuosity in many different styles of writing. The sense of great emotion and imagination makes this collection popular and immediately appealing to pianists and listeners.

\footnotetext{
138 Ibid., 315.

${ }^{139}$ Wylie, “Argentine Folk Elements in the Solo Piano Works of Alberto Ginastera," 135-136.
} 
Samuel Barber: Excursions, Op. 20

\section{Un poco allegro}

The first movement is a stylized boogie-woogie, accompanied by an ostinato bass. It is important that the student performer understand the characteristics of American jazz in order to play this piece in a correct style. The boogie-woogie style defined by the New Grove Dictionary is

characterized by the use of blues chord progressions adapted to a percussive, forceful, repetitive left-hand bass figure. There are many such bass patterns, but the most familiar are the "doubling" of the simple blues bass and the "walking bass" in broken octaves. ${ }^{140}$

Basically, Samuel Barber utilized the most common walking bass that was used by pianists in the earlier part of the twentieth century (See Example 27). ${ }^{141}$

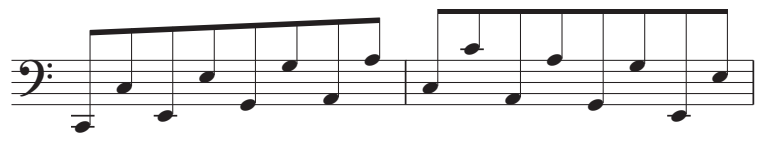

Example 27. Typical boogie-woogie bass from New Grove Dictionary, vol.3, 39.

In spite of the classic boogie style, there are several characteristics in Barber's work that differ from the boogies of the 1920s. Although the chord progressions that Barber used (I-IV-I-V-I) followed the typical blues pattern (I-IV-I-V-IV-I), the traditional twelvebar pattern has been abandoned. ${ }^{142}$ Also, the bitonality and meter changes that Barber incorporated, based on a twentieth-century technique, are innovative. Generally speaking, Barber expressed boogie-woogie in an imaginative way.

\footnotetext{
${ }^{140}$ Paul Oliver, "Boogie-woogie", The New Grove Dictionary of Music and Musicians, ed. S. Sadie and J. Tyrrell (London: Macmillan, 1980), vol. 3, 39.

${ }^{141}$ Ibid.

${ }^{142}$ Young, "The Solo Piano Music of Samuel Barber," 36.
} 
Young argued that the boogie-woogie is only "fake and superficial" if the performer fails to interpret it in an idiomatic manner. ${ }^{143}$ In her dissertation, she presented several examples of dotted bass figures and argued that they are characteristic of a real boogiewoogie (See Example 28). ${ }^{144}$

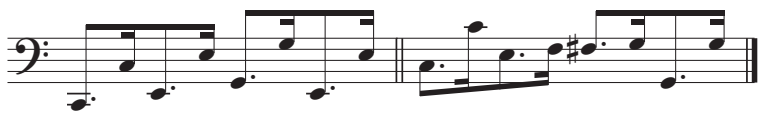

Example 28. "Real" boogie-woogie using dotted bass figures, from Young, "The Solo Piano Music of Samuel Barber," 34-35.

She felt Barber's writing of even eighth notes in the bass seems to establish a mechanical beat, making it difficult to capture the essential spirit of boogie-woogie rhythm. However, Friedewald commented on the "sharp rhythm" of the left hand set against a rhapsodically free right hand, ${ }^{145}$ and Miller also noted that the bass accompanies a freely-improvised right-hand melody. ${ }^{146}$ Given these observations and the author's impressions, it seems likely that Barber deliberately chose even eighth notes in the accompaniment to balance the freedom of the right hand. In order to draw attention to the rhythmic contrast between melody and accompaniment, the student performer should play this movement evenly, with no variability in tempo (note that Barber even specified "senza rit." in the last four measures).

Rhythmic vitality is particularly important in this boogie-woogie and can be created by coordinating the physical motions with the boogie character. An ideal way to interpret the rhythmic boogie-woogie in the opening and throughout the movement is by playing with a slightly detached sound (See Example 29).

\footnotetext{
143 Ibid., 40.

144 Ibid., 34-35.

145 Friedwald, "A Formal and Stylistic Analysis of the Published Music of Samuel Barber", 123-124.

146 Miller, “A Study of Samuel Barber's Piano Music”, 7.
} 


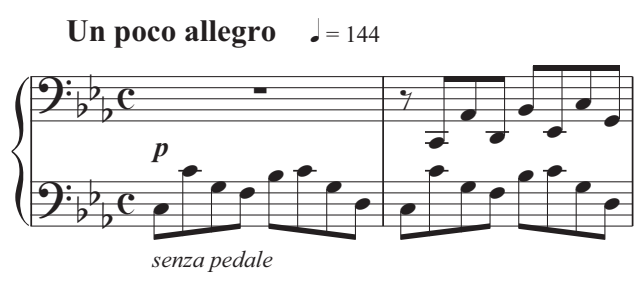

Example 29. Boogie-woogie introduction, Barber's Excursions, I, mm. 1-2

Essentially, the hand motion of a detached touch is similar to that of the legato, except for lifting the fingers. Such a slightly non-legato walking bass will produce more rhythmic vitality than a legato touch. The student performer must be sure the boogie-woogie bass is played evenly with a supportive arm, moving flexibly and smoothly between the different hand positions.

In measures 2 and 3 of the introduction, freedom of the right arm movements is critical during the awkward hand crossings. Beginning in measure 4, the sharp, rhythmic righthand melody (with its repeated notes and short reiterated figures) sounds freely improvised (See Example 30).

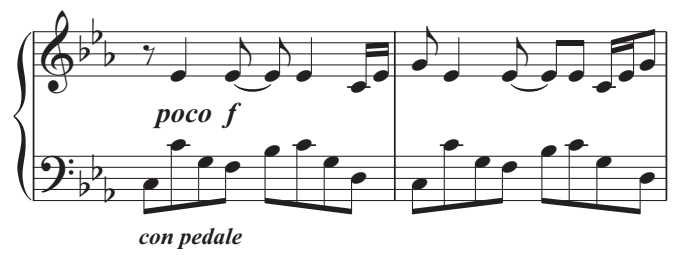

Example 30. Opening motive, Barber's Excursions, I, mm. 4-5

In the opening theme, the student should emphasize the three consecutive up-beat syncopations with a percussive tone in measures 4 and 5 . Where the composer indicated staccato and senza pedale in measures 6 and 7, be sure the student performer plays with active fingers in order to make short and sharp sounds.

In measures 9 through 11, special attention should be paid to the rhythmic complexities of changing meters that go from $5 / 4$ via $3 / 2$, back to the original $4 / 4$ meter (See Example 31). 


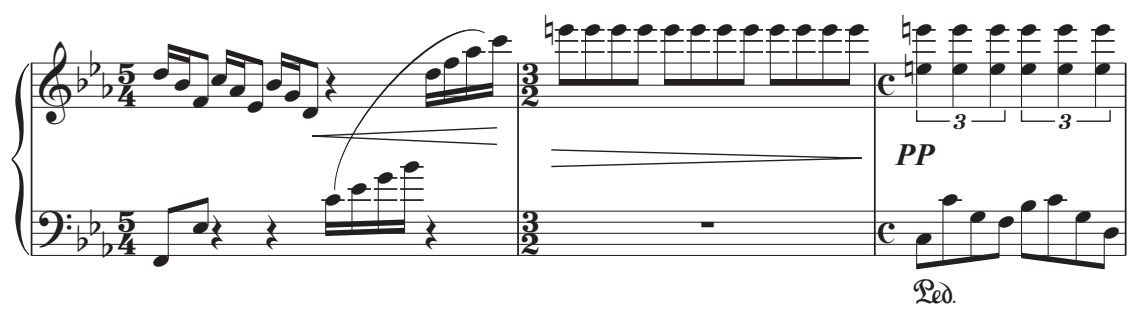

Example 31. Natural rhythmic ritardando, Barber's Excursions, I, mm. 9-11

A natural rhythmic ritardando is achieved when Barber changed from sixteenth notes to eighth notes and finally to quarter note triplets. It is important that the student be able to hear both voices when playing and feel the lazy triplet against the duple meter in measures 11 and 12.

This rhythm sets up a return of the opening theme in measure 13, which is then varied in terms of pitch and rhythm beginning in measure 17; fragments of the opening passage, culminating in over a three-octave, right-hand scale, create excitement in measures 18 through 23 . The counterpoint between the bass and soprano not only creates many dissonances between the voices but also challenges the student's technique. Be sure to bring out the contrary motion between the two voices and emphasize the voice that has the sixteenth-note pattern. The rapid scale in measure 23 should sound like a glissando (See Example 32). In order to imitate a fast glissando, the student must use quick fingertips and a light touch to produce the desired effect.

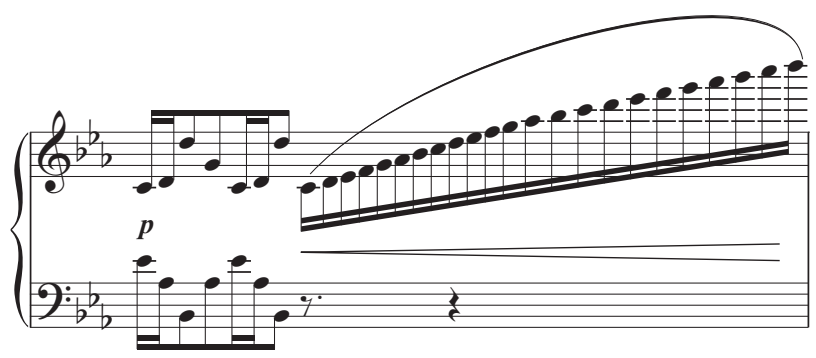

Example 32. Glissando-like scale, Barber's Excursions, I, m. 23 
After the glissando, Barber uses the same rhythmic ritardando technique he used in measures 10 through 12 to gradually slow down the rhythmic movement and return to the main theme. A well-planned rhythmic and dynamic control is crucial in this section (measures 24-26). In measure 25, as well as in several other sections (measures 11-12 and 56-57), much attention should be paid to the complex rhythmic pattern that occurs when quarter-note triplets sound against the even eighth notes. The student must practice these passages carefully in order to achieve precision and smoothness.

Starting at the marcato in measure 29, the performer should play with a percussive tone to draw the listener's attention to the startling dissonance of the bitonality. In the contrasting sections, marked leggero from measures 32 through 34, a light touch is required. There is a canon in measures 35 (See Example 33) and 37 when two similar motives appear only an eighth note apart. In order to produce energy and to play the right accents in both hands, the student should use strong, active fingers that are supported by arm weight. It is important to use well-defined articulation and dynamics to differentiate the canonic and boogie-woogie sections to audiences.

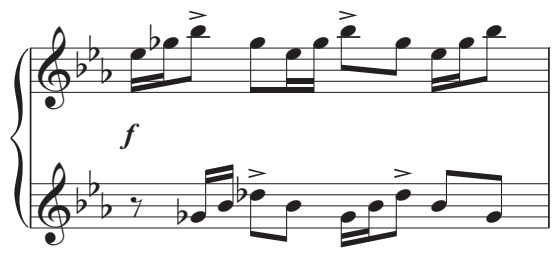

Example 33. Short canon, Barber's Excursions, I, mm. 35

The motive beginning on the last beat of measure 38 is repeated three times through measures 39 and 40, starting at different places within the measures (See Example 34). In practice, stabilize the hand by grouping the sixteenth-note motives; emphasis on the high note, $E^{b}$, is critical. Basically, use of finger articulation and arm rotation will help to achieve those even sixteenth notes. The music intensifies during each crescendo of these short, repeated phrases. 


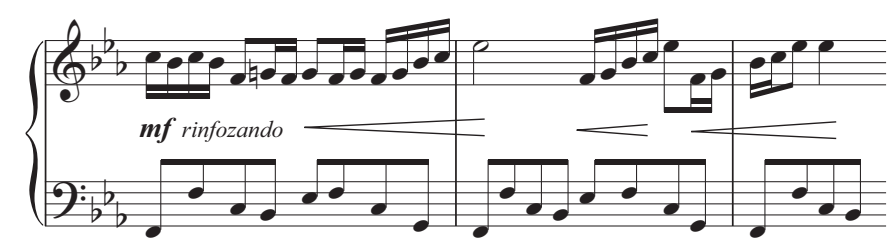

Example 34. Repeated sixteenth-note motives, Barber's Excursions, I, mm. 3840

Pay attention to the dramatic connection between phrases; an abrupt dynamic contrast appears as the crescendo goes right into a subito $p$ in measure 41. Barber also indicated cresc or cresc. sempre from measures 46 through 52 . From there to the ff in measure 53, the performer should make a continual crescendo without getting softer. A tremolo is created by the repetition of double thirds, such as in measures 44, 50, and 77 (See Example 35). In order to achieve a rattle sound for these sections, the student should use straight fingers and a rotary movement, supported by a floating, relaxed arm.

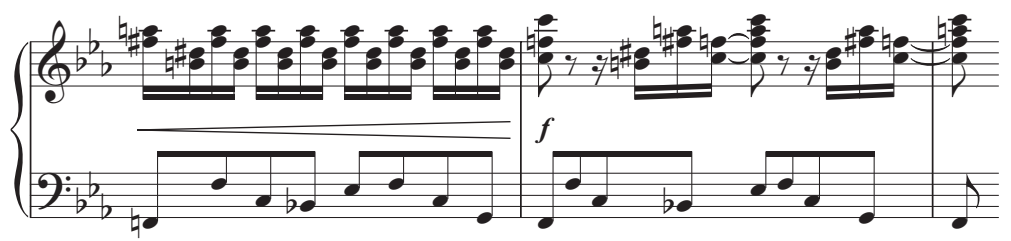

Example 35. "Harmonica" passage containing tremolo and repeated, double sixteenth notes, Barber's Excursions, I, mm. 44-46

The most technically demanding section of this dance lies in measures $45-46,51-52$, and $78-80$, as the repetition of phrases containing a series of single pitches, such as in measures $38-40$, becomes phrases containing double-third chords. Sifferman noted that,

With regard to Barber's 'local instruments ... easily recognized,' one could imagine the main theme (m. 4-9) played on saxophone, while the right hand figure in measure $44-46$ sounds like harmonica, imitating the alternately in and out breath motions. ${ }^{147}$

${ }^{147}$ Sifferman, “Samuel Barber's works for Solo Piano," 8. 
Holding the ties in the right hand in these measures makes these sections extremely hard to play clearly. It is important that the student practice this passage by dividing the double notes into two groups, preventing an accumulation of tension in the hands. Try to emphasize the fifth finger of each group by leaning the hand over to support the fifth finger. The quintuplet arpeggios in measure 53 should be played with as big a sound as possible, using a long pedal to help maintain the sound and create excitement. From measures 54 through 57, like in measures 24 through 25 , the passion eases as a result of gradually softer dynamics and slower rhythmic motion.

The free melodic eighth notes in measures 61 and 66 should be played rhythmically with a staccato touch. The third and fourth beats of measures 62 and 67, although in the alto voice, should be stressed, perhaps imitating a car horn (See Example 36).

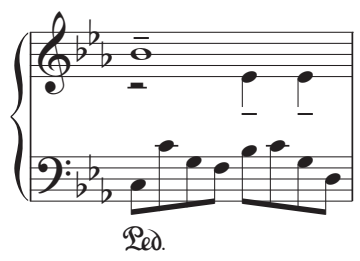

Example 36. Imitation of a car horn in soprano and alto voices, Barber's Excursions, I, mm. 62

In measures 81 through 83 , the repeated triplet chords need to be played with full force (accented and $f f$ as indicated by Barber) on strong and balanced fingers, such as the first, second, and fifth fingers (See Example 37).

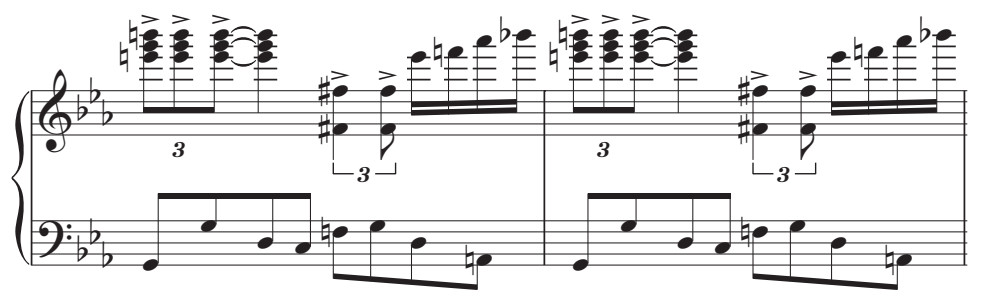

Example 37. Repeated triplet chords, Barber's Excursions, I, mm. 81-82 
Much attention should be paid to the rhythmic complexity created by the triplet chords against the even eighth notes. Let the right-hand chords lead and the repeated left-hand bass fit into the section. Eventually, the student performer should be able to hear both rhythms at the same time.

The passage from measures 84 through 89 will need to be played evenly with light and agile fingertips. A legato fingering should be used to smoothly connect the transitional material between measures 84 and 86 during the register changes (See Example 38).

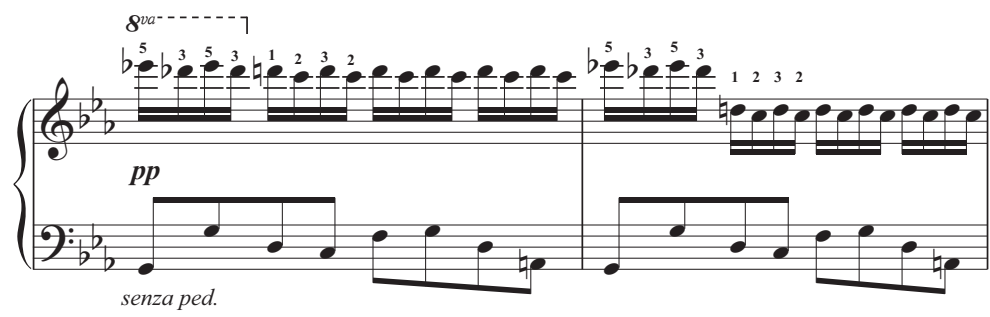

Example 38. Rapid sixteenth notes with suggested fingering in the right hand, Barber's Excursions, I, mm. 84-85

In the final section, beginning in measure 90, the boogie-woogie bass returns as it appears in the opening except one octave lower (See Example 39).

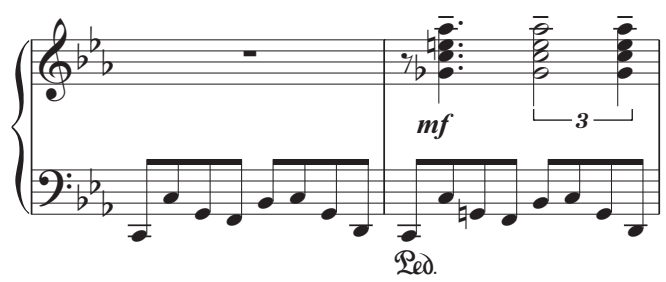

Example 39. The return of opening boogie-woogie accompanied by right-hand block chords that imitate the sound of train whistles, Barber's Excursions, I, mm. 91-92

The syncopated melody in the right hand is harmonized with block chords. As a special sound effect, be sure these chords sound like a train whistles signaling an important juncture, the 
approaching end of this movement. Following Barber's rhythmic and dynamic indications literally in this section is important. Also, be sure to project the top note of these chords. Regarding the interpretation in this section, Carter felt that,

Rhythmic control is the performer's primary concern. As a unifying device, the ostinato should be consistently steady. Otherwise, the syncopations will be ineffective. ${ }^{148}$

From measures 98 through 106, the harmonized melody shifts between the tonic major and tonic minor modes. Note that in measures 105 and 106, the eighth rest that begins the regular rhythmic pattern is lengthened (See Example 40).

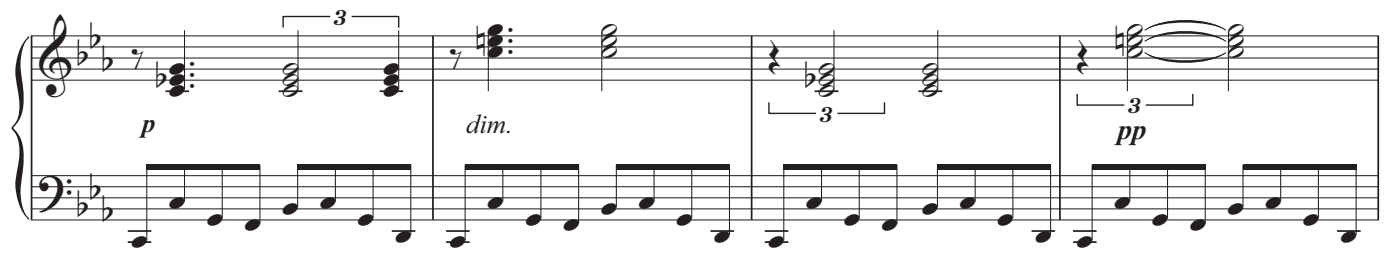

Example 40. Alternating major and minor chords with lengthened rests continue to imitate train whistles, Barber's Excursions, I, mm. 103-106

The rhythmic irregularity gives the whole final section a sense of improvisation. In these two measures, it is especially important to maintain the rhythmic flow during the half-note chords. In the last four measures of the piece (measures 110-113), be sure to end this work without a ritardando and without pedal as Barber indicated.

Like Ginastera, Barber offered very few pedal marking in his compositions. Therefore, the original pedal markings are crucial, and the performer must follow them attentively. General speaking, excellent pedaling can be inferred through careful observations of the rests, dynamics, and articulation indications such as slurs and staccato signs. Use of the pedal is very important to create the desired contrasts in this movement. Basically, a shallow, constant touch of the pedal is used wherever Barber marks con pedale. Sections with Ted. indication usually should be played with a long and deep pedal.

${ }^{148}$ Carter, “The Piano Music of Samuel Barber," 37. 
Normally, the character of an arpeggiated $\mathrm{Cm}^{13}$ chord on the last two beats of measure 9 and the repeated note, E, in measure 10, would each be enhanced by use of pedal for resonance and sonority. However, since Barber's original marking of senza pedale in measure 6 is still in effect, and since he did notate rests in the bass in measures 9 and 10, the performer should not use any pedal. Barber's pedal markings should be followed exactly as they are notated, and the performer should not alter Barber's markings until he indicates a change in the score. From measure 11 to 12 , use of one pedal (damper pedal) or two pedals (damper and una corda pedals) for contrasting sonority is needed.

The glissando-like, rapid, ascending scale passage in measure 23 will benefit from the use of a long pedal to sustain the sound and enhance the brilliance. This measure can be heavily pedaled since there is a crescendo marking. In the marcato section of measures 29 through 31 , it is important to play the three syncopated chords in a way that imitates a car horn. The pedal will also improve the drama in several short crescendos, as in measures 3940 and 42-43; use light pedals on the short, ascending motive to enhance the crescendos. In measures 44, 50 and 77, in the tremolo passages marked with crescendos, each measure should be pedaled to capture the full harmony.

In the technically demanding passages in measures $78-80$, be sure to use pedal to increase the excitement. Using a short pedal on the first beat, and a long pedal on the arpeggios of the third and fourth beats will strengthen the sound and improve the connection between notes. It is also necessary to hold the repeated eighth-note triplets of measures 81 through 83 with a single pedal so that the performer can achieve the required $f f$ dynamics. The $u n a$ corda pedal can be used throughout the ostinato pattern from measures 84 to 90 when Barber indicated $p p$. In measures 92 through 106, the use of the damper pedal is critical to sustain the long chords. The unbroken sonority of each measure is essential for creating the sound of a train whistle. 


\section{II. $\quad$ In slow blues tempo}

The second movement is an elegant blues. In general, its characteristics are borrowed from the typical jazz style but with alterations. Overall, there are four sections in this movement; while the standard blues form consists of twelve measures, Barber uses irregular phrasing in this movement that results in sections with thirteen measures. Only the third section follows the traditional twelve-bar pattern. Also, Barber follows closely the blues harmonic progression that is limited to the tonic, dominant, and subdominant. Basically, the blue notes that Barber uses in this movement are the lowered third $\left(\mathrm{B}^{\mathrm{b}}\right.$, sometimes $\left.\mathrm{A}^{\#}\right)$ and the flat seventh (F) based on the G tonal center.

The most important style element of this movement lies in the rhythmic patterns. Throughout the movement, the uses of syncopation, triplets, and weak beat accents are prominent. The use of the triplet figure establishes a "swing" sense and the weak beat accents are types of rhythmic effects derived from African music. The accurate musical notation for the blues is difficult because of the rhythmic complexity of improvisation. Barber tries to notate the complicated jazz rhythm in three different ways: the triplet, dotted, and even eighth notes (See Example 41). ${ }^{149}$

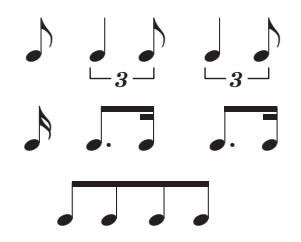

Example 41. Three types of Jazz swing rhythms, Owens, 18

According to Young, "a professional jazz player would not make any distinction between these rhythmic patterns. ${ }^{\prime 150}$ Besides his complicated rhythmic notation, Barber has attempted to solve stylistic problems by notating every possible nuance for dynamic, articulation, and

\footnotetext{
149 Owens, "Aspects of Interpretation in the Solo Piano Music of Samuel Barber," 18.

${ }^{150}$ Young, "The Solo Piano Music of Samuel Barber," 33.
} 
expression markings. The result seems to freeze the spontaneity of performance.

Young raises an important pianistic issue for this movement: should a pianist follow the score or the accepted jazz interpretation? ${ }^{151}$ When Horowitz premiered the Excursions at Carnegie Hall in 1945, due to his lack of understanding of the style, the performance was described as "drab blues." 152 How much can a classical musician modify the score in order to give an aesthetically pleasing performance? In author's personal opinion, as in the first Excursion, an interpretation of the blues requires the pianist to have an adequate knowledge of jazz characteristics as well as a concept of jazz band performance. Carefully observing the performance indications in the score is critical to comprehending Barber's intentions. Then, stretching the notated rhythm cautiously by responding to the sound is appropriate in the blues. In terms of sound production within the marked articulation and dynamic range, the performer should always use his/her imagination to reproduce the sonority that is reminiscent of jazz performance. It is our goal to achieve a lively and idiomatic performance of this composition.

The first measure begins by establishing the steady four-beat rhythm that Young felt is characteristic of jazz of the 1930s (See Example 42). ${ }^{153}$

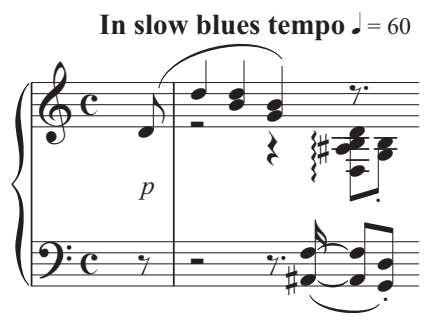

Example 42. Opening motive, Barber's Excursions, II, m. 1

Try to imitate the sound of a trumpet in the opening right-hand melody. The broken seventh

\footnotetext{
151 Ibid.

152 Heyman, "Samuel Barber: The Composer and His Music," 233.

153 Young, "The Solo Piano Music of Samuel Barber,” 28 quoting Winthrop Sargeant, “Jazz: Hot and Hybrid," $3^{\text {rd }}$ ed. (New York: Da Capo Press, 1975), 293.
} 
chord in the lower voices interrupts the melody with slightly stronger dynamics. With the sound of two tenor saxophones in mind, each note needs to be sustained by both the fingers and the pedal in order to create the desired sonority.

Also, make measures 3-4 one long phrase accompanied by the triplet figures. Such loping triplets are important since they establish a "swing feel" to the movement (See Example 43).

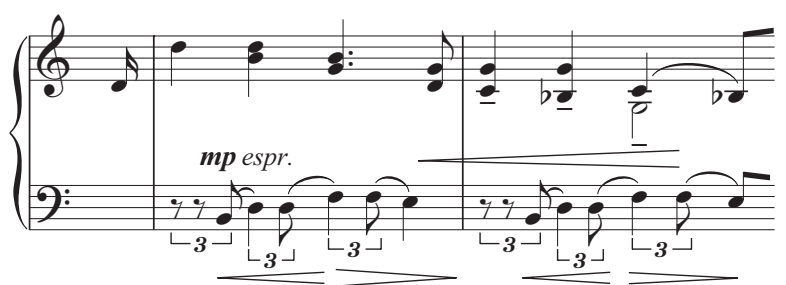

Example 43. Loping-triplet accompaniment figure, Barber's Excursions, II, mm. 2-4

A layering of different rhythms occurs from measures 4 through 6 . This type of rhythmic feature is carried over from the African music tradition because "African music uses polyrhythm and polymeter, and emphasizes weak beats." 154 It is necessary to follow Barber's dynamics and expression marks in this passage. From measures 7 through 8, a variation of the accompaniment motive from the opening theme returns but it is varied rhythmically (See Example 44).

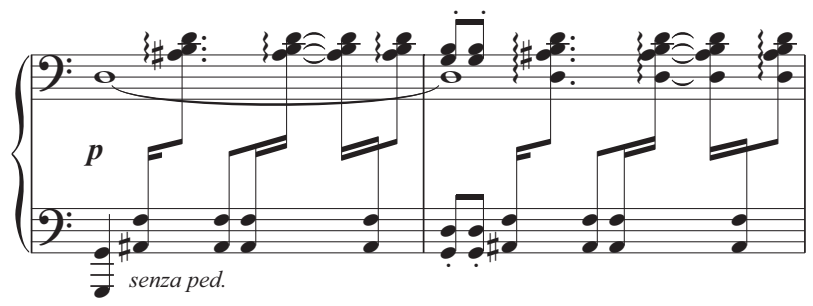

Example 44. Varied accompaniment motive returns as part of the melody, Barber's Excursions, II, m. 7-8

${ }^{154}$ Ibid., 29 
Frequent use of $\mathrm{A}^{\#}$ against $\mathrm{B}$ natural creates many dissonances, such as in measures 1-2, 78,34 , and 50 . On these broken chords, try to play rhythmically and energetically within the $p$ to depict the sound of a wailing saxophone. However, Sifferman felt this type of rolled chords resembles the strumming of a guitar. ${ }^{155}$ In measure 7, the downbeat D as well as the broken chords in the right hand should sound longer by holding them with the fingers since the composer indicated senza ped (without pedal). The student needs to focus on different articulations by experimenting with various touches.

Measure 9 functions as a cadence for the section (See Example 45).

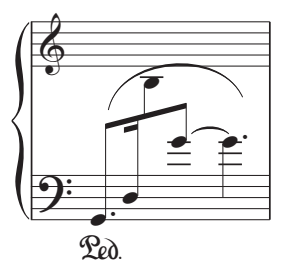

Example 45. Cadence, Barber's Excursions, II, m. 9

The rhythmic pattern in this measure (as well as those in measures 12, 13, 19, 20, 44, and 45) should be played with a swing rhythm, a typical Jazz rhythmic feature. The sense of swing can be achieved by playing the second beat eighth-note loosely, similar to that of a triplet.

Stress is often placed on the accompanying voices, such as the tied blues note in the first two measures. These kinds of figures will require special emphasis in order to create a "sighing effect." 156 A similar feature occurs throughout the entire movement with some variation. The sighing effect is especially important on the octaves from the last beat of measure 9 to the downbeat of measure 10 (See Example 46).

\footnotetext{
155 Sifferman, "Samuel Barber's works for Solo Piano," 12.

${ }^{156}$ Owens, “Aspects of Interpretation in the Solo Piano Music of Samuel Barber," 19.
} 


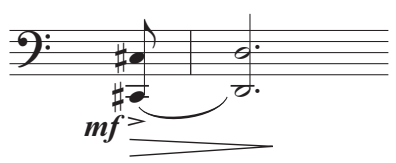

Example 46. Tied blue notes, Barber's Excursions, II, mm. 9-10

Try to emphasize this passage by seeming to create a slide between the sounds. A smooth connection between these two octaves can be achieved by using two hands - tenor voice in the right hand and bass voice in the left hand - or simply by applying the "slide pedal" technique and the left hand alone. In measures 10 and 11, the student will need to project the tenor melody. The melody should imitate a tenor saxophone, with a singing and lazy sound, especially on the triplets. Moreover, the cadence in measures 12 and 13 should be played with a muted sound, like that of a different voice.

Section two (measures 14-26) consists of a variation of the theme and a free melodic line. Since this section is freer than the original theme, the performer could, therefore, strive for a more improvisatory quality to his/her interpretation. The right hand controls the melody until measure 21. In measures 15 and 16, the reiterations of the triplets as well as the rhythmic movement from triplets to duplets heighten the musical excitement (See Example 47).

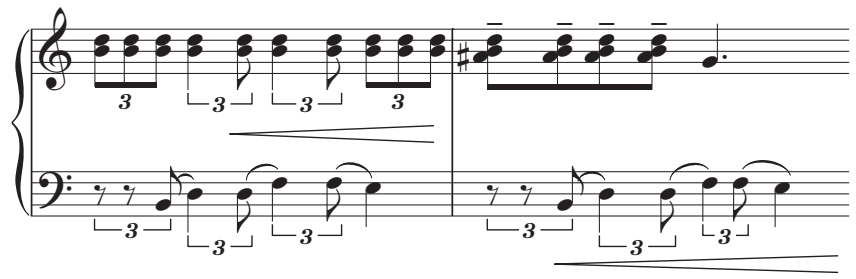

Example 47. Rhythmic movement from triplets to duplets, Barber's Excursions, II, mm. 15-16

In measure 16 , the harmonic dissonance on the $\mathrm{A}^{\#}$ should be emphasized with a tenuto touch. It is interesting that in this movement, dotted rhythms and triplet rhythms become a 
norm, while the even eighth notes, such as in measure 16 , become a contrasting element.

The eighth notes in the right hand of measures 19 and 20 should be played with a swing rhythm (See Example 48).

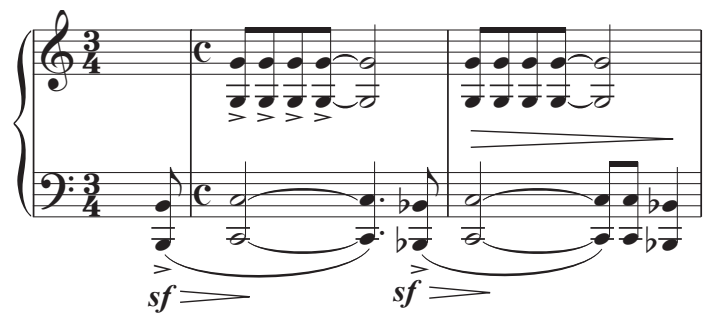

Example 48. Emphasize swing rhythm on the even eighth-note melody, Barber's Excursions, II, mm. 18-20

It is important to bring out the tenor melody from measures 21 through 24 . The sextuplets on the last beat of measure 24 should sound like a slide, similar to the sound effect suggested for measures 9 and 10 .

There is a close relationship between sections one and three in their use of similar melodic and harmonic patterns. Section three (measures 27-38) is the softest, most lingering section in the entire movement. Measure 27, where the composer marked $p p$, must be played very easily, as in a dream (See Example 49).

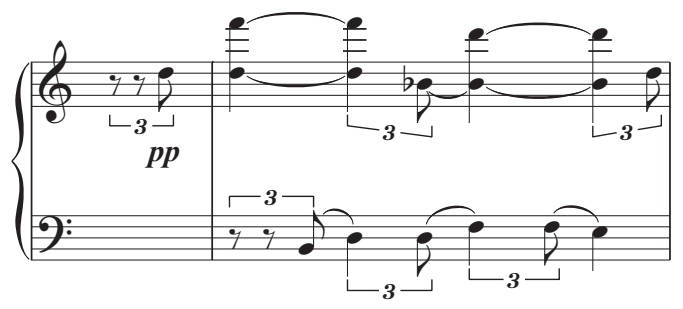

Example 49. Dreamy opening motive of section three, Barber's Excursions, II, mm. 26-27

In measures 29 and 30, since Barber indicated cantando, try to imitate a trumpet sound in the melody (See Example 50). 


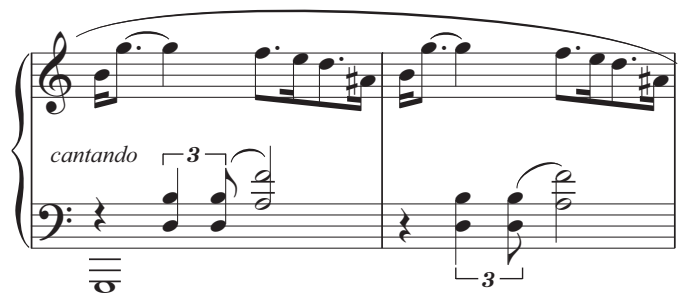

Example 50. Cantando passage, Barber's Excursions, II, mm. 29-30

Also pay special attention to an idiomatic jazz interpretation of the rhythm in these two measures. A typical jazz style will require the pianist to play with less rhythmic precision (loose and lazy) on the dotted rhythm. This means that the sixteenth notes and dotted eighth notes on the first beat of each measure (as well as on the third and fourth beats) should be played almost like triplets.

The repeated sixteenth-note sextuplet in measure 31 (similar to measure 18) should be given the feeling of improvisation. Measures 32-33 are a variation of measures 29-30, but with more rhythmic complexity in the left-hand accompaniment. The student performer should practice each hand independently with rhythmic precision before putting two hands together. Enjoy the three chromatic octave chords on the last beat of measures 35 and 36; using two hands to play these octaves will really help to achieve the melodic slide (See Example 51). When playing the counterpoint in measures 36 and 37, emphasis should be placed on the two upper voices, especially the part with triplets.

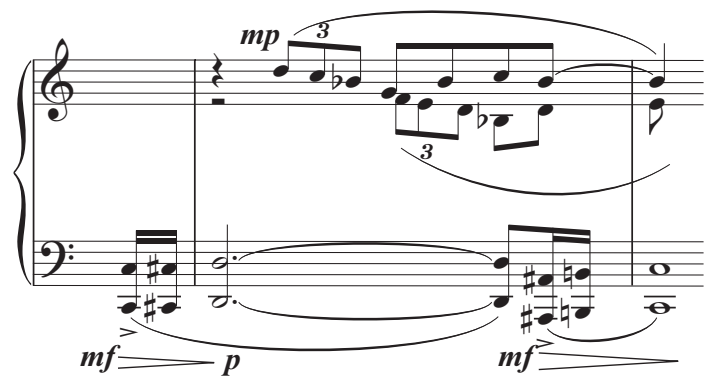

Example 51. Three chromatic octaves, Barber's Excursions, II, mm. 35-37 
Starting softly, section four (measures 39-51) resembles section two in the even eighthnote triplet motives, in the dynamic intensity characterized by $s f$, and in other dynamic markings. The triplets need to be played with ease and musicality in general. From measures 40 to 41 , it is crucial to increase the dynamic volume and push the tempo somewhat forward to set up the accented $\mathrm{F}^{\#}$. As previously mentioned, the performer should swing the rhythm in measures 44-45. It is interesting that the piece ends in mid-phrase, on the subdominant harmony. Despite Barber's allargando sino alla fine indication in measure 48, try not to make too large a ritardando in the last two measures (measures 50-51). In measure 50, the broken chord motives must still be energetic, even though they are marked $p p$.

An imaginative use of the pedal is important for a stylistically correct performance of this movement. However, Barber offers only three pedal indications: two imply the use of a long pedal at the cadences in measures 9 and 26, and one indicates senza ped in the contrasting broken chord in measure 7. Other than that, the student performer must use his/ her own judgment and pedal according to the blues style. In general, a clever use of pedal will help to blur and sustain the single notes, and help to achieve the required sound effects in imitation of jazz instruments.

Aided by the pedal in measure 9, the tension that has built from the broken seventh chords can be easily resolved with contrasting sonority in this cadence-like phrase. Here, a loose swing rhythm is necessary. In measure 21, holding the pedal during beats 1 and 2 is the only way that the pianist can sustain the half note in the bass for its full value and still play the remaining notes using both hands. A long pedal is necessary on the last beat of measure 24 , in order to imitate a sighing or sliding tone from a double bass or trombone.

In measure 27 , the first measure of section three, the pedal will help the student with small hands to sustain the wide interval of a tenth. Since Barber indicated $p p$ in this section, the soft pedal can be used to create a contrasting, dream-like atmosphere. From measures 35 through 38, a longer and deeper damper pedal on the chromatic octave passages in the bass is recommended to produce a "slide pedal" for particular jazz sonority. A slide pedal 
is a blurring pedal effect that lifts the damper pedal gradually from the bottom to a shallow surface, but without clearing the pedal thoroughly (See Definition of Terms in Chapter I). The use of the slide pedal on the two eighth-note chords in between measures 41-42 and measures $42-43$ will require the student to respond to the ear rather than to counting. In the last two measures (measures 50-51), be sure to use the soft pedal to maintain a quiet energy.

\section{III. $\quad \underline{\text { Allegretto }}$}

In the third Excursion Barber moves away from the use of jazz idioms in his search for "Americanism." 157 This composition is a theme and variations in which the theme is based on a popular cowboy tune, The Streets of Laredo. These cowboy tunes originated on the open plains and were "sung in the late watches of the night to maintain peace in a herd of cattle and to keep cowboys awake."158 Barber's lyrical and elegant style of song writing represents his romantic treatment of the image of American frontier life. This movement features a conventional binary theme made up of two four-bar phrases. Moreover, this movement could be divided into a theme, seven variations and a coda as follows: Theme (measures 1-8), Variation 1 (measures 9-16), Variation 2 (measures 17-24), Variation 3 (measures 25-32), Variation 4 (measures 33-40), Variation 5 (measures 41-48), Variation 6 (measures 49-56), Variation 7 (measures 57-64), and Coda (measures 65-72). Each variation keeps the same phrasing of the theme but not the whole binary structure. As Cater stated, in variations three, five, six and seven, while the first four-measure phrase (A phrase) is omitted, the last four-measure phrase (B phrase) is used twice. ${ }^{159}$

Despite the fact that melody, harmony and formal patterns of this movement are completely traditional, the rhythmic structures are very complex. The most prominent rhythmic effect produced by Barber is the use of cross-rhythms, in which the hands coincide

${ }^{157}$ Ibid., 22.

158 Young, "The Solo Piano Music of Samuel Barber," 43.

${ }^{159}$ Carter, "The Piano Music of Samuel Barber," 42. 
only on the downbeat. Such complicated rhythms like 7 against 8 (measures 1-7) or 6 against 8 (or 3 against 4 in measure 8 ) will challenge the student in terms of precision (See Examples 52 and 53).

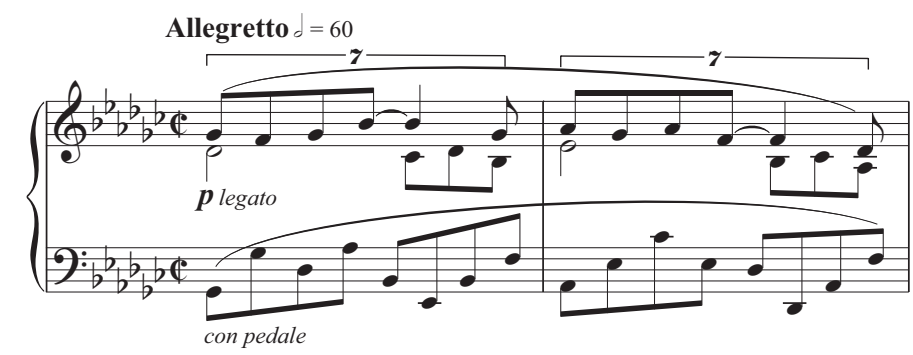

Example 52. Opening motive with 7 against 8 rhythm, Barber's Excursions, III, mm. 1-2

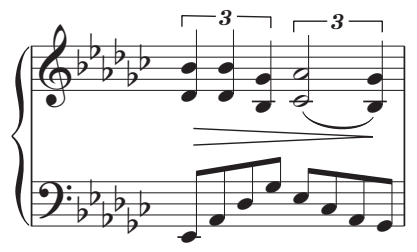

Example 53. 6 against 8 rhythm, Barber's Excursions, III, m. 8

When teaching the student to decipher complex rhythms like 3 against 4 (e.g., measure 8), have him determine the lowest, common denominator of the two numbers and then figure out the exact placement of the rhythms relative to that number of beats. For example, the lowest, common denominator of 3 and 4 is 12; therefore, plot 12 numbers on a graph and insert the placement of the 3 notes in the right-hand triplet on top and the 4 left-hand eighth notes on the bottom as follows (See Example 54):

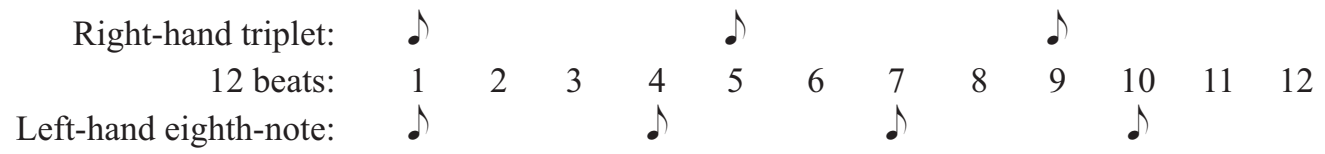

Example 54. Illustration of 3 against 4 rhythm as in Barber's Excursion, III, m. 8 , first beat 
Then, have the student play both hands together while counting to 12, playing each rhythm at the appropriate time as illustrated above. This should help the student play the rhythm in measure 8 correctly.

Other rhythms, such as the 7 against 8 rhythm in the opening of the movement, are more difficult to handle (since the lowest common denominator is much larger), but the procedure is the same. Have the student plot the rhythms as illustrated in Example 55 below:

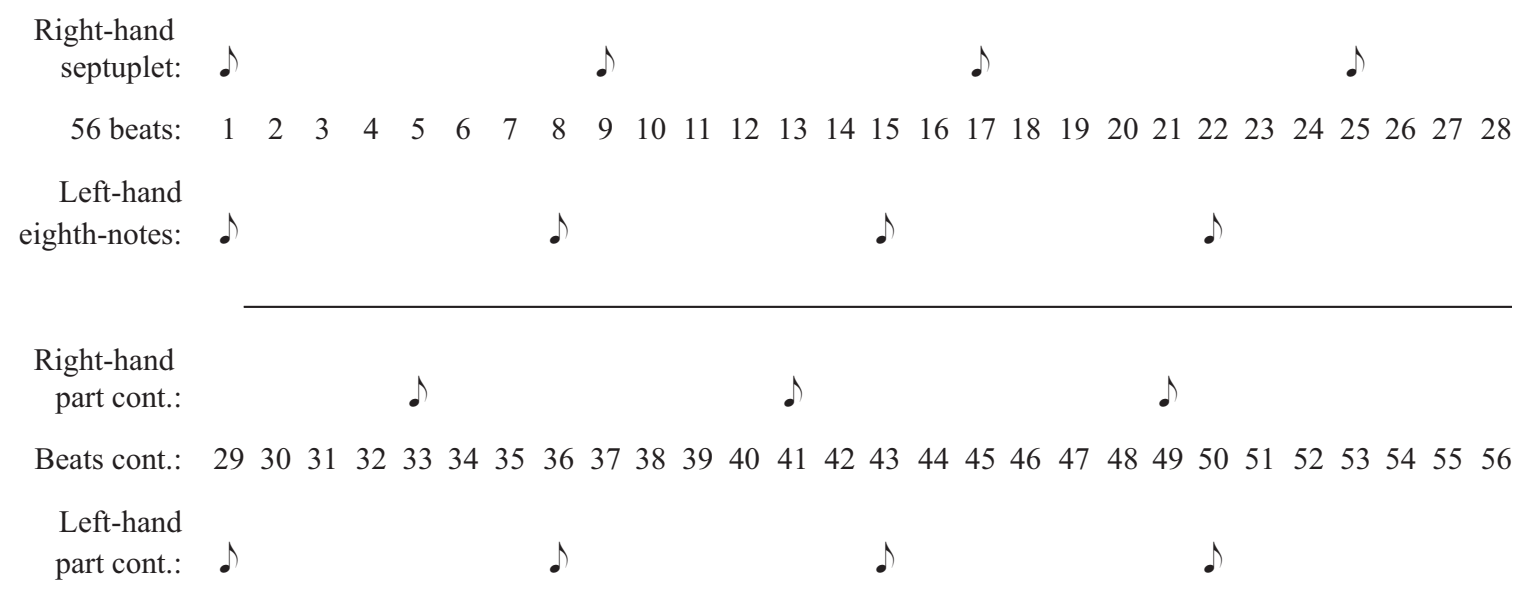

Example 55: Illustration of 7 against 8 rhythm, Barber's Excursion, III, mm. 1-7

While 56 beats are far too many for the student to count, at least this graph illustrates that the rhythms in the two parts coincide only on the downbeat of the measure, that the second and last notes of each part occur in closest succession, and that in the middle of the measure, the notes of one part occur roughly midway between the notes of the other part. This information should help the student combine the parts when first learning this piece; ultimately, he is aiming for a consistent rhythmic flow and an expressive interpretation of the music. Have the student emphasize the soprano part (because the melody and technical difficulty lie here) while using the bass to maintain the pulse. Once the student performer can listen to the passage by phrases (rather than note by note), he may gain a truly virtuoso 
lightness of playing while feeling less preoccupied and more in command. Subsequently, the student will be able to capture the nature of the simple, melodic cowboy song no matter how difficult the rhythm is.

To achieve a successful performance of this movement, it is essential that the student keep the rhythm steady from one variation to another within an Allegretto tempo. Throughout the entire movement (especially the opening theme), the student should be able to play the underlying basic rhythm correctly before adding and shaping the soprano melody. The lefthand eighth notes will need to flow smoothly at a pianissimo dynamic level. In this bottom voice, emphasizing the first note in each measure to stabilize the beat and support the melody is critical. As for the cowboy tune, playing with a beautiful sound can be achieved by using firm fingers to outline the top voice, and by adding arm weight to improve the quality of the sound. In order to produce a colorful sonority, try playing each note with good control by touching the key before playing as well as by pressing into the key more slowly. Furthermore, the counter melody in the right hand must be played softly to set up the melodic entrances. In measure 8 , the end of the phrase, pay attention to the rhythmic change to four against three between the two voices (See Example 53 above).

The first variation consists of the repetition of the A phrase of the opening theme, but presents the B phrase in syncopated form with harmonic doubling, two-note slurs and an accompaniment that now also includes quintuplet eighth notes. The performer will need to highlight the rhythmic interest, and textural and articulation contrasts between the A and B phrases. In the first half of Variation 1 (measures 9-12), although the pitches and rhythms are identical to those in measures 1 through 4 (except for the first ties in measure 9), the dynamics are different ( $p p$ rather than $p$ ). When playing at such a soft dynamic level, the student's fingers will need to press down only about half way into the keys. In the B phrase, from measures 13 through 16, spotlighting the top voice and unifying the chord tones of the harmonies are critical (See Example 56). 


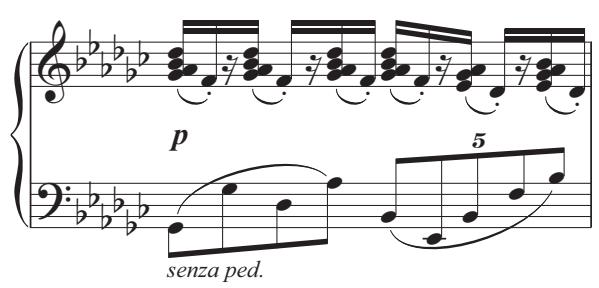

Example 56. Part of the first variation, Barber's Excursions, III, m. 13

The student should utilize "stick" fingers and set a hand position associated with active physical motion on the dropping and lifting. Rhythmic vitality is especially important in the right-hand syncopated clusters. Be sure to synchronize the rhythmic motion with the physical movement. Try to encourage the student to experiment with a rotary movement of the hand, wrist, and arm. Do not hesitate to exaggerate the physical motions in practice because almost all the physical activity will be minimized later on.

In the right hand of the second variation, the A phrase is featured an octave higher and the B phrase is changed into a continuous sixteenth-note pattern. This variation demands hand independence for the pianist as the syncopated clusters in the B phrase (measures 2124) become more sonorous. The quintuplet left-hand accompaniment in measure 17 will also challenge the student, especially since the first note is tied from the previous measure (See Example 57). The student should use arm movement to smoothly connect the disjunct accompaniment in the left hand.

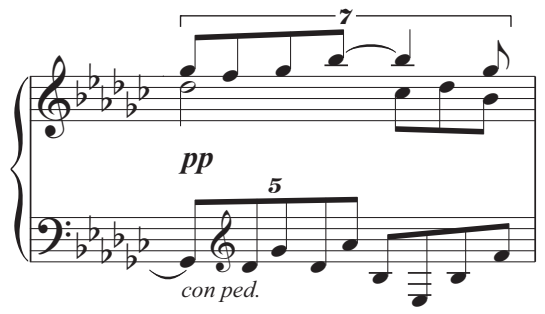

Example 57. Opening motive of the second variation, Barber's Excursions, III, m. 17

In the $\mathrm{B}$ phrase, be sure to use a right-hand motion similar to that used in the first variation (measures 13 through 16) (See Example 58). 


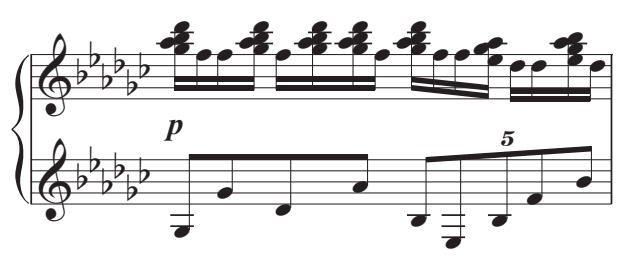

Example 58. Cluster chords melody, Barber's Excursions, III, m. 21

In this section, the student should start to feel the musical excitement created by the consecutive cluster chords even though they are marked $p$. As in the first variation, emphasizing the top notes of every right-hand block chord to project the folk tune melody is important. This will require some height for the hand to play above the keys to exert the constant downward motion. The student should play these four measures with the same physical motion based on the most comfortable and natural hand movement for him.

The third variation presents a great number of rhythmic problems and technical challenges for the performer. The B phrase of the theme is ornamented in dotted triplets over groups of ten eighth notes (See Example 59).

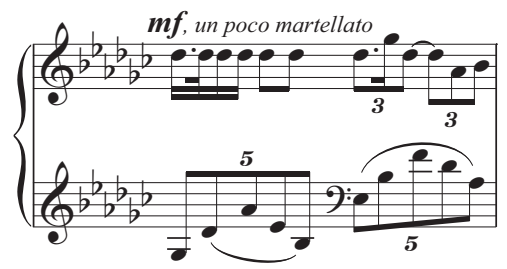

Example 59. Un poco martellato, Barber's Excursions, III, m. 25

According to Owens, to produce a convincing performance of Barber's music, the performer must be careful to "observe the expressive nuance caused by rhythmic diversity and dynamic subtlety." 160 In this variation, rhythm and dynamics are two essential elements. As for rhythm, it is important that the overall tempos as well as the left-hand quintuplet figures remain absolutely even no matter how many dotted and triplet rhythms are used to vary the theme. One of the tools for achieving a basic rhythm could begin by outlining and

${ }^{160}$ Owens, “Aspects of Interpretation in the Solo Piano Music of Samuel Barber," 24. 
simplifying the composition. That means the student can simply play the downbeat of each quintuplet while the right-hand melody is played omitting some of the figuration. Let the strong beats of the measures set the pace during practice. The full version of the melody will need to be played precisely and expressively before adding the accompaniment.

The B phrase, marked scherzando, presents great rhythmic difficulty for pianists by varying the melody of the previous phrase to include more dotted sixteenth notes one octave higher. The abrupt change of rhythmic pattern from measures 28 to 29 will take much effort for the student to be able to play smoothly.

Dynamics, another important element, must be carefully observed since Barber marked many expression and dynamic marks particularly in this variation. Be sure to use active fingers and sufficient arm weight in un poco martellato and $m f$ at the beginning of the variation (measure 25), and to feel the delicacy of fingertips associated with a light forearm in material marked scherzando (measures 29-30). In measures 27 through 28, the crescendo and decrescendo can be achieved by emphasizing the sextuplet melody, and also the gradual decrease in the broken chord sonority in measure 28 (See Example 60).

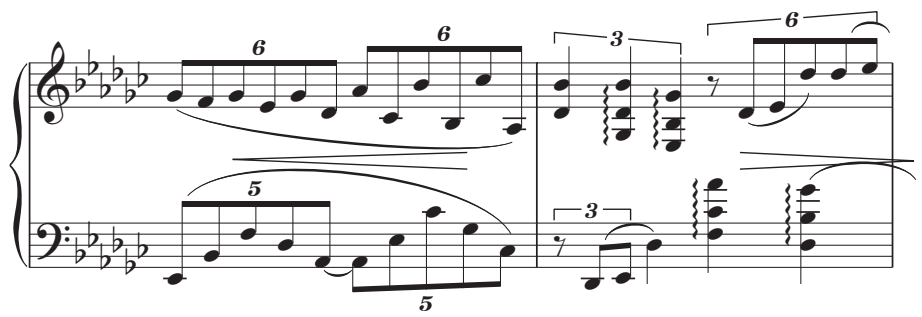

Example 60. Sextuplet and broken chord melody in the third variation, Barber's Excursions, III, mm. 27-28

In order to create a beautiful sound in the melody, a slower finger action during these two measures is required, especially when highlighting the $\mathrm{A}^{\mathrm{b}}, \mathrm{B}^{\mathrm{b}}$, and $\mathrm{C}$ melody notes from the sextuplet pattern or when producing a slower roll on the broken triads.

The dynamic shading is even more important to color the sonority of the short, rhythmic phrase marked scherzando (See Example 61). 


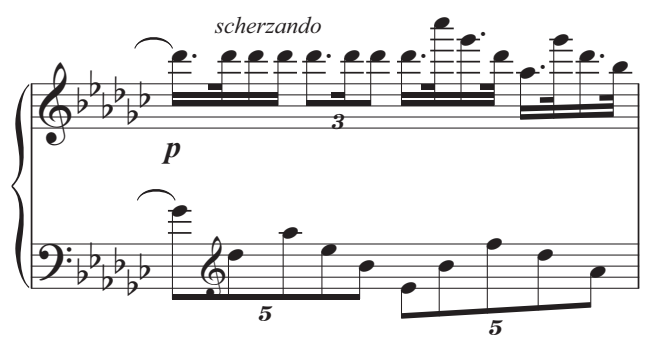

Example 61. Opening of scherzando from the third variation, Barber's Excursions, III, m. 29

Use a staccato touch in the rapid, repeated sixteenth notes. A controlled but fast finger action is appropriate to create a light-hearted mood for this section. As technical difficulty increases in the right-hand part, be sure the student plays the fourth intervals (i.e., the $\mathrm{C}^{\mathrm{b}}$ to $\mathrm{G}^{\mathrm{b}}$ on the second beat of measure 29 and the corresponding pitches in the following sequences) clearly. While the student should try to resolve this technical problem by landing on the longer notes (dotted notes), he should always be aware of which pitches need to be projected musically as important melody notes. Be sure the technical and musical considerations are inseparable. In measure 32, which contains a Ravel-like ascending arpeggio, it is important to simulate a glissando with an impressionistic tone color in the left hand (See Example 62). Carter recommended using "a very relaxed thumb and closed hand position" in this passage. ${ }^{161}$

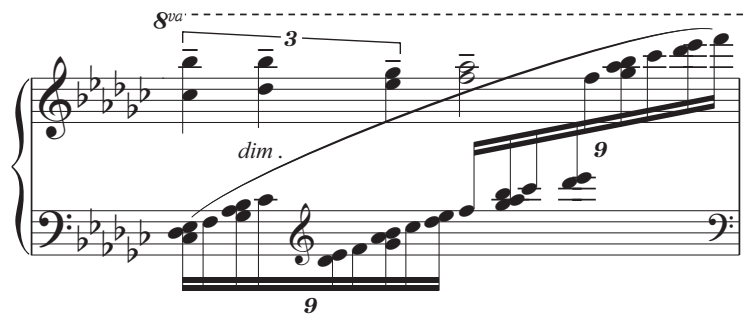

Example 62. Ascending arpeggio, Barber's Excursions, III, m. 32

${ }^{161}$ Carter, "The Piano Music of Samuel Barber," 44. 
Variation four re-states the A phrase of the theme, but alters both voices of the B phrase, transforming the bass part into a harmonized statement of the melody. Dramatic dynamic contrasts appear between these phrases, as the A phrase is marked $p p$ and the $\mathrm{B}$ phrase is accented and marked $m f$. Texture and articulation changes also occur with the addition of staccato notes and block chords in the B phrase. In measures 37 through 41, the left-hand melody in parallel sixth chords should be played with a rich sound as well as clear voicing by using the large part of the finger surface to touch the key and create a more ringing and singing tone; the staccato sixteenth notes in the right hand will need to be played evenly in terms of both rhythm and duration (See Example 63).

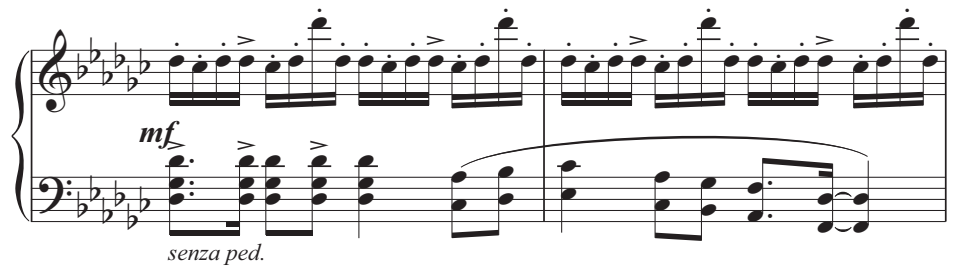

Example 63. Left-hand melody accompanied by right-hand staccato sixteenth notes, Barber's Excursions, III, mm. 37-38

Since the rapid weak-beat accents will almost always challenge the performer, a stepby-step practice procedure that begins by playing the right-hand part mainly with heavy staccato notes but not accents is necessary. Once the right hand becomes proficient in this practice, then put the accents back. Special attention should also be paid to measure 39 when the rhythms change from duple to triple patterns.

The remaining three variations feature only one phrase, the B phrase. In the first four measures (measures 41-44) of variation five, the left hand presents the theme surrounded by figuration. Tempo control is important in this section. Be sure that the staccato sixteenth notes remain absolutely even. In measure 41 where Barber indicated leggero, maintaining firm fingers but reducing arm weight will easily produce a light sound (See Example 64). 


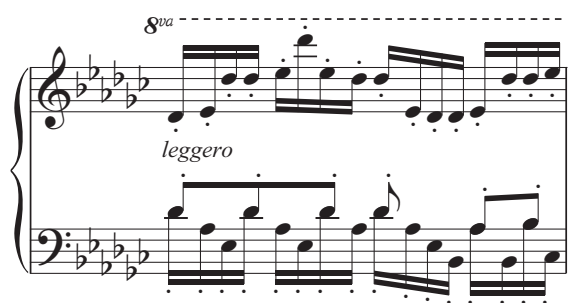

Example 64. Opening of variation five, leggero, Barber's Excursions, III, m. 41

Always remember to shape the melody. Projecting the tenor melody by using either the first or second finger in the left hand and by using arm weight aided by rotary motion is crucial. The second half of this variation (measures 45-48) generates excitement with thicker texture and stronger dynamics (See Example 65).

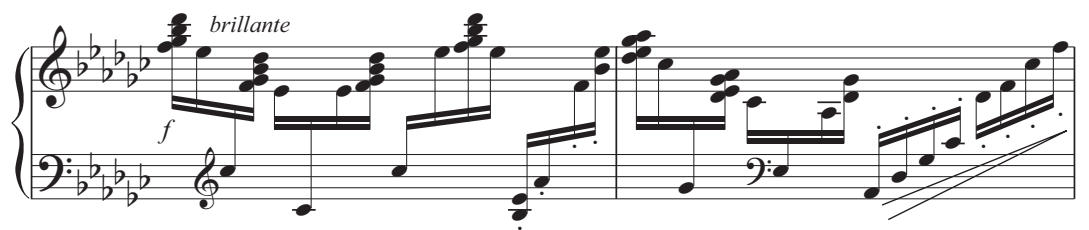

Example 65. Brillante of variation five, Barber's Excursions, III, mm. 45-46

A brilliant sound can be obtained by using a slightly detached finger action fully supported by the arm. Within the short arpeggiated figures, try to sustain a long musical line with a brilliant sound. Aim for a pizzicato sonority when playing the ascending, arpeggiated, staccato, sixteenth notes in measure 46. This variation ends quietly in measure 48 on widely-spaced chords that should be played using slow and steady release of arm weight to support gentle finger actions on each chord.

Variation six is the climax of the movement (See Example 66). Not only are the dynamic levels louder and the texture thicker throughout this variation than throughout any other, but for the first time, the rhythm of all parts corresponds, with all voices having the same rhythmic subdivisions (except in measure 55). The rhythmic complexity (a hallmark of 
the movement, which was evident from the very first measure and which increased as the movement progressed) has finally been resolved in variation six.

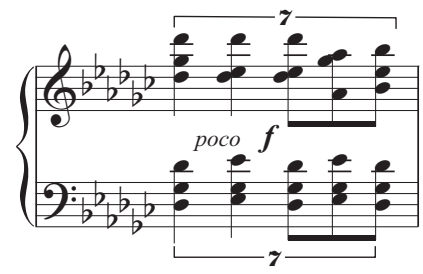

Example 66. Opening of variation six, Barber's Excursions, III, m. 49

To highlight the significance of variation six, the student must maintain power and rhythmic energy throughout the whole variation. Since the rhythms in both hands are totally the same from measures 49-54, emphasizing the septuplet division is crucial to obtaining a sense of stability. As the variation starts with the B phrase in the right-hand top voice, be sure to shape this melody with rich sonority and balanced voicing for both hands. From measures 53 through 56, the dynamic level increases due to the intervallic expansion when the lefthand is played one octave lower. In measures 54 to 55 , the change in rhythmic pattern from septuplet to even eighth notes in the left hand should be emphasized with a portato touch.

Variation seven begins with the B phrase which is varied harmonically but not texturally, melodically, or rhythmically (except for the half note in measure 60). Try to shape the cowboy tune expressively and bring out the lower bass voice to enrich the harmonic sonority. The many dynamic contrasts (from $m f$ to $p p$ ) will need special attention. For example, since the tonality of the B phrase is altered starting in measure 61 , the performer should try to create a different shade of tone color in his performance. An abrupt dynamic change occurs since Barber indicated a crescendo in measure 63 and then a sudden $p p$ in the following measure. In this dramatic section, make sure the student performer relies on his ears (not only on his hands) when creating dynamic nuance. The A phrase returns in its original form in the coda. From measures 69 to 70, when this phrase is ornamented, be sure to shape the music expressively. The rall. in the last two measures (measures 71-72) 
highlights the end of the cowboy tune, stated one last time; this rall. should be felt as well as counted, and should be played smoothly.

According to Owens, the original pedal and dynamic markings suggest Barber's quasiprogrammatic interpretation of the cowboys peacefully serenading their herds. ${ }^{162}$ Pedaling is very important for the legato, cantabile sound of the cowboy tune. In the opening theme as well as its variations, a long but shallow, half pedal is appropriate to create the desired mood. In the first variation, use the soft pedal to obtain dynamic contrast. Pedal the tied quintuplet note in between measures 16 and 17 carefully without a gap. In the scherzando of variation three, from measures 29 through 30, more frequent pedal changes on every note of the quintuplets are recommended. A long pedal for measure 32 is necessary to sustain the sound of those cluster arpeggio glissandos in order to produce an impressionistic sonority. Although Barber marked senza ped. from measures 37 to 40, some pedal may be needed for a student with small hands to sustain the harmony of the widely-spaced chords (particularly in measure 39.)

In variation five, from measures 41 through 44, the leggero character can be heightened by using the una corda pedal to lighten the continuous staccatos. The student should use the damper pedal and change it with the harmony when playing the arpeggiated chords in measures 45 through 48 . The pedal should be lifted during the eighth-note rest in measure 48. This rest is prominent for offering a complete silence and an abrupt mood change for the piece. Subtle control of the pedal is crucial in the last variation and in the coda in order to produce a specific tone color. During the abrupt dynamic change in measure 64, and during the entire coda (as the main theme returns $p p$ ), use of the una corda pedal is appropriate to create a precious intimate sonority.

162 Owens, “Aspects of Interpretation in the Solo Piano Music of Samuel Barber,” 22. 


\section{IV. $\quad$ Allegro molto}

The fourth dance is an example of Barber's use of stylized folk idioms in a type of country square dance. Listeners can easily identify the use of 'local instruments' such as the fiddle, mouth organ or harmonica that Barber described in his preface. ${ }^{163}$ The harmonic foundation of the movement is diatonic with basically two chords: the tonic and subdominant triads. The rather limited harmonic plan suggests that the composer was inspired by the sounds of American folk instruments. The formal design is ternary, in which a short opening and closing section surround a lengthy middle section. Basically, the rhythms in this movement are much simpler and more straightforward than those in the previous three movements.

When interpreting this dance, the performer should focus on its rhythmic energy and vitality in order to express the exuberant mood of the dance. Technically, many repeated notes and chords will challenge the performer in terms of evenness and clarity. The A section (measures 1-13) presents two important motives on which the piece is based. The A motive (measures 1-2) consists of alternating tonic and subdominant block chords and the B motive (measures 3-5) is a passage based on repeated sixteenth-note patterns. The A motive serves as an introduction and the B motive is a principal theme of the composition. In general, these two alternated motives are repeated, varied rhythmically and melodically throughout the entire movement.

In the beginning, the A motive may be interpreted as dancers stomping their feet in a square dance (See Example 67).

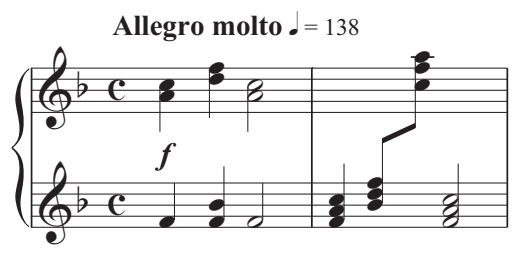

Example 67. The A motive in the introduction, Barber's Excursions, IV, mm. $1-2$

${ }^{163}$ Sifferman, "Samuel Barber's Works for Solo Piano," 18. 
When playing these chords, the pianist should use a natural motion of the hand directly into the key. Be sure that the performance of each chord produces the same sound quality. When the B motive appears in measure 3, it is critical that the student performer plays the fast repeated notes with the right technique (See Example 68).

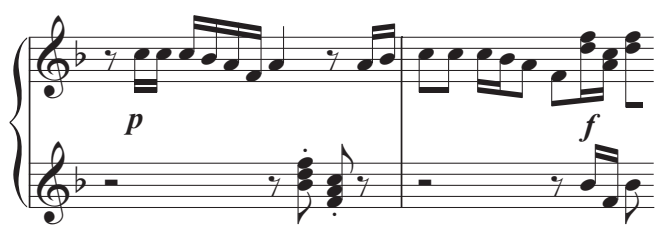

Example 68. B motive in the principal theme, Barber's Excursions, IV, mm. 3-4

There are two ways to play the repeated sixteenth notes: the first is with alternate fingers of one hand, and the second is by incorporating alternate hands. The author suggests that when playing short passages (fewer than three notes), the performer should use alternate fingers of one hand, and when playing long passages (three or more notes), the performer should incorporate alternate hands. In both situations, be sure not to inhibit the hand movement. Even though the music is marked $p$, the pianist should always bounce his wrist freely, and treat the individual fingers or hands as drum sticks. In order to make the repeated notes sound even in performance, using stronger dynamics and playing high above the keyboard is necessary during practice.

The performer should notice that from measures 1 through 6, when the chords accompany the melody, they are played at the prevailing dynamic level, but when they interrupt the melody, they are played with greater force. Pay attention to this distinct dynamic contrast that is similar to the sudden changes of terrace dynamics in Baroque performance practice. Also, be sure to emphasize the strong rhythmic feel on the downbeat that is idiomatic to the square dance; the student should feel a strong downbeat even when the measure begins with a rest (e.g., measure 3). In measure 7 and in other similar sections that include alternating tonic and subdominant repeated chords, use a firm wrist and pointed fingers to 
achieve greater brilliance. In measures 10 and 11, the sequences of repeated notes should be played very softly ( $p$ or $p p$ ) in both hands (See Example 69).

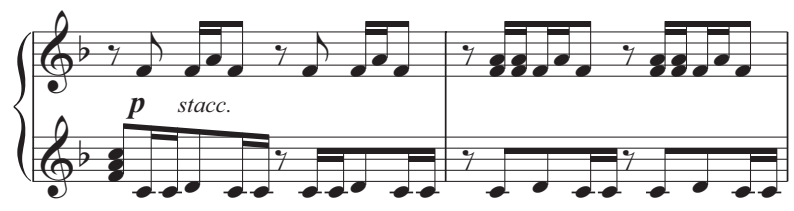

Example 69. Sequence of repeated notes, Barber's Excursions, IV, mm. 10-11

Use alternate fingers, such as 3 and 2, on the two repeated notes of the left hand in measure 10 , whereas in measure 11 , bounce the right-hand wrist freely to articulate the fast repeated chords. In these two measures, maintaining the rhythmic energy and a constant tempo are very important. In measure 13, when the texture becomes thicker and intensity increases by means of the chordal tremolos, emphasizing the crescendo and diminuendo by using arm weight is necessary (See Example 70).

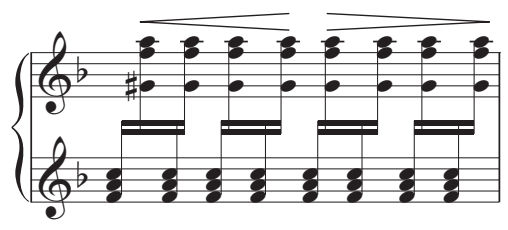

Example 70. Chordal tremolos, Barber's Excursions, IV, m. 13

Both Sifferman ${ }^{164}$ and Oswalt ${ }^{165}$ claimed that the large B section, which comprises measures 14-56, can be divided further into a small ternary form (a: measures 14-33, b: measures 34-40, a: measures 41-56). Basically, the B section consists of the original melodic material from section A (A and B motives), transformed by means of texture, dynamics, rhythm, melody and harmony. In terms of interpretation, voicing and a clear dynamic contrast are critical. Furthermore, the many passages with fuller texture and louder

\footnotetext{
${ }^{164}$ Ibid., 20-21.

165 Oswalt, "The Piano Music of Samuel Barber: A Brief Stylistic Analysis," 49-51.
} 
dynamic level will require exuberant performance.

In measures 14 through 18, an altered A motive opens the B section accompanied by the staccato ostinato figures; then, the passage from measures 19 through 22 consists of a fragment of the B motive in the right hand over staccato double notes. In this section, technical difficulty occurs due to hand crossing that requires the pianist to choreograph his movements carefully (See Example 71).

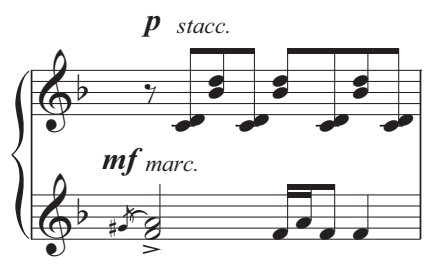

Example 71. Opening of the B section, Barber's Excursions, IV, m. 14

Regarding hand placement decisions, it is important that the performer decide early in the learning stage which hand will play above and which will play below as well as where they will switch their positions; once this is decided, it should always be practiced in this same way. Since the hand can produce a better sound if assigned a more comfortable position, significant left-hand melodies from measures 14-18 and right-hand melodies from measures 19-23 should be played by the hand on top. Be sure the rhythmic energy is maintained with a solid rhythm. Project the subtle nuances of melodic articulations and accents by using pointed fingers and fixed wrists controlled by sufficient arm weight to depict vividly the spirit of the square dance. In these passages, the eighth-note accompaniment will need to be played lightly and absolutely evenly.

Excitement increases from measures 24 through 33 as the B material (measures 14 through 22) reappears in extended form and is varied by characteristics such as register changes and harmonic doublings. As in the previous section, rhythmic energy controlled by smooth coordination between hands and a steady tempo is important, particularly as the technical difficulty heightens. From measures 24 through 27, try to exaggerate the many 
accents (especially the one on the last beat of measure 26) with corresponding physical motion. Pay attention to the crescendo on the last beat of measure 27 before the piu forte double-note melody enters; when playing this rapid arpeggio, the performer should use a single gesture in each hand while applying the damper pedal to maintain the sonority.

Starting in measure 28, great technical difficulty occurs as a mutated B motive appears in double thirds played $f f$ in a rapid tempo (See Example 72).

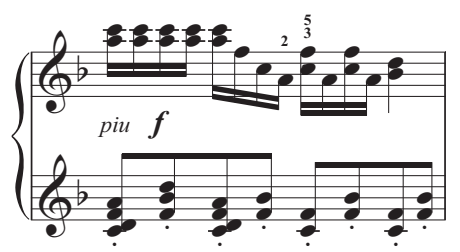

Example 72. Opening of the B motive in double thirds, Barber's Excursions, IV, m. 28

As great brilliancy is demanded on the repeated double notes, a fixed wrist and pointed fingers helped by a rotary arm motion is necessary. Make sure to bounce the wrist freely, especially when playing the repeated sixteenth-note broken chords (e.g., in measures 28, 31 and 33). Endurance is important in these sections with prolonged loud playing. The performer must exert conscious control over the playing mechanism in order to reduce strain and prevent fatigue. Injury can be avoided by distributing the work among different groups of muscles. Instead of pushing the hand into the keyboard continuously, try to lift and fall with the forearm, which varies the muscles used and helps avoid tension. As for the ostinato left-hand chords, steady eighth-note staccato should be played.

The second part (b) of the B section begins with syncopated tonic and subdominant alternations marked con forza (See Example 73). 


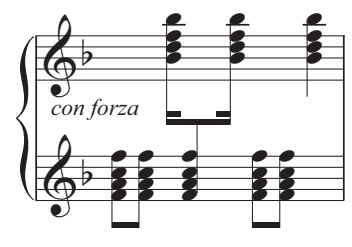

Example 73. Opening of con forza from the B section, Barber's Excursions, IV, m. 34

In measure 36 , the volume suddenly drops to $\mathrm{mp}$ before another syncopated chord outburst marked marcatissimo with scattered sforzandi. To create these dramatic dynamic changes, different pianistic touches are required. The amount of weight, the different parts of the playing mechanism (fingers, hands, arms) applied to sound production, and the speed with which the finger strikes the key can all contribute to changes in volume. Owens felt that in this section, "establishing humor" is an important goal for the performer. ${ }^{166}$ Whereas the con forza eighth notes in measures 34 and 35 depict the dancers stomping their feet, the material in measures 36 and 37 require a very articulate and shallow touch. The performer should stretch the last beat (the dominant quarter-note chord) in measure 35, and then gradually return to the regular tempo in measure 36. A special sound effect, or a sense of humor as Owens described it, can be achieved by using a more sustained and heavy touch in con forza which contrasts with the light and delicate touch in the material marked $m p$.

In measures 38 and 39 , the performer must focus on the irregular $s f$ block chords in the left hand that punctuate the minor seconds in the right hand (See Example 74).

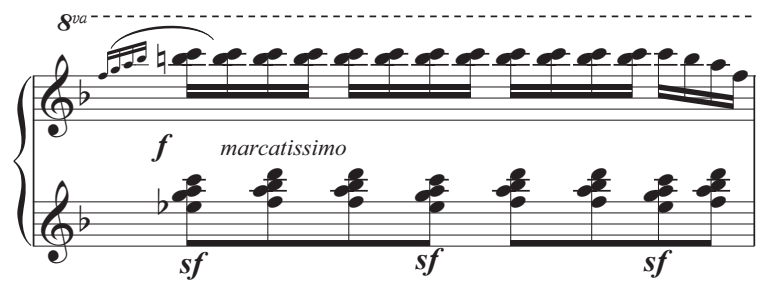

Example 74. Opening of marcatissimo, Barber's Excursions, IV, m. 38

166 Owens, "Interpretation in the Solo Piano Music of Samuel Barber," 30. 
While the musical excitement increases with these repeated seconds, the student must be careful not to allow tension to build up in the hand. Use firm fourth and fifth fingers supported by a floating forearm to produce an even-touched sound, and incorporate in/ out and up/down hand and forearm movements to release unwanted stress. The student performer also needs to project the top melody note from the left-hand chords and to apply distinct $s f$ as well. In the sequence of descending seventh chords in measure 40, highlight the decrescendo to relieve the musical emotion.

Measures 41 through 48 are identical to measures 14 through 22 with measure 17 omitted. Like the prior section, voicing is important in typical melody and accompaniment texture. In measure 44, pay attention to the marked crescendo and syncopated accents as in measure 18 (See Example 75).

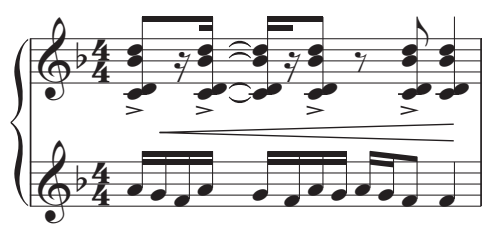

Example 75. Repeated right-hand chords with syncopation, Barber's Excursions, IV, m. 44

The voice crossing in this passage should be handled by playing the left hand on top of the right hand in order to bounce the wrist freely on the repeated chords. The crescendo in measure 48 is particularly important in drawing the listener's attention to the single-voiced passage that begins in measure 49 .

A transitional passage, measures 49 through 56, begins with heavily-accented clusters of thirds and seconds which gradually lead to a single=note line. As the texture becomes thinner, the dynamic level decreases. However, the intensity is still sustained by a tempo acceleration (stringendo) and the progression to shorter rhythmic values culminating in a tremolo in measure 56 (See Example 76). 


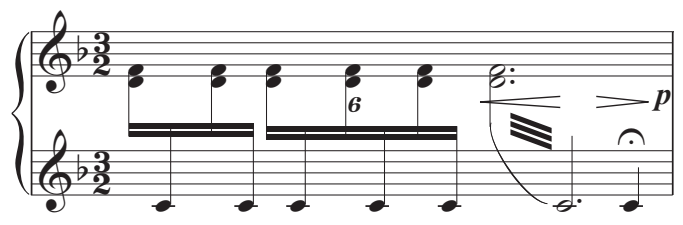

Example 76. Tremolo chords, Barber's Excursions, IV, m. 56

A well-planned rhythmic and dynamic digression is important for the student during practice. This section ends with a fermata as the excitement is created and eased by a crescendo and decrescendo on the tremolo chords in measure 56. Be sure the tremolo chords are played absolutely evenly between two alternating hands, and try to focus on the inner voice D-C. When performing this repeated two-note pattern, the author feels that it is somehow easier to hear and play if the performer focuses on C-D instead of D-C.

Following the fermata, the slightly modified A motive from the opening returns. The tonic and subdominant chords in measures 57 and 58 restate the theme with appoggiatura embellishments that Sifferman likened to the sound created from breathing alternately in and out on a harmonica (See Example 77). ${ }^{167}$

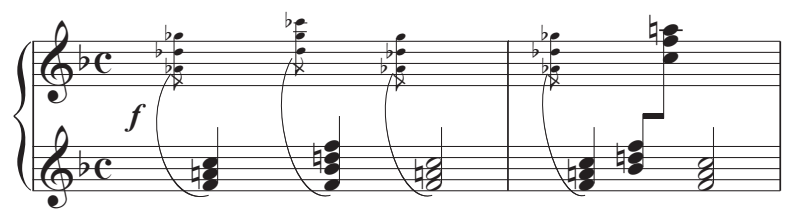

Example 77. Appoggiatura embellishments of Tempo I, Barber's Excursions, IV, mm. 57-58

Since rhythmic vitality is important in the whole section, the performer should use physical energy parallel to the musical energy. Basically the repeated staccato figure from measures 66 to 69 is derived from measures 10 to 11 . As the piece gradually fades away, it is important that the short repeated notes be played absolutely evenly while making a decrescendo.

In measure 70 , the piece ends with an ascending, arpeggiated tonic ninth chord $\left(\mathrm{F}^{9}\right)$

${ }^{167}$ Sifferman, “Samuel Barber’s Works for Solo Piano," 19. 
(See Example 78).

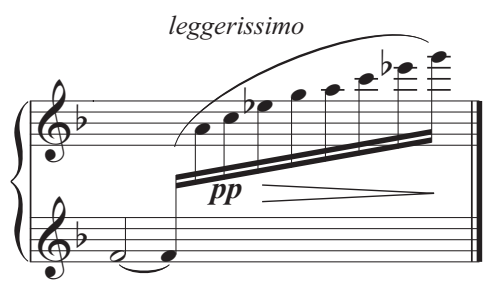

Example 78. Leggerissimo ending, Barber's Excursions, IV, m. 70

Since the ending is short and seems inconclusive, the performer needs to find a way to make the final arpeggio sound conclusive. In addition to following Barber's original articulation marking (leggerissimo) and dynamic indication ( $p p)$, using the damper pedal and varying the pace are crucial. There are three options to finish this composition: 1) in strict time with pedals, 2) in strict time without pedals, and 3) at a slower pace and with pedals. When playing the third option, a melodic arpeggio is crucial to achieving a special sonority and a convincing ending. The student should experiment with all three ways in order to find a better interpretation based on his personal preference.

In this movement, accent pedaling (a pedal technique consisting of pressing and releasing the damper pedal as the key is pressed and released), is most popular in passages requiring a heavy touch and with notes marked $s f$. In general, accent pedaling is closely related to dynamics since this kind of pedaling can be used to increase the volume of sound and to emphasize the beat. For example, the first two measures would profit from accent pedaling since it would help to prolong, sustain and enhance the sonority of each chord. However, when playing the tonic and subdominant chords in the first measure, it is necessary to lift the pedal simultaneously with the hand to create a break between each harmony. Also, this type of pedaling can help to create a specific sound image, e.g., the stomping feet of dancers in the beginning of a square dance. On the last beat of measure 5, using a long pedal to hold the sound on the portato is important.

In the $\mathrm{B}$ section, the student must use pedal cautiously due to the light texture in 
passages filled with staccato or non-legato notes. Since contrasting articulations occur simultaneously, careful pedaling that does not alter one articulation at the expense of another becomes critical. In both measures 14 and 15, touches of pedal on the accented lefthand melody are advised for adding sonority even though the right hand is played staccato. In measure 23, a long pedal is necessary as an aid in building the crescendo.

Beginning in measure 24, more touches of pedal are required since Barber indicated con pedale. In measures 24 and 25, the student should lift the pedal on the third beat, as the eighth note is played staccato. Be sure to emphasize the weak-beat eighth-note accent at the end of measure 26 with pedal. As the altered B motive appears in measures 28 and 31 with double notes, use a longer pedal changing on every quarter note. A series of halfpedals that changes with the harmonic changes may be used in measure 40 on the sequence of descending broken chords. In measure 56, be sure to apply a full pedal on the tremolo passage. It is important to use the una corda pedal on the two-voice repeated patterns from measures 69 through 70, enhancing the $p p$ sonority. The swift arpeggio in measure 70 demands the use of both una corda and damper pedals for special sound effect.

\section{Summary}

The Excursions belong to Barber's later period of composition. The use of traditional forms and lyrical emphasis reveal the conservative elements of his style; for example, note the formal patterns (e.g., the use of rondo form in the first movement, theme and variations in the third movement, and the ternary structure in the fourth movement) as well as the lyrical melodies that are primarily diatonic in orientation. According to Sifferman, "Barber is a composer writing in the twentieth century whose heart is still in the nineteenth century." "168 The Excursions present new musical expression in harmony and rhythm fused with the style of Romantic character pieces. Barber used polychords, added notes to triads, changed meter and used cross rhythms. Ostinato is frequently employed and serves as a

${ }^{168}$ Ibid., 125. 
tonal reference beneath melodic lines as seen in the first and third movements.

Barber's compositions make a significant contribution to the twentieth century repertoire. In general, Excursions presents both interpretive and technical difficulties. The performer must understand the style of American folk and popular idioms, including boogie-woogie, blues, a folk-like cowboy song and a barn dance. Barber's piano music is thoroughly idiomatic. The lyricism of the melody and a wide range of tone color require a cantabile, well-developed legato technique of the performer. The rhythmic variety based on complex rhythms and dynamic nuances also should be carefully observed. When problems occur in repeated notes and rapid scales and chords, firm fingers with agile finger action and fixed but flexible wrists are necessary. Although Barber's piano music is difficult to learn and play, it is very rewarding since one can become more familiar with modern music as a whole in Barber's piano music.

\section{Aaron Copland: Four Piano Blues}

\section{Freely poetic}

Kern described the first of Copland's Four Piano Blues as "a blue note study in pastoral style."169 Written in a lyrical, folksong-like blues, this piece reveals Copland's style of fusing jazz and American folk melodies. The jazz elements, which are treated freely, include the following: 1) a melody incorporating flatted thirds or sevenths, based on a stylized blues scale; 2) harmony characterized by chord extensions, added and altered notes, and slow harmonic rhythm; and 3) rhythm featuring frequent use of syncopation, metric shifts, and meter changes. However, Case felt Copland avoided the metric regularity and tempo evenness likely to depict the sing-song character of jazz. ${ }^{170}$ In addition, Lynch noted that Copland felt open fields were a prominent part of the American landscape and he depicted

\footnotetext{
${ }^{169}$ Case, "Stylistic Coherency in the Piano Works of Aaron Copland", 493 quoting Kern, "Ragtime Wins Respectability," Clavier 15, no. 4 (April 1976): 29.

${ }^{170}$ Case, "Stylistic Coherency in the Piano Works of Aaron Copland", 504.
} 
these with widely-spaced chords, simple melodic material, static harmony, and transparent texture. ${ }^{171}$

In terms of tempo for the performance, since the first Blues is the only piece of the collection that has no metronome marking, we can assume that Copland wanted more freedom of tempo and that his marking, "freely poetic", suggests use of rubato. To express the "freely poetic" mood that Copland indicated at the beginning of the piece, freedom of tempo is important even though the composer had already created a sense of freedom through frequently shifting metric patterns. Despite the many meter changes, the pianist must always maintain a consistent unit of pulse. In places with rests, carefully calculating and counting by eighth notes (the smallest metric unit in the meters of $6 / 8,5 / 8,8 / 8,7 / 8$, $3 / 8,9 / 8$ and $3 / 4)$ is crucial.

The first Blues is characterized by fragmentary thematic material and rhythmic figures. The first section (measures 1-12) consists of three statements of two motives, with each statement presenting a varied and more extended version; meter changes from $5 / 8$ and $6 / 8$ to $7 / 8$ and $8 / 8$ allowed for these extensions in the third statement (See Example 79).

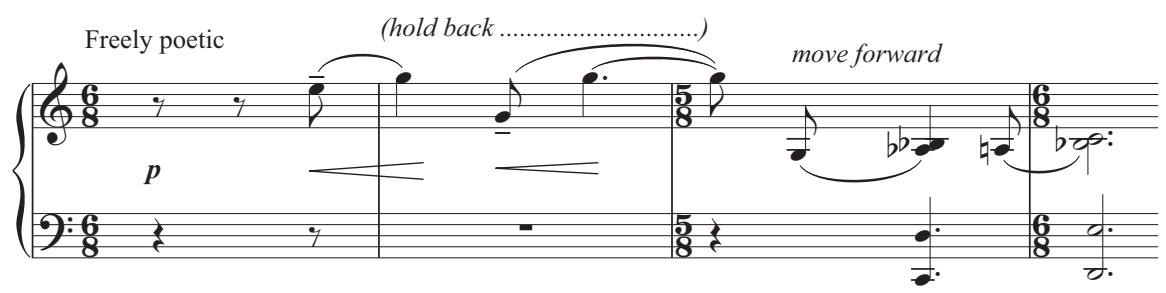

Example 79. Opening motives, Copland's Four Piano Blues no. 1, mm. 1-4

According to Leo Smit, to whom Copland dedicated this piece, two elements, the open call and its gritty, jazzy answer, are present in the opening four measures and in the answering phrases (measures 3-4, 6-7); Smit hears muted jazz trumpets in these measures. ${ }^{172}$

\footnotetext{
${ }^{171}$ Lynch, "Emblems: Signifiers of Stylistic Coherence in Selected Works of Copland", 24.

172 "New Music Corner: Aaron Copland," Keyboard Classics and Piano Stylist, 4 (March-April 1984): 22.
} 
Suggestions for the interpretation of these varied motives and statements are offered in the following paragraphs.

The first four-note motive is organized by an ascending minor third (E-G) and an octave (G-G) in a single-line texture. When trying to create the feeling of "holding back" marked by the composer in these two, short-long units, the performer should emphasize the repeated crescendos as well as the stressed, first pitches which occur on upbeats. In order to produce a lyrical sound on the portato eighth notes, the pianist will need to use firm fingers, and sink into the key bed a bit more slowly. As for the crescendo, be sure to lean towards the high note - G - with arm weight.

The opening two motives are divided by a sudden change in register; the second motive appears in measures 3-4, and is made up of intervals of ninths and seconds. The answering gesture of this motive is prominent, with its short-long rhythmic pattern similar to the opening motive. Copland helps the performer to move forward by changing the meter from 6/8 to 5/8. The added major seconds outside the tonic C, which Lynch felt sounded like blue notes, color the basic harmonic structure. ${ }^{173}$ Moreover, Lynch noted that the repeated use of a minor third in the melody ( $\mathrm{E}-\mathrm{G}$ in first motive, $\mathrm{G}-\mathrm{Bb}$ in second motive) is a prevalent feature of melancholy vocal singing in the blues. ${ }^{174}$ To create this blues quality and sonority in the second motive, the performer should use a slide pedal technique.

After restoration of the 6/8 meter, the head motive returns in measures $4-5$ with the same "hold back" indication from the opening motive and with the addition of a new pitch, A. Be sure the student builds up tension by emphasizing this high note. In measures 5 through 7 , the second motive returns in extended form. In measures 7 to 9 , the third statement of the opening motive appears in the top voice with the addition of new pitches. A short canon occurs as the left hand then doubles the right-hand melody an octave lower. The performer must shape each line properly with different accents and independent contour since the

\footnotetext{
${ }^{173}$ Lynch, "Emblems: Signifiers of Stylistic Coherence in Selected Works of Copland," 56.

${ }^{174}$ Ibid., 55.
} 
bottom voice echoes the expanded opening motive two eighth notes behind.

In measures 10 through 12, the second motive returns for the third time with sequential expansion in the right and left-hand voices. To comply with the "moving forward" performance suggestion from the composer (which also accompanied the original statement of this motive), increases in tempo should be emphasized as the soprano ascends all the way to $\mathrm{B}$, the leading tone, and then moves back to $\mathrm{A}$. In the $8 / 8$ meter of measures 10 and 11 , eighth notes are grouped into $2+3+3$ and $3+2+3$, respectively. Lynch noted that the dissonance from the major seconds resolves inward to a unison, providing a forward motion. ${ }^{175}$ The performer should use the same slide pedal technique as that used in measures 3-4 when performing these jazz harmonies.

The second large section of the piece occurs from measures 12 through 21 . A new soprano melody is introduced in measures 12-15 (See Example 80), and repeated almost exactly in measures $15-18$ with a slight alteration at the cadence and with contrasting dynamics ( $m f$ versus $m p)$.

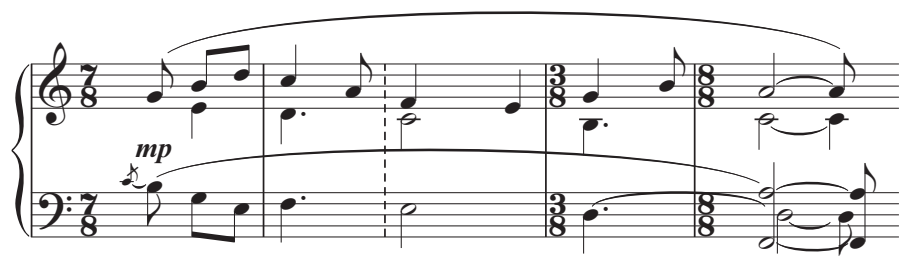

Example 80. Introduction of new soprano melody, Copland's Four Piano Blues, no. $1, \mathrm{~mm} .12-15$

For the performer, imitating the sonority and tempo flexibility of saxophone playing in the soprano voice is critical to achieving an idiomatic jazz sound in this section, as well as in the entire movement. Make a clear break at the end of each phrase (measures 15 and 18) to help clarify the rhythmic diminution which occurs when the $8 / 8$ from measure 15 becomes $6 / 8$ in measure 18.

${ }^{175}$ Ibid., 56. 
From measures 18 to 21, short melodic units from the third phrase appear in both right- and left-hand voices with repetition, variation, and extension. In this passage marked "warmly", playing with a sonorous, richer cello-like sound is crucial. A forward motion is felt as the six-note melody is re-stated and varied so that each statement concludes with a higher pitch from $\mathrm{G}$, to $\mathrm{A}$, to $\mathrm{E}$. In measures $21-22$, the third phrase ends as the texture is reduced to two voices. In this passage, the student performer must follow the indicated rit. carefully as well as emphasize the dotted quarter notes in both the soprano and tenor voices.

The entire first section (measures 1-12) returns in measures 22-32 with slight modification of the head-motive in measure 22, metric alteration from measures 23 to 25 , and extension of the second motive. In measure 29, the second motive re-appears transposed down a fifth (as the second theme would be in the recapitulation of a sonata). In the beginning of the second motive in measure 29, playing firmly and steadily are important. The pianist should also pay attention to the unique timbre of the piano when playing open-chord spacings, such as in the frequent tenths in the harmony. During the ascending eighth notes of the melodic line from measures 30-31, make sure the performer gradually increases tempo and dynamics (as indicated by the markings, accel. and cresc.) in order to project the melodic line passionately.

Case felt that measures 32 through 33 could be described as the revised return of the beginning of the second subsection (measures 12 through 15). ${ }^{176}$ With continued tension from the previous passage, this work reaches its climax beginning with the highest pitch "E" and the strongest dynamic indication, "ff" (measure 32) (See Example 81). Be sure that the student performer emphasizes the marked accents with pointed fingers. It is important to strive for a bright, glassy sonority in the high register, soprano melody in measures 3234 that is marked "ff, with emphasis."

${ }^{176}$ Case, "Stylistic Coherency in the Piano Works of Aaron Copland," 534. 


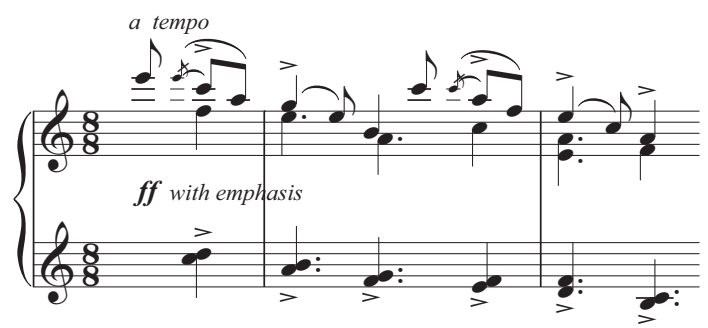

Example 81. Climax, Copland's Four Piano Blues, no. 1, mm. 32-34

After the emotional climax comes a complete relaxation of tension in the phrase from measures 34 to 37 . Basically this passage is quoting from measures $18-22$, the ending of the second subsection. Following the breath mark in measure 37, the coda starts with an upbeat in a slower tempo, a much softer dynamic level, and the marking "pensive" (See Example 82).

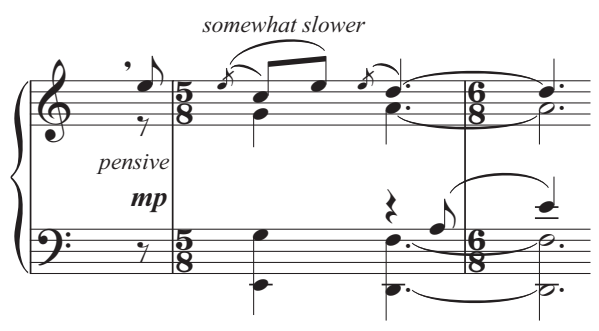

Example 82. Beginning of coda, Copland's Four Piano Blues, no. 1, mm. 3840

From measures 38 through 42, three melodic pitches, C-E-D, are extended and exchanged in the soprano and bass. It is crucial that the student performer follow each dynamic indication carefully throughout the passage. The grace notes in the soprano part generally function as a connection to the preceding measure. While playing these grace notes, be sure to play them slowly as well as ahead of the beat.

From measures 43 through the end (measure 46), the opening thematic material reappears and concludes the entire movement. In the final melody notes of measure 45, although both staccato and portato are marked, using a staccato touch with a sustained damper pedal is crucial to producing a bell-like sonority. When playing the final pitches marked with a 
fermata in the last measure, the student performer should listen attentively until the sounds completely die away and then release the pedal and hands at the same time.

\section{II. $\quad$ Soft and languid}

Copland's Blues No. 2 is in three-part song form (ABA') and exploits literal jazz material, suggesting the blues with its use of major and minor thirds harmonically and melodically. A ragtime texture is represented in the B section (measures 28-38) through the use of syncopated dotted rhythms and disjunct bass accompaniment. In the return of the A section, the main themes from both the A and B sections are combined. Unlike Blues No. 1 , the rhythm of Blues No. 2 is less variable, with the common meter of $4 / 4$ maintained throughout. Harmonic ambiguity is another significant feature of this composition. Although there is no real key signature, the A section is apparently bitonal, with the right-hand part suggesting D major presented over the left-hand part suggesting F major (although both parts contain pitches foreign to these keys); in addition, the opening melody is pentatonic. The $\mathrm{B}$ section is in five flats, suggesting the key of $\mathrm{D}^{\mathrm{b}}$ major.

Much of the melody in this composition is notated with eighth notes which are meant to be swung. The sense of jazz is heightened through the use of syncopated eighth-note patterns (such as in measure 4). There are two possible ways to interpret the swing rhythms in jazz style: 1) using a looser rhythmic suggesting a 12/8 meter (i.e., $\left.\left.\tau^{3}\right\rfloor^{3}\right\rfloor$ ), or 2 )

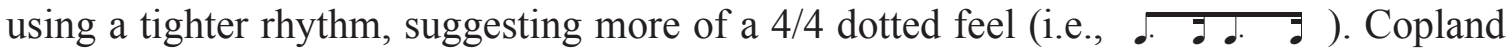
composed these Four Piano Blues with jazz rhythms in mind. Notice that in the slower sections, where Copland indicated a metronome mark of quarter note equals 108, he marked even eighth notes; however, in the faster section of this piece, where Copland indicated a metronome mark of quarter note equals 120 , he actually notated the tighter rhythm using dotted eighth and sixteenth notes. These differently-notated rhythms should be performed

differently. The rhythmic interpretation should be influenced by the tempo taken by the performer. This might suggest using a looser, 12/8 interpretation in the slower section, and 
a tighter, dotted $4 / 4$ feel in the faster section.

The opening right-hand melody (measures 1-2) consists of a sequence of descending major triads preceded by grace notes; this melody is then repeated throughout measures 3-4 (See Example 83).

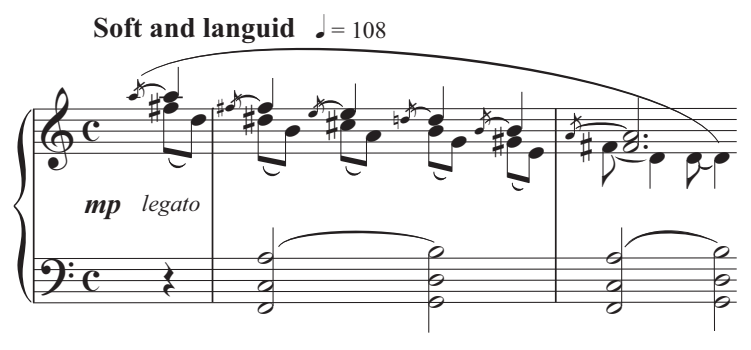

Example 83. First phrase of the opening theme, Copland's Four Piano Blues, no. $2, \mathrm{~mm} .1-2$

Overall, the melodic ornament provides interesting musical variety and a lazy, "bluesy" feel. However, in order to achieve the desired "soft and languid" mood that Copland indicated for this composition, the student performer will need to play without rhythmic drive and maybe even with slight rubato or diminuendo at the end of the phrase. It is also crucial to keep a legato articulation throughout the whole section.

Bitonality is produced when the left-hand accompaniment lowers the "blue" third and seventh notes of the D major melody. In the first four measures, the accompaniment alternates between $\mathrm{F}$ and $\mathrm{G}$ major triads which are a whole step apart; Lynch felt this is "vaguely reminiscent of the stride piano and ragged rhythms of the 1920s." ${ }^{177}$ Like the slow, on-the-beat, right-hand grace notes, the left-hand chords spanning tenths could be rolled gently from bottom to top if the performer cannot play them blocked as written. When playing two voices together, be sure the bass articulates the pulse and provides a stable, solid rhythm to the melody. Although the tempo in many jazz compositions is usually free, in this piece the tempo is much stricter since Copland added metronome indications at the

${ }^{177}$ Lynch, "Emblems: Signifiers of Stylistic Coherence in Selected Works of Copland," 58. 
beginning and elsewhere in this piece.

In contrast to the thick chordal line in the first two phrases, the third phrase, from measures 4 to 8, reduces the texture into a single line for each voice (See Example 84).

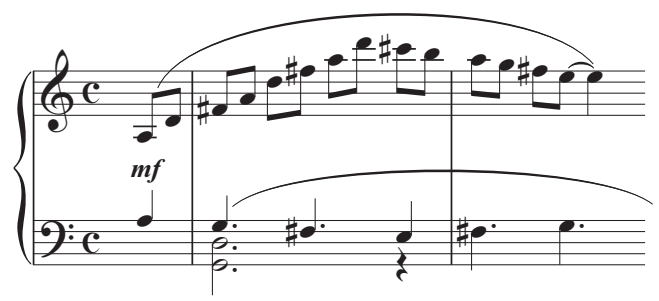

Example 84. Third phrase of the opening theme, Copland's Four Piano Blues, no. 2 , mm. 4-6

Although a D major tonality is clearly present in this passage, the rhythmic definition is very loose. A cross-rhythm occurs when the left-hand rhythmic pattern articulates three pulses per bar against the right-hand rhythm of $4 / 4$, the notated meter of the composition. According to Case, such a rhythmic pattern is known as "secondary rag" in popular music of the early twentieth century. ${ }^{178}$ While the melody in measures 4-6 is almost the same as that in measures $6-8$, the rhythmic pattern is different $(3+3+2$ in measures $5-6$ and $2+3+3$ in measures 7-8). For the performer, the bass countermelody presents challenges in the areas of rhythm and also musical balance to the melody.

From measures 9 through 12, the opening thematic material returns with the original chordal structure of the left hand divided into two levels (See Example 85).

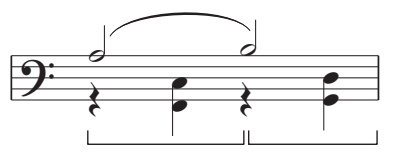

Example 85. Revised left-hand accompaniment with suggested pedaling, Copland's Four Piano Blues, no. 2, m. 9

${ }^{178}$ Case, "Stylistic Coherency in the Piano Works of Aaron Copland," 550. 
Case noticed how this revised accompaniment distorts the common swing bass pattern, where the chord roots are normally struck on strong beats in the bass and the weak beats complement these chord tones in the tenor range. ${ }^{179}$ In order to catch the harmony of the whole chords, which span intervals of tenths, the student performer should use pedal on the first beat and release it on the third beat when the harmony is changed.

The cadential extension from measures 12 through 14 is basically derived from the opening theme. Instead of releasing the harmonic tension, the dynamic level rises along with the notated accents. From measures 15 to 17, the melody is reduced to one single line and highlights the descending minor third, F-D. In this passage, the performer should pay attention to the syncopation, notated accents, and tenuto playing on the long notes $\mathrm{F}$ and D. When the right-hand melody descends closer to the left-hand chords in measures 14-16, the performer can avoid rolling the left-hand chords by playing the top note of the chordal accompaniment with the right hand.

The main melodic motive from measures 18 through 27 is borrowed from the opening theme while the rhythm is now dotted and the articulation is non legato (See Example 86).

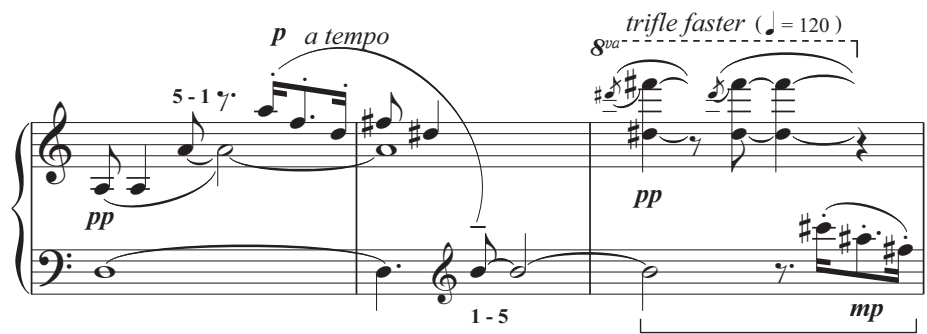

Example 86. Variation of opening theme with suggested fingering, Copland's Four Piano Blues, no. 2, mm. 18-20

For the listener, the sudden change from the lazy, "bluesy" mood to the lighthearted jazzy sonority is a pleasant surprise; for the pianist, the abundance of dynamic, articulation and

${ }^{179}$ Ibid., 552. 
phrase marks indicated by the composer should be watched very carefully in order to achieve the desired musical motion and effect. From measures 17 to 20 , the student performer must pay attention to several tied notes by using appropriate fingering between hands so as to fulfill the marked duration (for example, using 5-1 fingering in the right hand on the third beat -A- of measure 18; then using 1-5 fingering in the left hand on the third beat -B- of measure 19). As for the upper octave bell-like figures on the first three beats of measure 20 , use of both hands is important. Therefore, the pedal should be applied on the tied note -B- from measure 19. The swinging figures from measures 24 through 27 appear in twovoice texture in contrary motion; Lynch observed that this material is based on an octatonic scale. ${ }^{180}$ The pianist should aim for a short, crispy sound and an improvisatory atmosphere during the continuous chain of dotted eighth and sixteenth notes to most effectively capture the style.

The graceful and flowing B section (tempo I) presents a new melodic idea in a ragtime fashion (See Example 87).

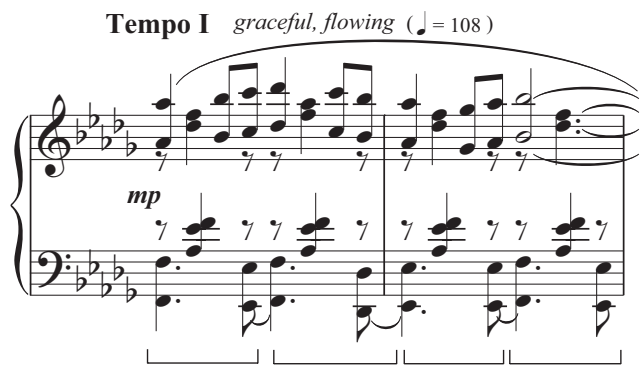

Example 87. Tempo I with suggested pedaling, Copland's Four Piano Blues, no. 2 , mm. 28-29

In general, this section shares many characteristic similarities with the A section in terms of meter, tempo, and overall texture. However, a constant syncopation in the left-hand voices, and the use of limited melodic and dynamic ranges, offer a stable and unvarying motion.

\footnotetext{
${ }^{180}$ Lynch, "Emblems: "Signifiers of Stylistic Coherence in Selected Works of Copland," 58.
} 
In ragtime, notes can be swung or played as notated. Therefore, the performer can either follow the notated, even eighth-note rhythm or he/she can alter the melodic rhythm slightly by means of swinging the eighth notes, just as in the A section. Unlike the predominantly slow tempos in Joplin's ragtime music, Caramia recommended playing this type of composition at fast, dance tempos, an idiomatic performance approach during Ragtime's popularity (1895-1917). ${ }^{181}$

Use of pedal in the B section is somewhat similar to measures 9-12, due to the parallel movement of the broken-chord accompaniment. With the thick texture of the octave melody, the performer should release the pedal on the dotted quarter-note bass notes (as indicated in Example 85 above). Surprisingly, melodic material from the opening theme emerges in the re-transition from measures 36 through 38 , echoing the cadential extension from section A (measures 12-14). These measures should be carefully pedaled, releasing the pedal only when $\mathrm{E}^{\mathrm{b}}$ becomes $\mathrm{F}$ in the bass; this use of long pedal gives this fragment of the opening melody an impressionistic sonority (See Example 88).

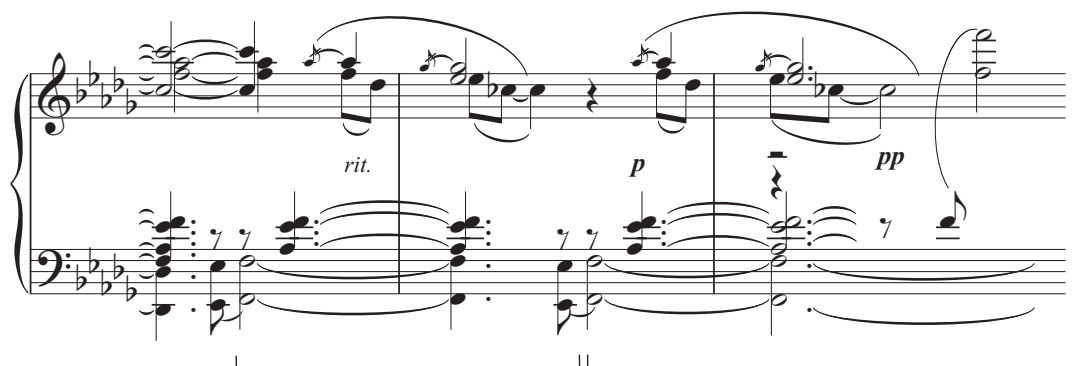

Example 88. Suggested pedaling in retransition to the opening theme, Copland's Four Piano Blues, no. 2, mm. 36-38

The A section returns in measure 39. In measures $41-42$ and $47-48$, the $\mathrm{B}$ theme appears transposed in the tenor range in counterpoint with the A theme. Playing impressively and projecting the $\mathrm{B}$ theme is important for the student performer and is also marked by Copland

\footnotetext{
${ }^{181}$ Tony Caramia, “An Approach to Jazz Literature," in Creative Piano Teaching. James Lyke, Yvonne Enoch, and Geoffrey Haydon (Champaign, IL: Stipes Publishing Co., 1987), 310.
} 
himself. The D major/F major bitonality conflict is resolved when the final return of the B theme in measures 56-57 is harmonized with a D major chord. Using one long pedal, play the $\mathrm{B}$ theme $p p$ and in a dreamy and melancholy manner.

\section{III. $\quad$ Muted and sensuous}

Blues No. 3, marked "Muted and sensuous," was composed last of the four movements and reflects Copland's Abstract Period due to its indistinct melodic outlines and ambiguous harmonies. Sparse and spacious voicings that are typical of Copland's style, as well as rich sonorities that emphasize quartal and quintal harmony, are exploited in this composition. ${ }^{182}$ Despite the opening and ending key signature of four flats, a definite sense of key is avoided. The syncopated rhythm combined with subtle metric changes $(4 / 4,7 / 8,6 / 8)$ provides a rhythmic instability to the piece. Like the previous two piano blues, this movement is also in $\mathrm{ABA}^{\prime}$ form (measures 1-12, 13-32, and 33-41, respectively). The return of the A section $\left(\mathrm{A}^{\prime}\right)$ contains an abbreviation of the initial A material. According to Lynch, this movement, which was composed in a highly organic and concentrated formal structure, "reflects Copland's penchant for statement, digression, and return."183

In line 1 (measures 1-4), the chordal opening motive is characterized by a short-longlong-long, square rhythmic figure (See Example 89).

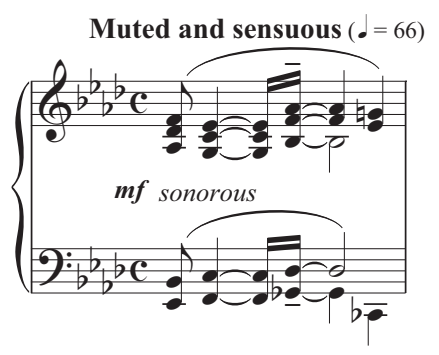

Example 89. Chordal opening motive in line 1, Copland's Four Piano Blues, no. 3 , m. 1

\footnotetext{
${ }^{182}$ Mark Anderson, “Aaron Copland's Piano Blues No. 3," Keyboard Classics and Piano Stylist 15 (MarchApril 1995): 62.

${ }^{183}$ Lynch, "Emblems: "Signifiers of Stylistic Coherence in Selected Works of Copland," 59.
} 
Copland achieved organic unity by deriving almost all of the motives in Blues No. 3 from a single musical idea in this first measure.

The initial rhythmic motive, according to Case, could be described as a "primary rag" that is, music with short notes on the accented beats and longer notes on the unaccented beats. ${ }^{184}$ Case also noticed how the composer attempted to explore the character of jazz improvisation by writing out improvisatory-sounding rhythms within a plain 4/4 meter. ${ }^{185}$ For the performer, the rhythmic challenge of this composition lies not only in the syncopation, but also in the slightly varied sixteenth and eighth note figures during syncopations of each passage. Moreover, the two opposing forces/ideas, lines 1 and 3 (measures 1-4 and 9-12) versus lines 2 and 4 (measures 5-8 and 13-17), will challenge the pianist in terms of projecting contrasting color and expression. The first idea (as illustrated in Example 89 above) is characterized by a five-voice texture marked sonorous; a contrasting idea, requiring different color and expression is illustrated in Example 90 below.

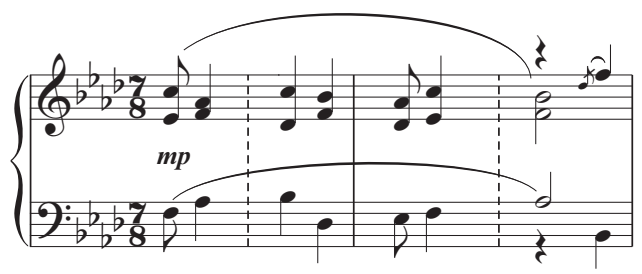

Example 90. Contrasting force, Copland's Four Piano Blues, no. 3, mm. 5-6

In this composition, the ultimate goal for the performer is to depict the feelings of "muted and sensuous" notated by the composer. Anderson felt that using the soft pedal as a colorist device and listening carefully to the richness of the harmony are two of the most important ways to achieve this goal. In the opening motive, playing $m f$ and with pedal is crucial to giving a sonorous quality to the sound. The performer should try to listen carefully to how the harmony is produced and blended by each of the five voices in measures 1-4.

\footnotetext{
${ }^{184}$ Case, "Stylistic Coherency in the Piano Works of Aaron Copland," 576. ${ }^{185}$ Ibid.
} 
Aim for an equal sonority for each individual voice as well as an awareness of the inner harmonies of every chord. An extra forward push on the first beat of each measure is required to clarify the syncopations with follow. ${ }^{186}$ The two equally extended notes as well as the metric accent in the middle of these measures produce hesitancy and unexpected tension. The performer should project a "push-pull" effect with such a rhythmic design. The two grace notes on the final beat of measures 2 and 4 function to fill out the beat and harmony of the previous sustained chords.

Contrasting force appears in line 2 (measures 5-8) when the texture is condensed from five to three essential voices, and the dynamic level is reduced from $m f$ to $m p$ (See Example 90 above). Copland depicted a scene from the American prairie by using a simple folklike tune in sparse chordal structure. Despite the continuation of the short-long-long-long rhythmic motive, the 7/8 meter further enhances the rhythmic instability. Besides keeping the tempo steady when moving from $4 / 4$ to $7 / 8$ meter, feeling the rhythmic energy change from hesitance to agitation is even more important for the performer. While it is possible to swing the eighth notes to produce a jazz feel in the measures in $4 / 4$ meter, the style of the material in the $7 / 8$ meter seems conducive to even eighth notes since unusual time signatures are not normally used in the Blues.

The second phrase of the A section (measures 3-4) returns in line 3 (measures 9-10) with slight alteration at the end. In measures 11 and 12, the student performer should pay attention to various dynamic details and emphasize the crescendos. As Anderson noted, these dynamics are particularly important in measure 12, marked piu $f$ with crescendo, where they emphasize the importance of the third beat, the high point of the phrase. ${ }^{187}$

The $\mathrm{B}$ section begins in measure 13 and is characterized by a slight acceleration in tempo and change of key (See Example 91).

\footnotetext{
${ }^{186}$ Anderson, “Aaron Copland's Piano Blues No. 3," Keyboard Classics and Piano Stylist 15 (March-April 1995): 62.

${ }^{187}$ Ibid., 63.
} 


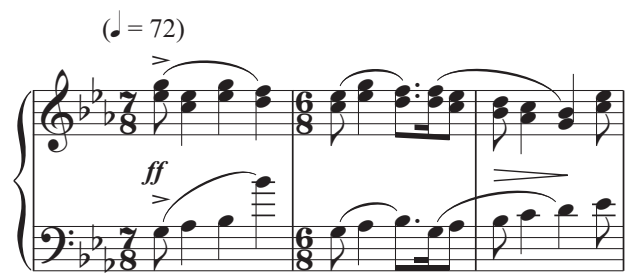

Example 91. Opening of the B section, Copland's Four Piano Blues, no. 3, mm. 13-15

Lynch observed that "the B section is generally higher in range and dynamic and more sparse in texture than both A sections." ${ }^{188}$ Measure 13, although it begins $f f$, is not the climax of the piece. While the rhythmic pattern of measure 13 is derived from the opening motive, the melodic design originated from line 2 (measures 5-8). From measures 13 through 21, use of thirds in the right hand and the contrary motion between upper and lower voices are most prevalent. When the longest melodic phrase (five measures) ends in a cadential pause in measure 17, the performer must pay attention to how the dynamic force decreased gradually from $f f$ to $p$.

The limited melodic range and motion from measures 18 through 21 are similar to those in line 1(measures 1-4), except the texture becomes thinner. In measure 22, starting with subito $p p$ is crucial as the changes in texture and melodic contour begin to take place (See Example 92).

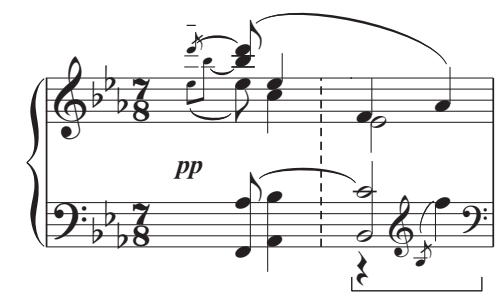

Example 92. Changes of texture and melodic contour, Copland's Four Piano Blues, no. 3, m. 22

${ }^{188}$ Lynch, "Emblems: "Signifiers of Stylistic Coherence in Selected Works of Copland," 60. 
It is interesting that although the pitch range in measures $22-23$ widens and stretches to almost four octaves, the dynamic level is $p p$, the softest of the movement. The student performer could use the una corda pedal to control the volume when playing the chords with large intervals. Case felt that this controlled approach to music requiring a high degree of emotion and energy creates a potentially stressful situation. ${ }^{189}$

Starting from measure 24, the tempo returns to the original slower marking despite the fact that the return of the A section does not occur until measure 33. In measures 24-25, the texture is reduced to only two voices, and the number of wide intervallic leaps increases (See Example 93).

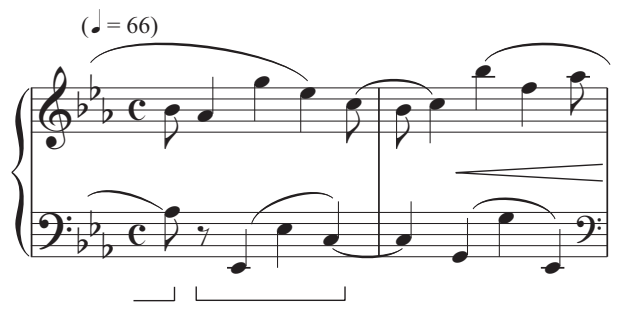

Example 93. Increased instability, Copland's Four Piano Blues, no. 3, mm. 2425

This is also one of the few spots in the piece where the beginnings and endings of righthand and left-hand phrases do not coincide. This fact, plus Copland's indication of a pedal change on a weak beat in measure 24 , contributes further to the feeling of instability and tension noted by Case. In the beginning of this phrase, measure 23, playing $m p$ is critical in order to make one crescendo to the real climax of the piece in measure 30.

The A section returns in measure 33 with the opening four phrases shortened to two phrases. The pianist must pay attention to the dynamic shift in which the first phrase (measure 33 ) is now marked $p p$ instead of its original marking, $m f$. Use of the una corda pedal is recommended to change the sonority. Basically, the entire A'section loses the initial vitality with the music merely fading away. Anderson feels that, because listeners will recognize

${ }^{189}$ Case, "Stylistic Coherency in the Piano Works of Aaron Copland," 601. 
the "familiar music/change expression" strategy, the pianist therefore should look deeper to determine the reason for the changes. ${ }^{190}$ While measures 35-36 varied the harmony from measures 7-8, measures 37-38 are almost parallel to measures 10-11 in pitch content.

The last three measures (measures 39-41) function as a codetta based on the first two pitches of the opening theme (See Example 94).

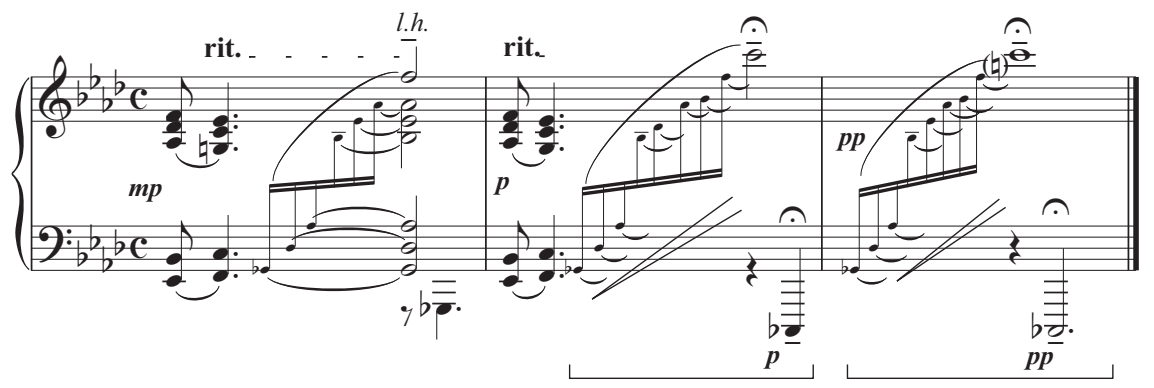

Example 94. Codetta, Copland's Four Piano Blues, no. 3, mm. 39-41

Regarding performance suggestions, Copland has provided very careful directions on how to control nuance, shading and sonority. It is important that the pianist follows these performance indications literally. The dynamic by level should progress from $m p$, to $p$, to pp. As for the arpeggios that embellish and extend the phrases, try to incorporate all the notes with both hands in a progressively slower tempo, as indicated by Copland. Use of pedal is crucial to prolonging the harmony and connecting the notes smoothly within the chord. Notice all the differences in Copland's markings among the final three measures. In measure 39, Copland did not indicate use of the damper pedal as he did in measures 40 and 41, but instead indicated use of finger pedal through his notation of grace notes tied to the following half notes. This suggests that the performer hold out these notes with the fingers alone as long as possible and then depress the damper pedal right before the left hand shifts up to avoid losing the sound of any of these pitches. This creates less

\footnotetext{
${ }^{190}$ Mark Anderson, “Aaron Copland's Piano Blues No. 3," Keyboard Classics and Piano Stylist 15 (MarchApril 1995): 63.
} 
resonance than would be created by depressing the pedal at the beginning of the arpeggio. In measure 40 , Copland notated a series of grace notes sustained by the damper pedal and not by ties to half notes; his notation indicates depressing the pedal on the first grace note, $\mathrm{G}^{\mathrm{b}}$. Although the dynamic level in this measure is softer, the greater use of pedal creates a richer sound, with more overtones, especially since the slower tempo allows more time for each note to resonate. In measure 41, the performer should use one pedal for the entire measure. However, the timbre, tone color and sonority should be changed by performing $p p$ and even slower, allowing even more time for the sound to ring and ultimately to fade away completely. If the performer chose to use una corda pedal in the last measure, this would alter the tone color and timbre even further. Thus, the performer needs to pay special attention to finger and pedal technique as well as to the dynamics and the ritards.

\section{With bounce}

Marked "with bounce," the fast tempo of Blues No. 4 provides a contrasting and jolly mood for this group of pieces. The order of Four Piano Blues does not reflect the chronological order of composition. Blues No. 4 was composed the earliest and reflects Copland's most overtly jazz-influenced movement of the set. ${ }^{191}$ In addition to the syncopations and shifts of accents that were seen in the other blues, Copland incorporates literal jazz materials such as cross rhythms, ragtime spirit, and blue notes in this movement. Despite its key signature of no sharps or flats, $\mathrm{F}$ major seems to serve as a tonal center. Thus, the opening $\mathrm{A}^{\mathrm{b}}$ and $\mathrm{E}^{\mathrm{b}}$ in the first chord constitute the lowered blues third and seventh.

The formal structure of this movement is a three-part form, ABA, plus a codetta (measures 1-14, 15-22, 23-36, and 37-41 respectively). Like the third movement, Blues No. 4 is also highly organic in that the entire piece is constructed from a single four-note thematic motive in the soprano voice (See Example 95).

\footnotetext{
${ }^{191}$ Lynch, "Emblems: Signifiers of Stylistic Coherence in Selected Works of Copland,” 62.
} 


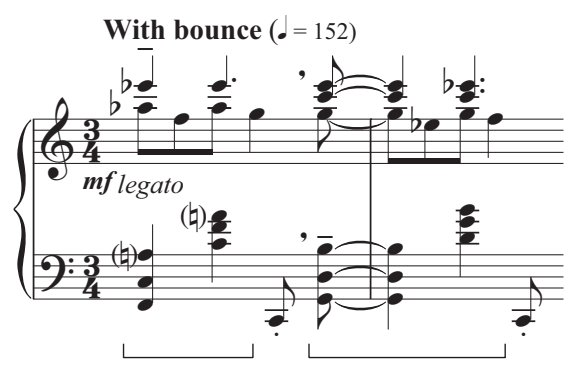

Example 95. Four-note motive in opening theme (with suggested pedaling), Copland's Four Piano Blues, no. 4, mm. 1-2

In measure 1 of the opening theme, bitonality appears when $A$ and $A^{b}$ are sounded simultaneously. Case felt that Copland used the clash in sound between $\mathrm{A}$ and $\mathrm{A}^{\mathrm{b}}$ "to approximate the intonation of a vocally produced 'blue' note." ${ }^{192}$ Bitonal elements can be explained as blue notes. This has been a common practice among blues composers for many years. Besides bitonal construction, Sayer noted that linear harmonic motion using neighbor-chord motion from the tonic is characteristic. ${ }^{193}$

This movement presents enormous complexities in rhythm. Copland is successful in creating rhythmic confusion. Noteworthy is the time signature of $3 / 4$ that differs from common time or $4 / 4$, which typically appears in jazz works. In fact, the grouping of note values in the upper two parts of the right hand implies time signatures more like $6 / 8$ while the left-hand accompaniment remains in 3/4. Cross rhythms result from the constant use of these two conflicting rhythmic patterns. Also, the composer tries to avoid a clear sense of meter by hampering the downbeat through the use of ties across the bar lines of almost every measure.

Case observed that Copland compressed the ragtime rhythm into 3/4 and used simultaneous syncopations in all voices. ${ }^{194}$ According to Smith, this symbolizes the flavor of the Charleston rhythm. ${ }^{195}$ Swinging the eighth notes is particularly important to achieving a

\footnotetext{
192 Case, "Stylistic Coherency in the Piano Works of Aaron Copland," 615.

193 Sayers, "Tonal Organization in Selected Early Works of Aaron Copland," 267.

194 Case, "Stylistic Coherency in the Piano Works of Aaron Copland," 613.

195 Smith, “Aaron Copland: His Works and Contribution to American Music,” 91.
} 
jazz feel. Also because of the fast tempo (quarter notes equal to 152) and the indication "with bounce," playing dotted rhythms instead of even eighth notes in both hands is appropriate. On the third beat from measures 1 through 9, the large intervallic leaps and the series of breath marks in between the two left-hand eighth notes challenge the student performer in terms of precision and pedal interpretation. During such a fast tempo, if students cannot reach the interval of a tenth comfortably, they may need to roll the left-hand chords from bottom to top in one rapid gesture supported by the wrist. How the performer should use the pedal is implied by Copland's meticulous articulation suggestions. Since the composer marked staccato on the first eighth-note C's, then inserted breath marks, and then marked portato on the final, large chords in these measures (to characterize the bounce), using one pedal before the breath mark to connect the disjunct chords of the same harmony and then releasing the pedal during the staccato eighth notes is necessary. Be sure to clear the damper pedal in the phrase before the breath mark, and after that, to depress a new pedal as illustrated in Example 95.

Basically, the right-hand upper voice in the first nine measures repeats the thematic material with sequential transposition over similar bass accompaniment figures. From measures 11 through 14, a new accompaniment figure is created despite the continued sequence and repetition of the upper melody. A faster tempo should be taken since Copland marks "a trifle faster" at the end of measure 10. Case also noted how the composer reduced the beat length from dotted quarter notes to quarter notes in the bass to increase the momentum of the accelerando (See Example 96). ${ }^{196}$ In this passage, with the disappearance of the breath marks, fast harmonic rhythm and displacement of the bar line, the nervous emotion is finally resolved. The left-hand accompaniment shifts from off-beat to on-beat and gives a stable $3 / 4$ pulse in spite of the continuous swing of the right-hand eighth notes. It is important that the pianist retains rhythmic momentum in his or her performance. Also be sure the student performer follows the articulation indications literally. Try to emphasize

${ }^{196}$ Case, "Stylistic Coherency in the Piano Works of Aaron Copland," 623. 
the weak pick-up note of the right-hand melody as the portato marking indicates.

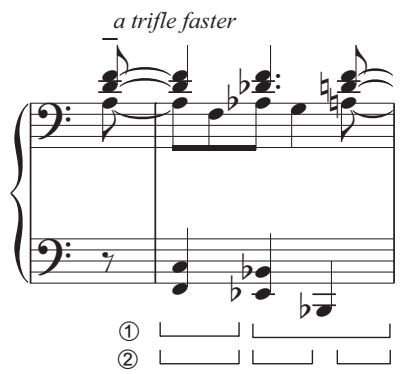

Example 96. A trifle faster passage with suggested pedaling, Copland's Four Piano Blues, no. 4, mm. 10-11.

The performer has two options for pedaling in the passage from measure 11 to measure 14: melodic and harmonic pedaling. When using melodic pedaling that follows the melodic structure of the right hand, constant changes of pedal on each quarter note are required. When using harmonic pedaling that follows the harmonic structure of the left hand, changing the pedal between the $\mathrm{F}$ and $\mathrm{E}^{\mathrm{b}}$ in the bass line is appropriate. It is suggested that the student performer pedal harmonically (as illustrated in Example 96 above) during this rapid tempo.

Measure 15 functions both as a transition from the A section to the B section and the beginning of the B section. In general, the brief eight-measure B section contains material developed from the A section. Significant change in rhythmic motion and musical material takes place such as the dropping of the left-hand accompaniment pattern and the introduction of a new right-hand motive, as well as frequent meter changes, and the dramatically slower tempo with a quarter note equal to 88 (See Example 97). Along with left-hand grace notes, measure 16 restates the new motive from measure 15 . The student performer should play the ornamentation with the special sliding pedal effect in order to imitate the sound of a trombone or cello. ${ }^{197}$

${ }^{197}$ See page 3, Definition of Terms, for directions on how to achieve a sliding pedal effect. 


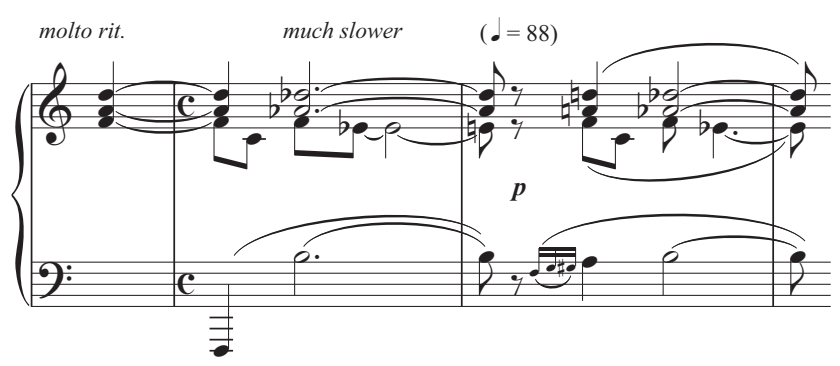

Example 97. Beginning of B section, Copland's Four Piano Blues, no. 4, mm. $14-17$

The two-measure phrase in measures 19-20 restates material (extended by one extra beat) from measures 17-18. A short dotted rhythmic motive in measures 21-22 concludes the B section; that same figure, extended by one measure (from measures 39-41) concludes the entire movement as well (See Example 98). The performer should play this single-line arpeggiated figure with both hands and with no pedal to create a crispy sound and light mood.

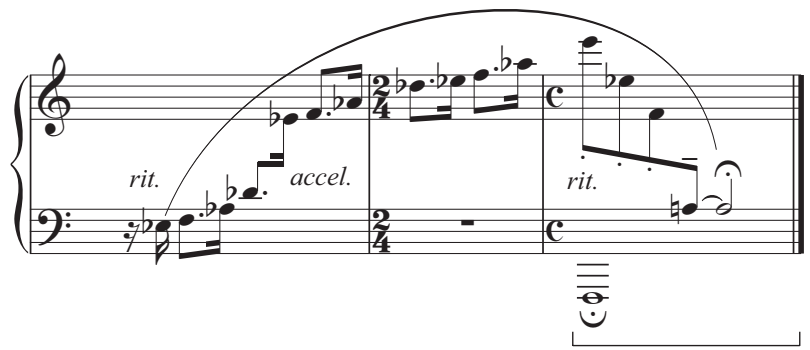

Example 98. Ending dotted rhythmic figure, Copland's Four Piano Blues, no. 4, mm. 39-41

Since the performer must observe Copland's pedal marking in measure 41, omitting pedal in measures 39-40 is critical to distinguishing these measures from those that follow. It is interesting that Copland also used a very similar arpeggiated, dotted rhythmic pattern from measures 23 through 27 in Blues No. 2 composed many years later.

After the brief retransition, the A section returns almost identically except with an extra beat of rest in measures 25, 28, and 30 (See Example 99). 


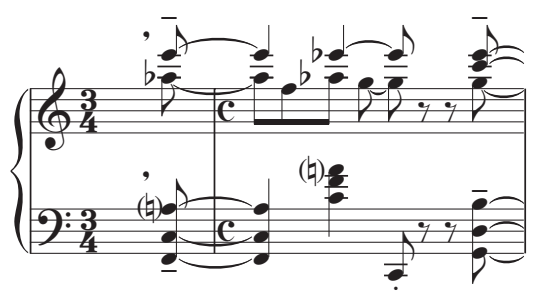

Example 99. Extra beat of rest added to return of opening motive, Copland's Four Piano Blues, no. 4, mm. 24-25

These rests exaggerate the hesitation and according to Smith, create the effect of a rhythmic variation in early ragtime. ${ }^{198}$ For the performer, these rests added in the 4/4 meters should be played clearly, and should interrupt the eighth notes with surprise.

The five-measure codetta (measures 37-41) basically depicts material from measures 15-16 and measures 21-22 of the B section. In measure 41, the scattered wide intervallic descending melody cuts off the piece abruptly (See Example 98). Use of the damper pedal and a slow tempo are important in the final measure to produce a contrasting sonority to the beginning of the movement. The tension between $\mathrm{A}^{\mathrm{b}}$ and $\mathrm{A}$ natural is finally resolved, with Copland's portato marking and his fermata on the final note of the movement, A natural.

\section{Summary}

The Four Piano Blues was published in 1948 and illustrates Copland's fascination with jazz and blues. Although these Blues were written in a span of over twenty years and were not originally composed as suite, there are striking similarities among them. Rhythm is the most important element of Copland's writing. The influence of jazz is evident and affects the rhythm in his use of syncopation, cross rhythms, and metric shifts. Most of Copland's melodies are diatonic and somewhat less inventive; they use a limited intervallic range and numerous repetitions and sequences. In terms of harmony, Copland achieved harmonic ambiguity through the use of bitonal and extended chords. Three-part form that

\footnotetext{
198 Smith, “Aaron Copland: His Works and Contribution to American Music," 91.
} 
is essential to jazz styles is found in the last three blues. As for the texture, Copland often wrote transparent as well as sparse and spacious voicing. Overall, the motivic development is significant. In a comparison among the Four Piano Blues, the performer should notice that in the first three movements, a calm atmosphere, the use of grace notes, and time signatures of common time or $4 / 4$ predominate; the last movement provides a contrast in motion and a fast tempo that are lacking in the first three movements.

Unlike Copland's other major works (Piano Variations, Piano Sonata, and Piano Fantasy), Four Piano Blues is not as technically challenging or lengthy, but more accessible for the listener and the performer. The student performer must pay close attention to the fast meter changes and harmonic dissonance resulting from cluster chords and added notes, while focusing on the subtle changes of melodic and dynamic contrasts as well. Also, interest should be maintained by varying tone colors and sonorities in each statement of the compact motive. In general, Copland's constant experimentation with jazz sounds clearly shows in the movements with unique pianistic sonority (such as the stride piano accompaniment in the middle section of Blues No. 2) and in his use of the prevailing lazy grace note that might suggest the slide from the saxophone.

Like many other twentieth-century composers, Copland clearly specified how to play the piece with meticulous articulation, dynamic and pedal indications, and even with performance suggestions described in words. This shows the composer's interest in the piano. In fact, almost all of Copland's works were composed at the piano. ${ }^{199}$ For the performer, these jazz-inspired movements along with their many shared elements, make the Four Piano Blues a very attractive and cohesive suite. Although it is possible for pianists to program each piece individually based on its historical origin, it would be more appealing if they could perform and record the entire set as a group.

\footnotetext{
${ }^{199}$ Lynch, "Emblems: Signifiers of Stylistic Coherence in Selected Works of Copland," 54.
} 


\title{
CHAPTER IV \\ SUMMARY, CONCLUSIONS, AND RECOMMENDATIONS \\ FOR FURTHER RESEARCH
}

\begin{abstract}
Summary
Twentieth-century music is sometimes considered to be too complicated for lessadvanced students to understand, and unfortunately, most important American composers tend to write few works of an easier nature. Therefore, it is important for piano teachers to search for piano repertoire that is appropriate for students' development. Choosing quality piano literature for students is always challenging for piano teachers despite the existence of a wide range of twentieth-century literature. In order to assist the piano teacher in teaching the finest early-advanced twentieth-century American piano compositions to college freshman and sophomore piano majors, this study presents a performance analysis of repertoire from three highly influential American composers: Four Piano Blues by Aaron Copland, Excursions, Op. 20 by Samuel Barber and Suite de Danzas Criollas, Op. 15 by Alberto Ginastera. These compositions combine important characteristics of twentiethcentury music with musical idioms from prior centuries, and thus will provide an excellent introduction to twentieth-century American music.

Basically, the purpose of this research project is to provide performance and pedagogical suggestions based on stylistic and interpretive analyses. When teaching this repertoire, it is important to help the student develop a performance interpretation through the understanding of musical style, including aspects of melody, rhythm, harmony, formal structure and texture. In addition to stylistic guidelines, this study also provides appropriate pianistic suggestions on technique, pedaling, phrasing, articulation, touch, and tone production. Some parts of this study are directed to kinesthetic awareness, and provide advice on guiding and controlling
\end{abstract}


physical movements of finger action, arm movement, and their coordination. The summary that follows highlights important findings regarding musical and style characteristics that affect the performance approach to these three compositions.

These pieces share many common features. Besides having been written around 1950 (with the exception of the second and third Piano Blues), they are all piano suites with each suite consisting of four (Excursions and Four Piano Blues) to five (Suite de Danzas Criollas) miniatures. They are well within the undergraduate student's technical capabilities but are challenging in terms of twentieth-century compositional techniques of rhythm and harmony, and idiomatic performance of the American popular styles of blues and jazz. The Excursions parallel the Four Piano Blues in their depiction of the sound of American popular music styles and/or Western frontier or rural life. Folk elements are often prominent in Latin American music as well; as a matter of fact, "all the melodies and rhythms in the Suite [Suite de Danzas Criollas] are Argentine." 199 Finally, while the lyricism of Excursions represents Barber's neo-Romanticism, the Four Piano Blues symbolize Copland's jazz-oriented neo-classicism, and the Suite de Danzas Criollas represents the writing of a nationalistic Latin-American dance suite of the highest order.

\section{Use of Rhythm}

Rhythm is one of the most outstanding features in these compositions. All three composers used rhythm in a sophisticated manner. Overall, these compositions incorporate polyrhythms, cross-rhythms, hemiola, syncopations, and frequent meter changes. Great rhythmic sensitivity is required to resolve these rhythmic difficulties. It is important that the rhythms be approached "intuitively and physically as well as arithmetically and mentally." 200

\footnotetext{
${ }^{199}$ Hanley, "The Solo Piano Compositions of Alberto Ginastera," 18 quoting Ginastera lecture, "Essay for An Autobiography," Dartmouth College, July 3, 1968.

${ }^{200}$ James Lyke, Yvonne Enoch, and Geoffrey Haydon, Creative Piano Teaching. (Champaign, IL: Stipes Publishing Co., 1987), 247.
} 
Ginastera's rhythmic usage is one of the most distinctive facets of his stylistic development. ${ }^{201}$ Whereas the Creole folksong material in Suite de Danzas Criollas features triple or compound meter with frequent hemiola, the Creole dance rhythms, especially the malambo, give Ginastera a model for building rhythmic excitement. The pounding malambo used in the last movement incorporates a variety of accents through syncopation in one part against a constant, steady bass part. While cross rhythms and rapidly shifting meter further heighten the restless, perpetual motion, the regularity of pulse is always maintained. The most difficult rhythms occur when the $6 / 8$ meter is subdivided in two different rhythmic subdivisions: three groups of two eighth notes against two groups of three eighth notes (e.g., in the second and fifth movements).

Barber's rhythms, in general, are more traditional and simple. However, the Excursions do contain many more complicated rhythmic elements such as cross rhythms, hemiola and meter changes, reflecting the strong influence of jazz. The improvisatory nature of jazz provided the composer great rhythmic freedom. His stylized boogie-woogie is characterized by a steady, repeated bass figure beneath slow blues rhythms featuring syncopation, swing triplet figures and weak-beat accents. It is important that the pianist maintain the feeling of perpetual motion to imitate a boogie-woogie style in the first Excursion, and play with lazy or dragged triplets in the second Excursion that features a blues style. In the rhythmic complexities of the third Excursion (e.g., a septuplet theme accompanied by eight even eighth notes), keeping the basic pulse steady is critical.

The rhythmic design of Copland's composition denotes a highly personal style. He strove to combine the steady pulse of a folk-like tune with the rhythmic flexibility of jazz rhythm. ${ }^{202} \mathrm{He}$ also attempted to eliminate barlines through rhythmic displacement with shifting accents and cross-rhythms. A syncopated rhythmic swing and ragtime are prominent in these blues pieces. In terms of an idiomatic performance of ragtime, although

\footnotetext{
${ }^{201}$ Wallace, "Alberto Ginastera: An analysis of His Style and Techniques of Composition,” 314.

${ }^{202}$ Lynch, "Emblems: Signifiers of Stylistic Coherence in Selected Works of Copland”, 33.
} 
the eighth notes can both be swung or played straight, the author recommends swinging the eighth notes particularly in the fourth piano blues as Leo Smit does in his recording. ${ }^{203}$ In contrast, the author recommends playing the ragtime march accompaniment in the second piano blues (Tempo I -measures 28-35) in a steady and crisp manner.

A natural rhythmic ritardando or accelerando is carefully planned by both Barber and Copland. For example, in the retransition to the opening motive of Excursions no.1, Barber achieved a rhythmic ritardando by gradually slowing down the rhythmic movement from sixteenth notes to eighth notes and finally to quarter-note triplets; in the first piano blues, Copland used a meter change from $6 / 8$ to $5 / 8$ to accelerate the rhythmic motion.

\section{Use of Harmony}

The harmonic style of all three composers includes tone clusters, polytonality, and chord extensions by using added and altered notes. The use of a broad harmonic range and the often occurring interval of a tenth will most likely cause reaching problems for the student with small hands. Use of pedal is critical in capturing the complete harmony.

Despite the Argentine folk roots of his harmonies, Ginastera consistently explored contemporary harmonic writing. His tertian sonorities incorporate extended seventh and ninth chords. The traditional harmony is present along with dissonant intervallic combinations of polychords and chords built in fourths. Tone clusters and successions of parallel chords are important parts of his harmonic vocabulary. Performing these tone clusters and widely-spaced chords can pose difficulties for the pianist. The weak beat placement of the cluster tones that are treated as a coloristic device in the first movement, the massive cluster chords played either with two notes for each finger or with the palm of the hand in the second movement, and the rapid leaping of octaves and chords may all challenge the performer in terms of precision.

\footnotetext{
${ }^{203}$ Leo Smit, The Young pioneers, Complete Copland Piano Music, Sony Classical, New York, 1994, CD. Smit's performance is considered authentic both because he was closely related to Copland as a friend and because the first piano blues was dedicated to him.
} 
Barber's tonal framework shows his conservatism in that the tertian sonority is predominant. However, tritones and quartal harmonies are effectively used. In the jazzinfluenced Excursions, bitonality and counterpoint occur in the first movement, and lowered thirds and sevenths are observed in the blues harmony of the third movement. In general, the improvisatory-like, double-third tremolo chords, rapid scale passages, cluster chords, and rapid repeated notes will require a rapid finger articulation by the pianist. Creativity is needed to produce subtle harmonic and dynamic contrasts during each repetitious section of his lyrical movements (i.e., the second and third Excursions).

In the Four Piano Blues, Copland emphasized bitonal harmonies and altered tones, creating an extension of the harmonic series that commonly occurs in jazz. Harmonic ambiguity is achieved through heightened use of chord extensions and the avoidance of logical harmonic progressions and traditional cadences. The wide chordal spacing creates a sparse texture. For the student performer with small hands who needs to roll the spacious block chords, careful pedaling is necessary. Alternatively, redistribution of notes between hands can sometimes provide a solution.

\section{$\underline{\text { Use of Melody }}$}

Most of the melodies in these compositions are diatonic with little chromaticism. All three composers were inspired by popular music and dance with pieces based on Creole folk songs, a cowboy tune, square dance, ragtime, boogie-woogie and blues. In terms of performance approach, the legato melodies should be played with lyricism and a singing tone. In general, the melodic material in these compositions is made up of short repeated motives where the repetition is usually altered in terms of rhythm, interval or accompanying pattern. In order to avoid monotony, the performer should approach the similar thematic material differently with contrasting color and dynamics.

Although most of the melodies in these compositions were inspired by jazz and folk materials, they are set in contrasting styles. While Barber wrote in the style of a lyrical song, Copland's single-line, angular melodies feature short, fragmentary motives. Ginastera's 
melodic material was inspired by gaucho love songs, the pentatonic scale, the malambo, and the gaucho's instrument, the guitar. A style of free, jazz improvisation is felt in Barber's jazz-influenced Excursions no. 1 and no. 4, but is less obvious in Copland's compositions owing to his transparent texture and meticulous performance indications.

A glissando occurs in the fifth movement of Suite de Danzas Criollas and is simulated in the first and third Excursions. As a comparison, Ginastera composed the glissando in a traditional way with rapid single notes; Barber's glissando-like passages are innovative, made up of either a scale passage or a combination of chords and notes. Often (as in the first two instances mentioned above), the glissando is used to increase the dynamic level and excitement; however, in the third Blues, on the contrary, Barber called for a diminuendo on the glissando as a conclusion of the third variation, acting like smoke disappearing in the air. When playing the glissando, employ agile fingertips with a light touch and a long damper pedal. If it is marked crescendo, the pedal will help to sustain and enhance the brilliance of sound; if diminuendo is noted, use pedal to simulate an impressionistic tone color and carefully control the touch and arm movement.

All three composers made liberal use of ornamentation in their writing. While in the fourth movement of Suite de Danzas Criollas, Ginastera used grace notes and rolled chords as an imitation of plucking and strumming on the guitar, and in the fourth Excursion, Barber exploited grace notes to reproduce a specific fiddle technique; in the second Piano Blues, Copland used the melodic ornament to create a lazy, bluesy feel. As in playing the glissando, the pedal must be used carefully to catch every note of the rolled, guitar chords or grace notes. Also (as in playing the glissandi), various performance approaches are required in the performance of ornaments. Clarity is required in the ornaments which create a subtle guitar sonority in the fourth movement of Suite de Danzas Criollas, sharp ornaments enhance the rhythmic feel of fourth Excursions, and a melodic-sounding ornament should be the aim in the slower movements of Copland's composition. 


\section{$\underline{\text { Use of Texture }}$}

Basically, the texture of these three compositions is not massively thick. Whereas melody with chordal or arpeggiated accompaniment is most popular, polyphony occurs particularly in the canon (measures 5-9) featured in the third movement of Suite de Danzas Criollas. This striking canon poses great difficulties with clarity of voicing, especially in the unusual meter of 11/8. A very brief use of canon appears in the first Excursion (measures 35 and 37) and in the first Piano Blues (measures 7-9); however, these instances are not as significant as Ginastera's use of canon since they do not really affect the overall form of these pieces.

Compared to the thick, cluster-chord texture of Ginastera's second movement and the sonorous chordal accompaniment and parallel octaves in Ginastera's fifth movement, Copland's music is characterized by lean and transparent textures, slenderness of sound and widely-spaced voicing. A fuller texture can be heard in Barber's music, whether in the repeated chords, octaves and double notes in the first and fourth movements or in the tone clusters and chordal accompaniment in the third movement of Excursions.

The alternation of two different textures is an interesting feature of Ginastera's and Copland's compositions. While there is a clear contrast of textures in the second movement of Suite de Danzas Criollas, in the third Piano Blues, two opposing forces are represented in lines 1 and 3 against lines 2 and 4. Producing contrasting colors in each different texture will challenge the pianist in terms of muscular control of tone production, sensitivity to hearing, and imagination as well.

\section{$\underline{\text { Use of Form }}$}

Basically, these compositions are characterized by brevity and simplicity of form. The majority of the movements in these suites are composed in short sectional forms such as ABA song form. According to Lynch, such three-part arch forms (consisting of statement, digression, and return) are essential not only to jazz music but also to the Western art music 
and folk music traditions. ${ }^{204}$

All three compositions illustrate economy of means in their limited number of motives. As a matter of fact, examples may be found from Suite de Danzas Criollas and Four Piano Blues where entire movements are derived mainly from the opening theme. For instance, in the third and fourth movements of Suite de Danzas Criollas, the music is based almost completely on the opening motive and its repetition. In the last two movements of the highly organic Four Piano Blues, Copland achieved unity by constructing the entire composition from either the first measure or a single four-note motive.

Whereas the singing melody and simple accompaniment styles are most prevalent, traditional forms such as canon and theme and variations are also exploited in these compositions. In the second Excursions, seven variations are derived from the original eight-measure melody. The canon, as noted earlier, is featured in the third movement of Suite de Danzas Criollas. Performance indications for breath marks are significant in the first and fourth Piano Blues as a suggestion of abrupt emotional alteration and a clear dividing line between phrases.

Some movements in both the Ginastera and Barber compositions begin with a short introduction. While the first movement of Suite de Danzas Criollas begins with an eightmeasure introduction, the short two-measure introduction in the fourth movement of Excursions may be interpreted as dancers stomping their feet in a country square dance. Another interesting formal feature is the attacca markings that Ginastera exploited throughout the entire Suite de Danzas Criollas. These repeated markings indicate that Ginastera conceived the entire work as a unit.

\section{$\underline{\text { Use of Tone Color }}$}

Both Copland's and Ginastera's compositions include passages which create an impressionistic sonority. Examples can be heard in the high register, bell-like, ornamented

${ }^{204}$ Ibid., 38. 
melody blended with long-held bass tones in the second piano blues; the long notes mixed with the fast arpeggiated notes in the conclusion of the "muted and sensuous" third piano blues; the last phrase of the first Danzas Criollas, which features arpeggiated chords in altered fourths ending in a soft, delicate arpeggio; the poetic quality of the fourth Danzas Criollas which calls for the use of both the damper and una corda pedals; and the successive parallel chords at the end of the fifth Danzas Criollas.

All three suites highlight the portrayal of instruments that include the fiddle and accordion in Excursions, the trombone slide in Four Piano Blues, and the guitar in Suite de Danzas Criollas. Ginastera's love for percussion instruments is evident particularly in the second movement of Suite de Danzas Criollas as the hammering cluster chords exploit the percussive qualities of the piano.

The order of Suite de Danzas Criollas demonstrates Ginastera's careful arrangement with contrasting timbres. The third movement ends softly and the fourth movement begins softly, but the timbre is quite different between these movements and between all the others as well. This dance suite alternates sonorous brilliant with cantabile and poetic movements as well as with percussive timbre with rhythmic drive, thus effectively varying the sonority.

In the first movement of Excursions, Barber experiments with some special sound effects associated with traveling. While the two stressed quarter notes of the same pitch (e.g., measures 4-5) are reminiscent of a car horn, the rattling sound from the alternating double thirds (e.g., measures 44 and 50) mimic the in and out breath of the harmonica ${ }^{205}$, and the long block chords (measures 92-106) represent a train whistle.

The sighing effect that appears in the blues like second movement of Excursions was inspired by the slide technique of a trombone and is a specific jazz sonority. Copland also exploited some distinctive tone colors in the Four Piano Blues. Open spaces in chord voicing provide a sparse but colorful tone color in his music. A glassy sound, created by

${ }^{205}$ Sifferman, “Samuel Barber's Works for Solo Piano," 8. 
a high-register single-line melody, can be heard in the climax of the first movement (i.e., measures 32-34) and in the staccato dotted eighth notes (i.e., measure 18-23) of the second movement in Four Piano Blues.

\section{Conclusions}

The selected piano works are valuable as introductory material for the inexperienced performer since they feature contemporary musical elements within the context of classical idioms. The compositional details of style elements are important issues to be considered in any study of music since an ideal interpretation should be based on logical analysis and meaningful discussion of essential characteristics such as formal structure and large harmonic plan (and not based only on abstract feeling and fascination of the music itself). For example, in these suites, the student must understand the characteristics of typical Latin American dances and American Jazz in order to achieve an idiomatic performance.

In terms of performance approach, since these three composers were fine pianists themselves, the compositional styles of these works and the performance techniques necessary for their realization are both very idiomatic to the piano. Basically, these works are not technically demanding; however, the nationalistic character of the Argentine and American folk melodies and dances, the popular style of ragtime, blues and jazz, as well as their incorporation into twentieth-century compositional technique (with emphasis on more complex rhythm and tonality, and varied texture) will challenge students in their performance approach.

The following conclusions may be drawn from this study:

1) Polyrhythms that combine different subdivisions of same pulse are often a feature of twentieth-century music and can be found in the third Excursions. When playing the passage with polyrhythms, students can use the technique of finding the lowest common denominator to figure out how to play unusual combinations of rhythms such as 7 against 8,5 against 8 , etc.

2) Students are often confused as to whether or not to swing the notated eighth notes 
in much of the jazz-featured compositions such as the second Piano Blues and second Excursions. Since passages where the rhythm is swung can be notated in a variety of ways (i.e., with dotted, even, or triplet eighth notes), students need to decide if and when to follow the notated rhythm strictly. The eighth notes can be swung or played straight in ragtime and the performer should make a performance decision that is idiomatic to jazz style. Basically, the faster the tempo, the less the swing, the slower the tempo, the more the swing. ${ }^{206}$ Despite the fact that rhythmic freedom is offered in such compositions, a consistent rhythmic approach should be applied in repetitions of the same section.

3) It is important to accent and stress syncopated notes and chords such as in the second Suite de Danzas Criollas, the first Excursion and the third and fourth Piano Blues to achieve a strong rhythmic feeling and clear meter.

4) There is a great amount of melodic repetition and development throughout these suites. When performing these and other twentieth-century compositions, the student must be extra careful to analyze the music thoroughly so that he is aware not only of these melodic relationships, but also of harmonic and formal relationships as well, and can highlight them in an intelligent performance of the work.

5) The suites that contain a number of consecutively played miniatures may cause problems in terms of creating a new mood in each different style, and changing moods swiftly between contrasting movements or sections. Relying only on technical skill is not enough; imagination and mental qualities are also essential in enabling the performer to project a new character with only a moment for thought.

6) Students who perform these and many other twentieth-century works must be able to project a wide range of emotion and tone color at the piano. The pedals

${ }^{206}$ William Heiles, “An Approach to Twentieth-Century Music," in Creative Piano Teaching. James Lyke, Yvonne Enoch, and Geoffrey Haydon (Champaign, IL: Stipes Publishing Co., 1987), 248. 
should be used not only to sustain notes, but also to enhance tone color and timbre, dynamics, and articulation.

7) Performing music (in these suites and in other compositions) written in simple homophonic texture requires good musicianship to produce and project a lyrical, singing tone as well as to control and listen attentively to the balance between melody and accompaniment.

8) This collection of suites makes an excellent set of studies to expand a student's technique, but the cluster tones, wide intervallic chords and successive octaves will cause reach problems for a student with small hands. In order to resolve these problems, students can arpeggiate large, block chords, distribute voices differently between hands, use a different playing mechanism (such as the palm of the hand on the cluster chords), or play on the outside edge of the keyboard. Careful use of the damper pedal can also be a big help to students with small hands.

9) While learning the piano music of Ginastera, Barber, and Copland, the earlyadvanced student performer may encounter many important twentieth-century compositional techniques such as use of bitonality, cluster chords, changing time signatures and polyrhythms, as well as characteristics of American jazz. It is essential for teachers to introduce these contemporary elements to students at this level of study or even sooner, and the majority of these students will find this mix of contemporary music and jazz idioms to sound fresh and exciting.

10) When more extensive and precise phrasing, dynamic, articulation and tempo markings are indicated by twentieth-century composers, interpretive freedom in performing these musical elements is far more limited for the performer. When playing contemporary works, more attention should be paid to following the original performance indications meticulously in order to achieve the composer's desired musical sonority or specific music effect.

Regardless of how clearly the composer indicated and explained his desired musical 
characteristics and performance approach, his music must be heard to be fully understood. To expand the student's knowledge of contemporary American music and to achieve a successful performance, the teacher should have the student listen to recordings or live performances of many works by the composer. While learning to play jazz, the same effort should be expended as when learning to play classical music. Although at the professional level, a strong rhythmic sense, superior harmonization skills and advanced improvisation abilities are necessary, ordinary pianists with a modest amount of talent can still develop good musicianship and a stylistic approach to performing jazz. This can be done by working with instructional materials, such as method books, play-along records and solo transcriptions offered by renowned jazz pianists; however, the most effective strategy for developing a stylistic approach to playing jazz is to listen to the performance of well-known jazz artists and analyze the chord progressions and melodic patterns in their playing.

\section{Recommendations for further research}

The present study investigates three piano suites written by three of the most prominent twentieth-century composers: Four Piano Blues by Aaron Copland, Excursions by Samuel Barber and Suite de Danzas Criollas by Alberto Ginastera. In order for college freshman and sophomore undergraduate students to become well-rounded contemporary pianists, they must study other style characteristics and learn much more twentieth-century literature besides three selected works. For the more advanced student performer, further study should focus on the larger scale compositions such as the piano sonata, variation, and fantasy, whether written by these three composers or other twentieth-century composers. Also, in addition to music that incorporates folk elements and jazz techniques, chance (aleatoric) music as well as music for prepared piano should be introduced. Although many contemporary compositional techniques have been explored in this paper, students should also study and perform works featuring atonal and twelve-tone techniques. Finally, besides the twentieth-century solo repertoire, twentieth-century music for two pianos or for piano, 
four hands, and twentieth-century piano concertos should also be studied and performed to develop the student's ensemble skills and a more complete understanding and familiarity with twentieth-century works.

Despite the increasing importance of contemporary American piano literature in Taiwan, the music education in that country has long been dominated by Western European-educated musicians who tend to neglect American modern and jazz-oriented music. This study was motivated not only by a desire to explore the style and interpretation of twentieth-century American piano repertoire, but also to provide a resource that can enable piano students in Taiwan and in other countries to gain insights into contemporary American music. It is hoped that this study will help students not only in playing each selected composition, but also in making twentieth-century American music more accessible to interested musicians. 


\section{SELECTED BIBLIOGRAPHY}

\section{Books}

Berger, Arthur. Aaron Copland. New York: Oxford University Press, 1953.

Broder, Nathan. Samuel Barber. New York: G. Shirmer, 1954.

Butterworth, Neil. The Music of Aaron Copland. New York: University Books, 1985.

Caramia, Tony. “An Approach to Jazz Literature." In Creative Piano Teaching. James Lyke, Yvonne Enoch, and Geoffrey Haydon, 260-94. Champaign, IL: Stipes Publishing Co., 1987.

Copland, Aaron and Vivian Perlis. Copland: 1900-1942. New York: St Martin's/Marek Press, 1984. . Copland since 1943. New York: St. Martin's Press, 1989.

Forte, Allen. Contemporary Tone-Structures. New York: Teachers College, Columbia University, 1955.

Heiles, William. "An Approach to Twentieth-Century Music.” In Creative Piano Teaching. James Lyke, Yvonne Enoch, and Geoffrey Haydon, 242-59. Champaign, IL: Stipes Publishing Co., 1987.

Hennessee, Don. Samuel Barber: A Bio-Bibliography. Westport, Connecticut: Greenwood Press, 1985.

Heyman, Barbara. Samuel Barber: The Composer and His Music. New York: Oxford University Press, 1992.

Lyke, James, Yvonne Enoch, and Geoffrey Haydon. Creative Piano Teaching. Champaign, IL: Stipes Publishing Co., 1987.

Pollack, Howard. Aaron Copland: The Life and Work of an Uncommon Man. New York: Henry Holt, 1999.

Sargeant, Winthrop. Jazz: Hot and Hybrid. New York: Da Capo Press, 1975. 
Skowronski, JoAnn. Aaron Copland: A Bio-Bibliography. Westport, Connecticut: Greenwood Press, 1986.

Smith, Julia F. Aaron Copland: His Works and Contribution to American Music. New York: E. P. Dutton, 1955.

\section{Theses and Dissertations}

Burnside, Joanna Tuley. "Use of Pedal in Selected Piano Music of Alberto Ginastera." D.M.A. diss., Louisiana State University and Agricultural and Mechanical College, 2000.

Carter, Susan Blinderman. “The Piano Music of Samuel Barber.” Ph.D. diss., Texas Tech University, 1980.

Case, Nelly Maude. "Stylistic Coherency in the Piano Works of Aaron Copland." Ph.D. diss., Boston University, 1984.

Friedewald, Russell Edward. "A Formal and Stylistic Analysis of the Published Music of Samuel Barber.” Ph.D. diss, Iowa State University, 1957.

Lynch, John Patrick. "Emblems: Signifiers of Stylistic Coherence in the Formulation of an American Sound in This and Other Selected Works of Aaron Copland." D.M.A. diss., University of Cincinnati, 1996.

Miller, Elaine K. “A Study of Samuel Barber's Piano Music.” M.M. Thesis, Kent State University, 1960.

Montgomery, Patricia. "The Latin American Piano Suite in the Twentieth Century." D.M.A. diss., Indiana University, 1978.

Oswalt, Lynda Lee Freeman. "The Piano Music of Samuel Barber: A Brief Stylistic Analysis.” M.M. Thesis, University of Nebraska, 1971.

Owens, Jeannette. "Aspects of Interpretation in the Solo Piano Music of Samuel Barber." M.M. thesis, Royal College of Music, 1993.

Sayers, Richard. "Tonal Organization in Selected Early Works of Aaron Copland.” Ph.D. diss., The Catholic University of America, 2000.

Schwartz-Kates, Deborah. "The Gauchesco Tradition as a Source of National Identity in Argentine Art Music (ca. 1890-1955).” PhD. diss., University of Texas at Austin, 1997. 
Sifferman, James Philip. "Samuel Barber's Works for Solo Piano.” D.M.A. diss., University of Texas at Austin, 1982.

Spicknall, Joan Singer. "The Piano Music of Aaron Copland: A Performance-Tape and Study of His Original Works for Piano Solo.” D.M.A. diss., University of Michigan, 1974.

Wallace, David Edward. "Alberto Ginastera: An Analysis of His Style and Techniques of Composition.” Ph.D. diss., Northwestern University, 1964.

Wathen, Lawrence Samuel. "Dissonance Treatment in the Instrumental Music of Samuel Barber.” Ph.D. diss, Northwestern University, 1960.

Whitten, Sammie G. “A Stylistic Comparison of Aaron Copland's Passacaglia, Piano Variations, and Four Piano Blues, A Lecture Recital, Together with Three Recitals of Selected Works of Beethoven, Brahms, Chopin and Others.” D.M.A. diss., North Texas State University, 1981.

Wylie, Roy "Argentine Folk Elements in the Solo Piano Works of Alberto Ginastera." D.M.A. diss., University of Texas, Austin, 1986.

Young, Lauri L. “The Solo Piano Music of Samuel Barber.” D.M.A. diss, University of Cincinnati, 1989.

\section{Journal Articles}

Anderson, Mark. “Aaron Copland's Piano Blues No. 3." Keyboard Classics and Piano Stylist 15 (March-April 1995): 62-63.

Broder, Nathan. “The Music of Samuel Barber.” Musical Quarterly 34 (July 1948): 325335.

Chase, Gilbert. “Alberto Ginastera: Argentine Composer.” The Musical Quarterly 43 (1957): 439-60.

Copland, Aaron. "Jazz Structure and Influence” Modern Music 4, no. 2 (January 1927): 9-13.

Ginastera, Albert. Untitled Review of Inter-American Music Festival. Boletin Interamericano de Música 14 (Nov. 1959): 3-4.

Hanley, Mary Ann. "The Solo Piano Music of Alberto Ginastera Part I." The American Music Teacher 24, no.1 (June/July 1975): 17-20. 
. "The Solo Piano Music of Alberto Ginastera Part II." The American Music

Teacher 25, no.6 (September/October 1975): 6-9.

Kern, Fred. "Ragtime Wins Respectability.” Clavier 15, no. 4 (April 1976): 24-30.

Kleppinger, Stanley V. "On the Influence of Jazz Rhythm in the Music of Aaron Copland" American Music 21, no.1 (Spring 2003): 74-111.

"New Music Corner: Aaron Copland." Keyboard Classics and Piano Stylist 4 (MarchApril 1984): 22-25.

Newlin, Dika. “The Piano Music of Aaron Copland.” Piano Quarterly 28, no. 111 (1980): 6-8.

\section{Encyclopedia Articles}

Chase, Gilbert. "Ginastera, Alberto." The New Grove Dictionary of Music and Musicians, ed. S. Sadie and J. Tyrrell (London: Macmillan, 1980), vol. 7, 387-390.

D. Schwartz-Kates. "Ginastera, Alberto.” Grove Music Online, ed. L. Macy (Accessed 1 August, 2005), http://www.grovemusic.com.

Oliver, Paul. "Boogie-woogie." The New Grove Dictionary of Music and Musicians, ed. S. Sadie and J. Tyrrell (London: Macmillan, 1980), vol. 3, 39- 41.

\section{Musical Material}

Copland, Aaron. Four Piano Blues. New York: Boosey \& Hawkes, 1949.

Barber, Samuel. Excursions, Op. 20. New York: G. Schirmer, 1945.

Ginastera, Alberto. Suite De Danzas Criollas, Op. 15. New York: Boosey \& Hawkes, 1957.

Sound Recording

Copland, Aaron. The Young pioneers. Complete Copland Piano Music. Leo Smit. Sony Classical, New York, 1994. CD. 